\title{
TOURISM DISTRIBUTION CHANNELS AND CAPACITY MANAGEMENT: \\ THE CASE OF THE BRAZILIAN ISLAND OF FERNANDO DE NORONHA, A WORLD HERITAGE SITE
}

by

\begin{abstract}
Amalina Andrade
A thesis

submitted to Victoria University of Wellington

in partial fulfilment of the requirements for the degree of

Master of Tourism Management
\end{abstract}

Victoria University of Wellington

2013 


\begin{abstract}
This research investigates the tourism distribution channels of Fernando de Noronha, an island off the Northeast coast of Brazil recognised by UNESCO as natural World Heritage Site. The novelty of this study is the examination of capacity management of this destination as a factor influencing supplier's distribution channels. With this main purpose, the structures of the channel mix and the factors influencing them were identified. The research took a supply-side perspective, recognising the challenges of both suppliers and intermediaries when selling the destination. 41 in-depth interviews were conducted with suppliers, intermediaries located at Recife and Natal and governmental organisations (local, regional and central).
\end{abstract}

A mass-market approach on selling the destination is in place by both the public and the private sector. Most of the tourists to Fernando de Noronha make use of indirect channels (via online reservation websites or travel agencies) or utilize the internet to reach suppliers. There are many factors influencing the structures of distribution channels. These were classified in three categories: general factors (market opportunity, partnership issues, price of channels, product's characteristics, reputation of the channel, business capacity and experience), the use of direct distribution (get higher profitability, market trend, ease and good results of word-of-mouth) and the reasons for indirect distribution (to get higher customer numbers, provision of payment ease for customers and price of information provision to consumers).

Although the carrying capacity measures of the destination were created in order to protect the natural resources of the Island for future generations, this is having an impact on the businesses when selling the destination and on tourists' travel decisions. The reason for this are: the payment of a conservation fee to gain access to the destination, the limited number of regular flights to the island (and regulated number of seats available), the restricted amount of airlines allowed to provide flights for the island and the controlled number of people that can get to the destination by plane and cruise ships each day.

The capacity management of the destination is influencing supplier's distribution channels because it increases the price of the destination, it means a lack of flight tickets in the high season and consequently it creates an image of expensive destination. As a result, it is making suppliers (especially accommodation providers) be obliged to work with tour operators (and their respective travel agencies) due to the tour operators holding the transportation tickets (by sea on a cruise ship or by air) to the destination in 
advance. Thus, stakeholders of natural world heritage sites, national parks and islands should think of distribution channels as a key tool to strategically reposition their product in order to provide sustainable development for the destination and preserve its natural resources. Also, capacity management must be considered as an external constraint influencing stakeholders' distribution mix choices.

Key words: tourism distribution channels, capacity management, World Heritage Site, Fernando de Noronha (Brazil), national park, island. 
"...by the time the effect of increased numbers on resources is noted, it may be too late to reverse this effect on the environment and on the image of the destination."

(Butler, 2010, pp.58)

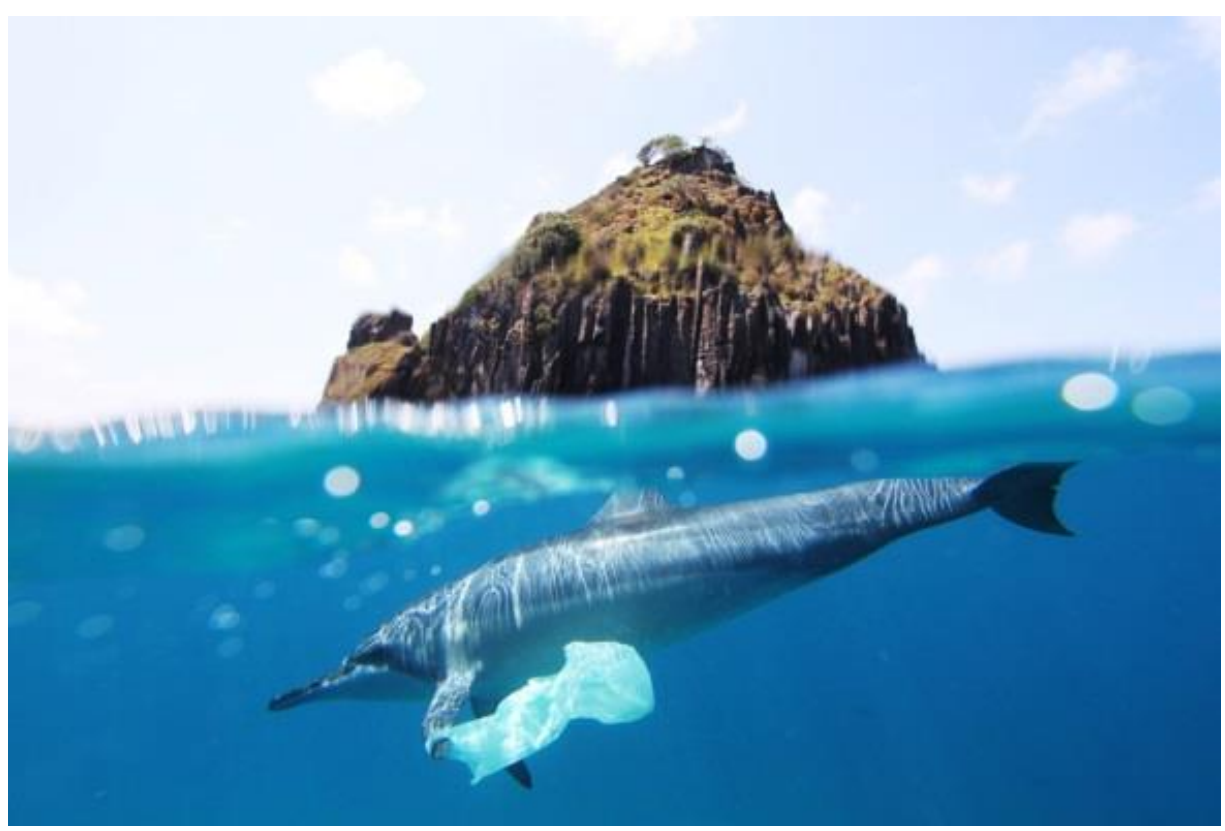

Source: http://g1.globo.com/platb/pe-viver-noronha/

(Picture from João Vianna at Cacimba do Padre, Fernando de Noronha). 


\section{Acknowledgements}

I would like to take this space to start thanking all New Zealand's taxpayers and specially the New Zealand Aid Programme which provided me with the opportunity to realise my dream of doing a Master's degree. This was in my mind since my first year as an undergraduate tourism student at Recife in 2003. Thank you NZAid for also supporting my country on gaining more knowledge as I was able to do research in my home country.

Of course this experience would not be possible without some incentive from: my former generous boss Vitinho and two former lecturers: Signe Dayse and Iara Brasileiro.

It was my pleasure to have Dr. Karen Smith as my supervisor, not only for the brilliant insights and motivation given to me but especially for her tremendous patience. Thank you for 'reading between the lines' and all support in difficult times.

Thank you to all Tourism Management Staff, the knowledge you all transmitted to me will follow my journey forever. Thank you Ian for the out of the box and unexpected paper. Thank you Doug for the wise advices.

I huge thank you must be given to every single person - business owners, managers, staff and government representatives - from Natal, Recife and Fernando de Noronha, who dedicated their time and patience to participate in this research as well as for sharing their passion for the destination and tourism. Recognition must be given to ADEFN, Victoria Management School, Pedro Henrique Neto and Livia Luana (from the comfortable Del Mares accommodation) for financially supporting the research. Moreover, I will never forget the efforts my gatekeepers took: Fernanda, Karem, Iran, Dayse and Rafaela.

To my mates: Elisante, Natalie, Peter and Rebecca, thank you for comforting my soul and become my family in New Zealand. "Churbro"! Thank you to my new lifelong friends: Daniel, Clo and Angela; you rapidly opened your arms and helped me and my partner after the earthquake in $\mathrm{CHCH}$. The close warming friends in this new city: Mateus, Lela, Ali, Pao, Trisha, Adella, Julio and Loretto. And all many friends in Brazil! Thank you so much NZAid staff, especially Julia Harrison.

The most important thank you is to Gil, my lovely husband. He accepted to join me in this incredible experience on the other side of the world; in a country he had never imagined visiting. Together, we became survivors after the earthquake in Christchurch. He still had patience to hang firmly all my stress, sickness period and every single 'stone' along the way! A special thank you to the unconditional love I have always got from mom and grandma! 


\section{TABLE OF CONTENTS}

Abstract .ii

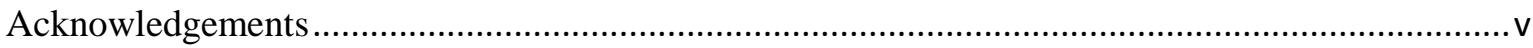

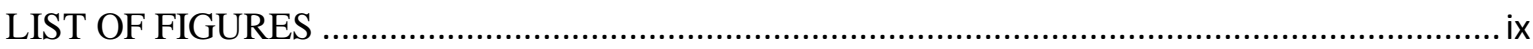

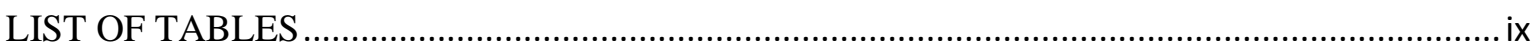

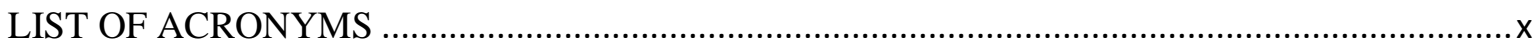

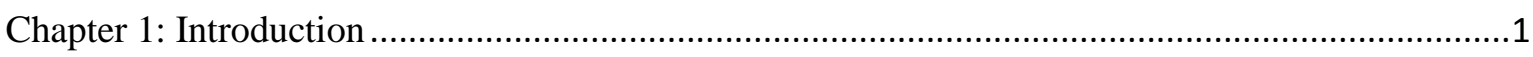

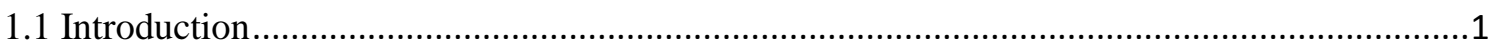

1.2 Tourism in Fernando de Noronha: history and characteristics ............................................

1.3 Importance of capacity management on islands and World Heritage Sites .............................

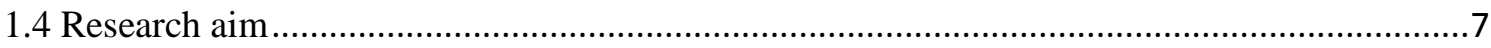

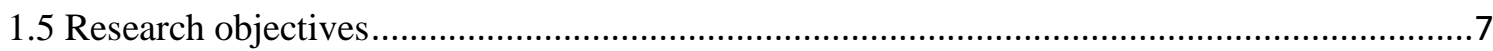

1.6 Thesis structure

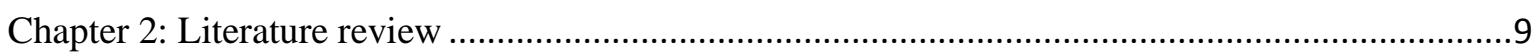

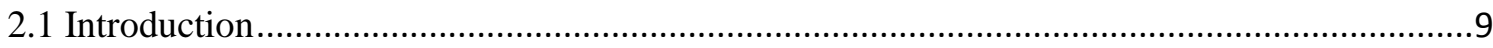

2.2 Marketing and Distribution Channels: the concepts ........................................................

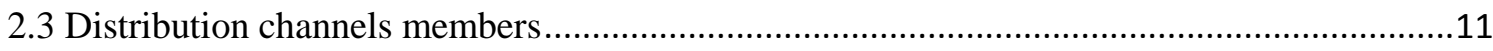

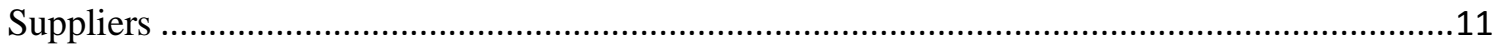

Intermediaries ………

Consumers …

2.4 Distribution mix and recent studies about tourism distribution channels ................................14

2.5 Research about distribution channels in Brazil and Fernando de Noronha ............................17

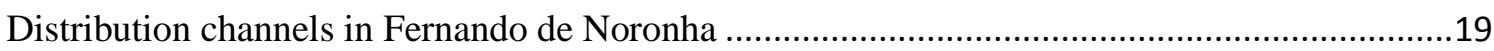

2.6 Capacity management: concepts, distribution channels studies and gaps in the literature .....23

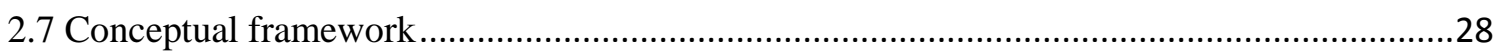

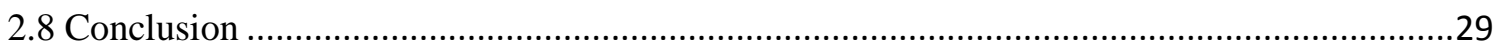

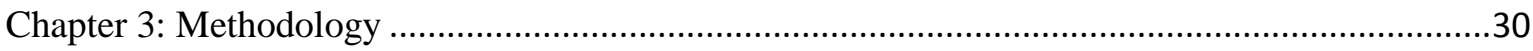

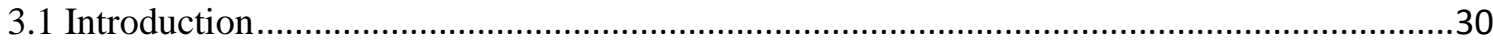

3.2 Research gaps and methods used in tourism distribution channels' research.........................30

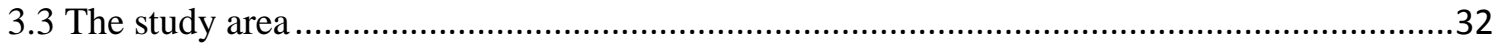

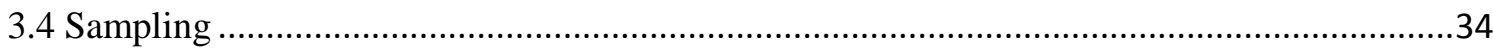

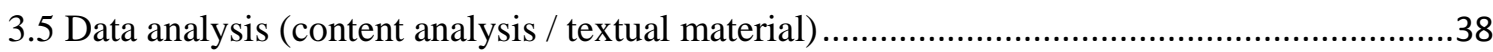

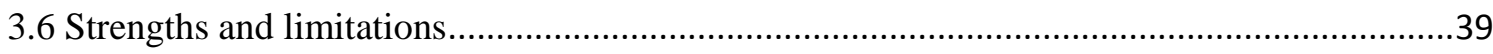

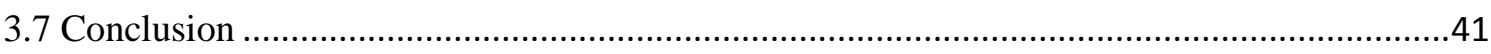

Chapter 4: Tourism distribution channels structures, factors and challenges at Fernando de Noronha 
4.1 Introduction .42

4.2 Dominant distribution channels structures for intermediaries and ground operators 43

4.2.1 Intermediaries' information provision to consumers .........................................46

4.3 Distribution channels structure of suppliers at Fernando de Noronha ...............................47

4.3.1 Distribution channels structure of luxury accommodations.......................................47

4.3.2 Distribution channels structure of non-luxury accommodations .................................50

4.3.3 Distribution channels structure of scuba diving ..................................................51

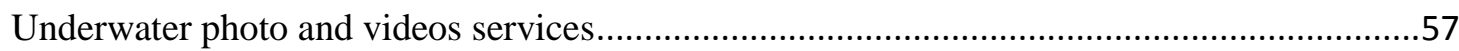

4.3.4 Distribution channels structure of the other activities.............................................58

4.4 Factors and challenges influencing the tourism distribution channels of Fernando de Noronha tourism products

4.4.1 Factors influencing the tourism distribution channels of Fernando de Noronha tourism products.

General factors influencing distribution .61

Factors influencing direct distribution 66

Factors influencing indirect distribution .67

4.4.2 Challenges in the distribution channels of intermediaries and suppliers 68

4.5 Capacity management as a factor influencing the tourism distribution channels of suppliers and ground operators

4.6 Promotion, destination image and capacity management: the public sector's roles and views

4.7 Conclusion .83

Chapter 5: Discussion .84

5.1 Introduction .84

5.2 Tourism distribution channels structures and factors at Fernando de Noronha .84

5.3 Factors influencing the Tourism distribution channels at Fernando de Noronha 90

5.4 Capacity management of the destination as a factor influencing the tourism distribution channels

5.5 Conclusion 100

Chapter 6: Conclusion. 101

6.1 Introduction 101

6.2 Structures of tourism distribution channels .102

6.3 Factors influencing the structures of distribution mix of the destination. .102

6.4 Relationships between capacity management and suppliers' distribution channels .103

6.5 Implications for businesses ..... .104

6.6 Implications for the government .105

6.7 Recommendations for suppliers, ground operators and the government .107 


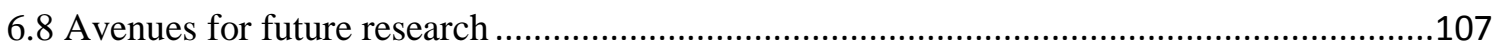

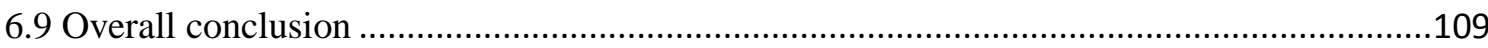

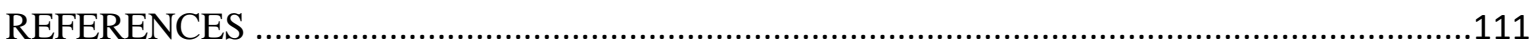

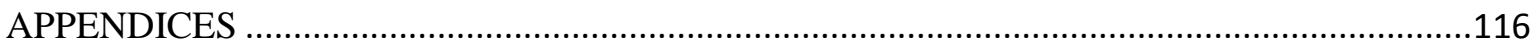




\section{LIST OF FIGURES}

Figure 1: Map of Brazil with the location of the archipelago of Fernando de Noronha, Natal and Recife.

Figure 2: Map of Fernando de Noronha with the delimitation of its two conservation areas.............4

Figure 3: Monthly tourist entry numbers from 2006 to 2011 . ........................................................

Figure 4: Length of stay at Fernando de Noronha, in 2011 ........................................................

Figure 5: Distribution Channels for Heritage and Cultural Attractions in Rotorua and Wellington by Pearce and Tan (source: 2004, pp.230) ................................................................................. 14

Figure 6: Functions involved in the distribution of packaged tours by Pearce (source: 2008a; pp.159)

Figure 7: Distribution channel structure for rural tourism at Ribeirão Preto by Lohmann and Nascimento (source: 2007, pp.12, with adaptations) .18

Figure 8: Tourist behaviour at Fernando de Noronha (source: MTur and ABETA, 2010, pp.48, with adaptations)

Figure 9: Relationships between suppliers at Fernando de Noronha (source: MTur and ABETA,

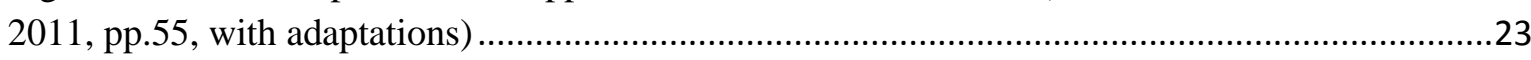

Figure 10: Hypothetical evolution of a tourist area (source: Butler, 2006, pp.5) ............................25

Figure 11: Stages of the tourist area life cycle of Fernando de Noronha (source: Falcão, 2010,

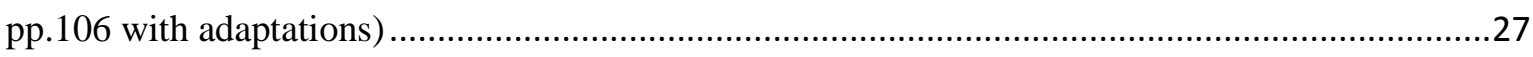

Figure 12: Population curve of psychographic groups by Plog (source: 1974, pp. 56) …................28

Figure 13: Conceptual framework: factors influencing tourism distribution channels in a capacity

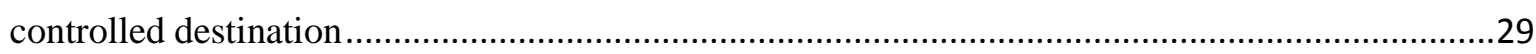

Figure 14: Map of the villages with businesses at Fernando de Noronha..........................................

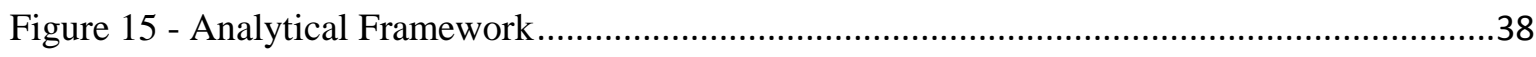

Figure 16: Dominant distribution channels structure at Fernando de Noronha ................................44

Figure 17: Distribution channels structure of luxury accommodations ..........................................48

Figure 18: Distribution channels structure of non-luxury accommodations ....................................50

Figure 19: Spots for scuba diving at Fernando de Noronha........................................................ 52

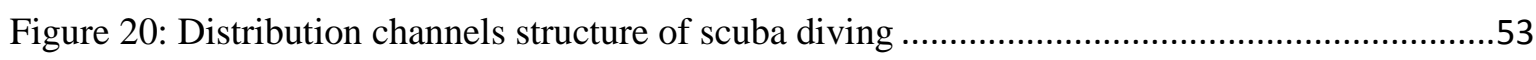

Figure 21: Distribution channels structure of the other activities .................................................58

Figure 22: Photos of the 'Campaign More Noronha' in practice.................................................... 81

Figure 23: Distribution channels structure and factors of Fernando de Noronha .............................85

\section{LIST OF TABLES}

Table 1 - Types of tourists of Fernando de Noronha (source: MTur and ABETA, 2011, pp.47-52,

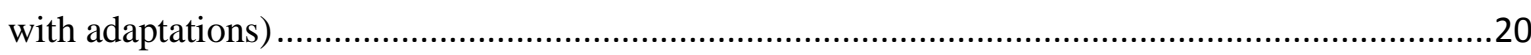

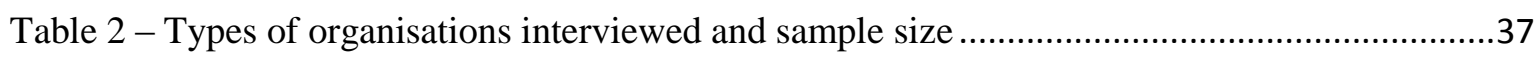




\section{LIST OF ACRONYMS}

ABETA - Brazilian Association of Ecotourism and Adventure Tourism

ADEFN - Fernando de Noronha State District

EMBRATUR - Brazilian Tourism Board

ICMBio - Chico Mendes Institute of Biodiversity

MTur - Ministry of Tourism

TALC - Tourism Area Life Cycle

UNESCO - United Nations Educational, Scientific and Cultural Organization 


\section{Chapter 1: Introduction}

\subsection{Introduction}

This research will investigate the relationship between tourism distribution channels and capacity management in the context of a Brazilian island destination recognised as a Natural World Heritage Site. This chapter will introduce the research and case study destination: Fernando de Noronha.

Distribution channels were initially a topic belonging to the body of knowledge of marketing, but over the last decade they have become a subject of more relevance and reoccurrence in tourism research (Lohmann, 2006; Pearce, 2010a). The reason for this is that in times of global competition where many companies may struggle for survival, especially small and medium sized enterprises, the development of a distribution network with the right selection of channel members may be one of the few key tools that will define the success or failure of a company (Kotler, Bowen \& Makens, 2006).

The objective of a tourism distribution channel is to connect supply with demand, which means, to link tourists or visitors to the tourist services they want to purchase. This 'connection' can be made directly between suppliers and consumers or indirectly when there is one or more middlemen involved: referred to as intermediaries.

Since tourism presumes the movement of a person from one place to another, for Fernando de Noronha, a small island located $360 \mathrm{~km}$ from the Brazilian coast, the role of distribution channels can be crucial for the development of the destination. The island can only be known if there are channels providing the opportunity for potential clients to get to know the place before their travel; and especially before making their travel choice. As a result, distribution channels play the functions of information provision, sorting, bundling, booking and purchase (Pearce, 2008). This will be further explained in the literature review. It is important to give more attention to the information provision function because it plays a significant role in the destination's image. Besides, identifying the information provision function of the distribution channels from a destination may reveal the situations/contexts in which the destination has been promoted and if this image might be influencing the sustainability of the island with regards to the type of tourists being targeted. When providing information to promote a destination, companies and even the government are targeting one or more types of consumers that will have different motivations for visiting the island. Based on these motivations, consumers express distinct behaviours. 
Consequently, these behaviours must match with the profile of the destination. When this match does not happen two things may occur: potential tourists may not choose to go to the destination or when tourists already are at the island, they may become unhappy with their travel experience besides causing negative impacts on the destination.

While tourism distribution channels are a growing area of research (Pearce, 2010a; Pearce, 2011), the investigation on distribution channels in developing countries is still emerging (Mkumbo, 2010) and there are very few studies on Brazil (Flecha and Costa, 2004; Longhini and Borges, 2005; Lohmann, 2006; Lohmann and Nascimento, 2007; MTur and ABETA, 2011; Filho, and Lohmann, 2012).

In this research, distribution channels are linked to capacity management which is a tool used by the public sector to manage a destination based on the principles of sustainability. This tool is commonly adopted in the Brazilian national parks which are areas for the conservation of ecosystems, as well as Fernando de Noronha. Therefore, it would be interesting to understand how a governmental management mechanism might be influencing the private sector's distribution channels.

\subsection{Tourism in Fernando de Noronha: history and characteristics}

Fernando de Noronha is an archipelago composed of 21 islands. However it is on the main island that all tourist activities happen, in an area of $26 \mathrm{~km}^{2}$. The archipelago is located in the Northeast Region of Brazil and at the Southern Atlantic Ocean; (Figure 1). It is a national park as well as a natural World Heritage Site recognised by UNESCO - United Nations Educational, Scientific and Cultural Organization - since 2001. The reason for being a World Heritage Site is justified by the archipelago being a key place for reproduction, dispersal, colonisation and feeding of marine species like shark, billfish, tuna and marine turtles as well as by marine organisms. At the same time, it is also home of the biggest concentration of tropical seabirds and Dolphins' Bay (Baía dos Golfinhos) is considered the only place in the world with a population of resident dolphins (UNESCO, 2012).

Reaching the destination from the Brazilian mainland is only possible via flights from Recife (capital of Pernambuco State) or Natal (capital of Rio Grande do Norte State), by cruise ship or smaller private boat. Beside the transportation costs involved, tourists must pay a daily conservation fee to be granted permission for visiting the place plus another charge to have access to the area of the marine national park (which is explained below). The fee is currently set at around NZD\$26 per day and the extra charge costs NZD\$76 for 
international tourists and NZD \$38 for Brazilians (this is charged for every 10 days of stay at the destination).

Figure 1: Map of Brazil with the location of the archipelago of Fernando de Noronha, Natal and Recife.

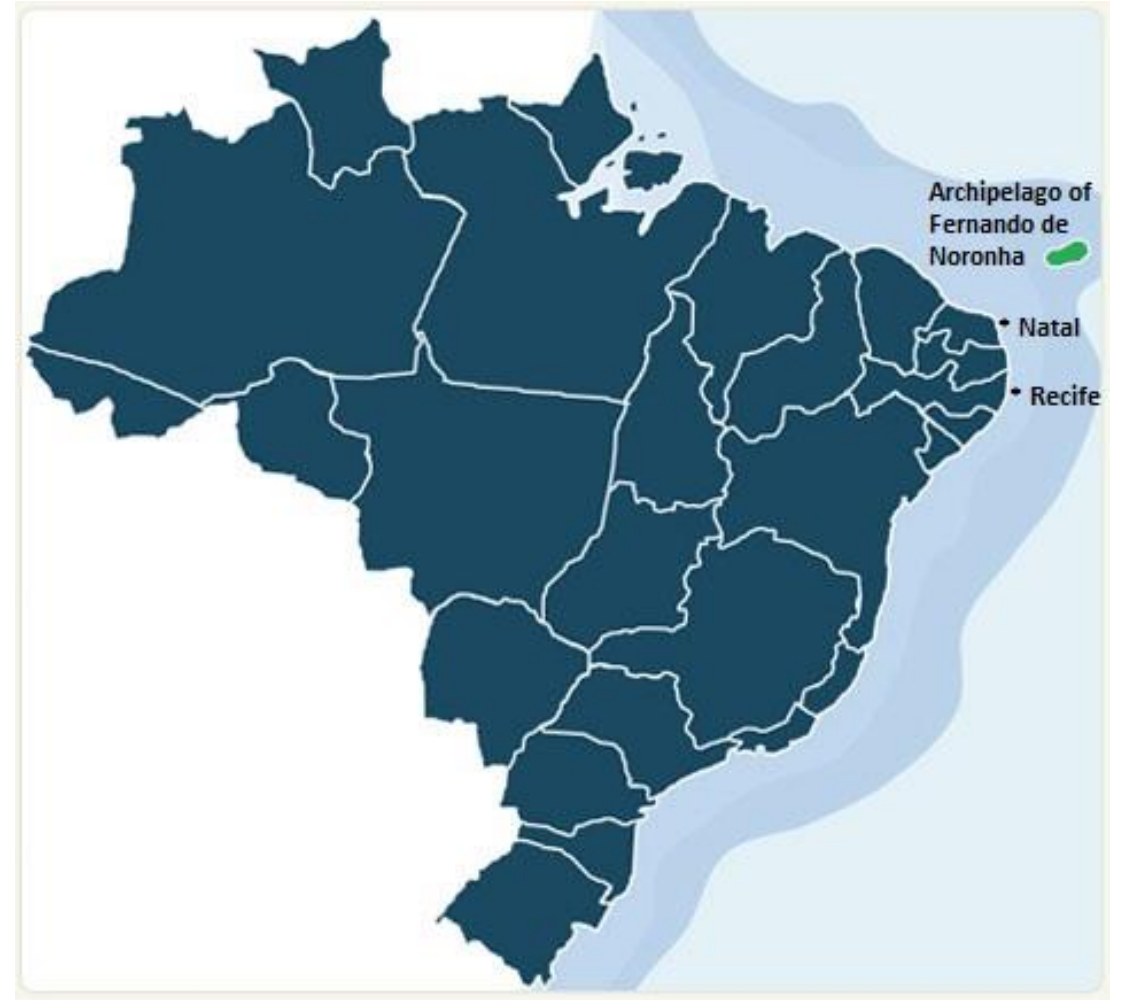

Source: http://www.brazilnuts.com/destination (with adaptations)

The archipelago's lands belong to the Brazilian Federal Government. On the main island, with a population of around 3,500 residents (PNUD, IBAMA \& elabore, 2007), the zone is divided into two conservation areas with different legislation regulating each. These are: the 'Environmentally Protected Areas' (more popularly called by its acronym in Portuguese as "APA") and the 'Marine National Park' (whose acronym in Portuguese is "PARNAMAR"); as illustrated on Figure 2. The APA is where the human settlement is allowed and tourism and community management is under the responsibility of Fernando de Noronha State District - ADEFN but it is also ruled by the Chico Mendes Institute of Biodiversity - ICMBio (which is part of the Ministry of Environment and is responsible for managing all national parks in the country). The 'marine national park' (PARNAMAR) is managed by ICMBio only. 
Figure 2: Map of Fernando de Noronha with the delimitation of its two conservation areas.

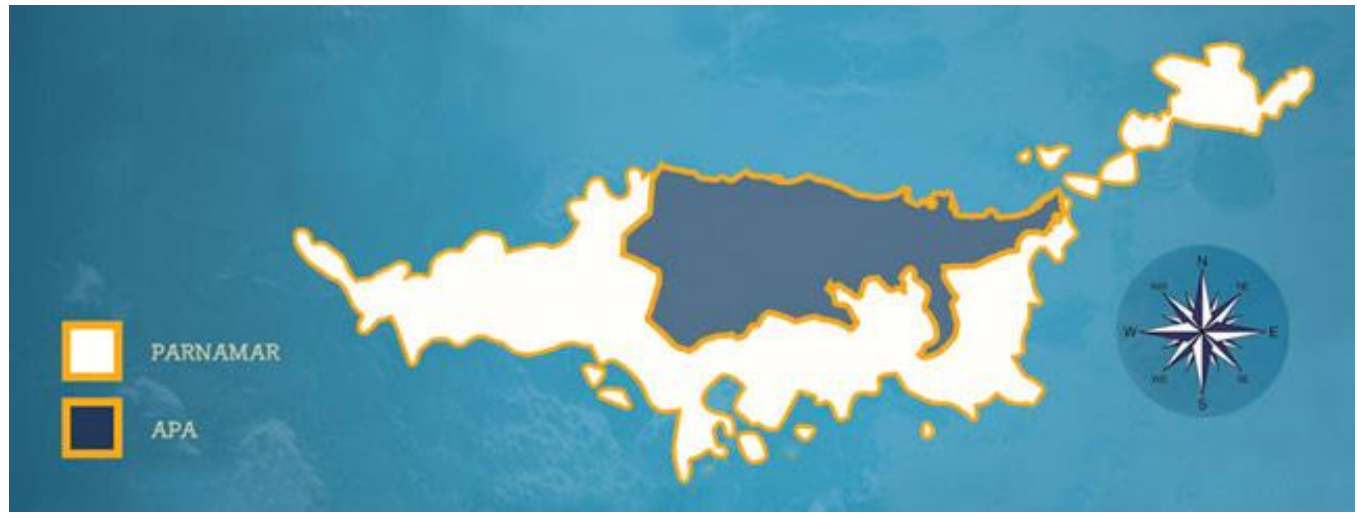

Source: http://www.parnanoronha.com.br/paginas/92-apa.aspx

In this tourist destination, the activities and tourist attractions offered are: fishing, diving, surfing, horseback riding, museums (about the wildlife found on the destination and its history), historical trails, beaches, scuba diving, fortress, chapels, wildlife viewing (of turtles, sharks and dolphins), trails, luxury accommodations, boat trips and planasub (which is a new way to observe the sea life by being pulled from a board tied to a boat and using some diving equipment). There are 122 tourism suppliers in the archipelago including accommodation, transport providers, event organiser, diving activities, ground operators, fishing activities and boat tours (Fernando de Noronha - Pernambuco Website, 2012, see chapter 3 for more details).

The most important events from the tourist point of view are: New Years' Eve, RecifeFernando de Noronha International Regatta and The Hang Loose Pro Contest. The regatta is held in September or October and departs from Recife; which is located $545 \mathrm{~km}$ away from the island's coast. The competition attracts not only the domestic market but also some international sailors where the participants can also sail from Fernando de Noronha to Natal. The Hang Loose Pro Contest is an internationally renowned surfing competition that offers 100,000 dollars prize and happens in January or February (Fernando de Noronha - Pernambuco Website, 2012).

Tourism demand in Fernando de Noronha is quite steady throughout the year (Figure 3). The steady period is from July to March and there is a reduced in number between April to June. The peak in tourist numbers is in January which almost reached the mark of 7,000 tourists in 2011; while the lowest number of tourists was in June, when it fell to around 4,000 visits in 2011. 
Figure 3: Monthly tourist entry numbers from 2006 to 2011.

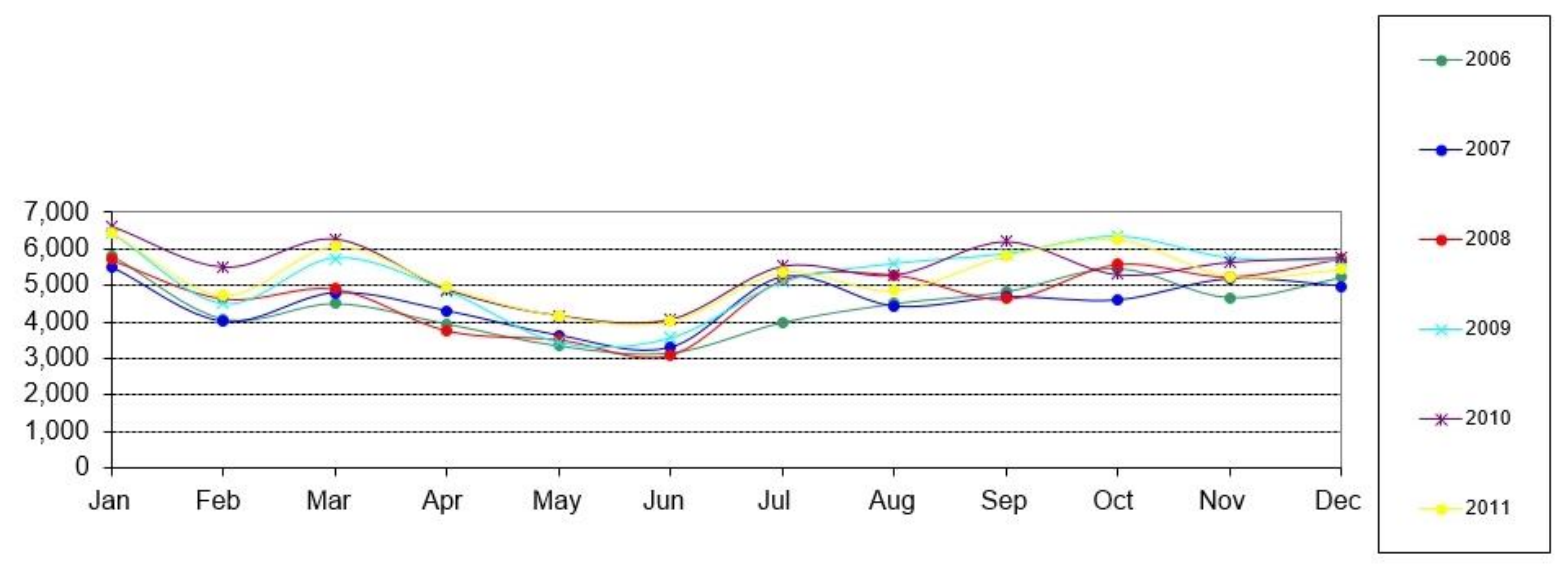

Source: ADEFN, 2012.

With regards to the amount of time spent by tourists at the archipelago, data from 2011 shows that the greatest number of the visitors spend three days at the island. However a number also stay four or five days (Figure 4).

Figure 4: Length of stay at Fernando de Noronha, in 2011

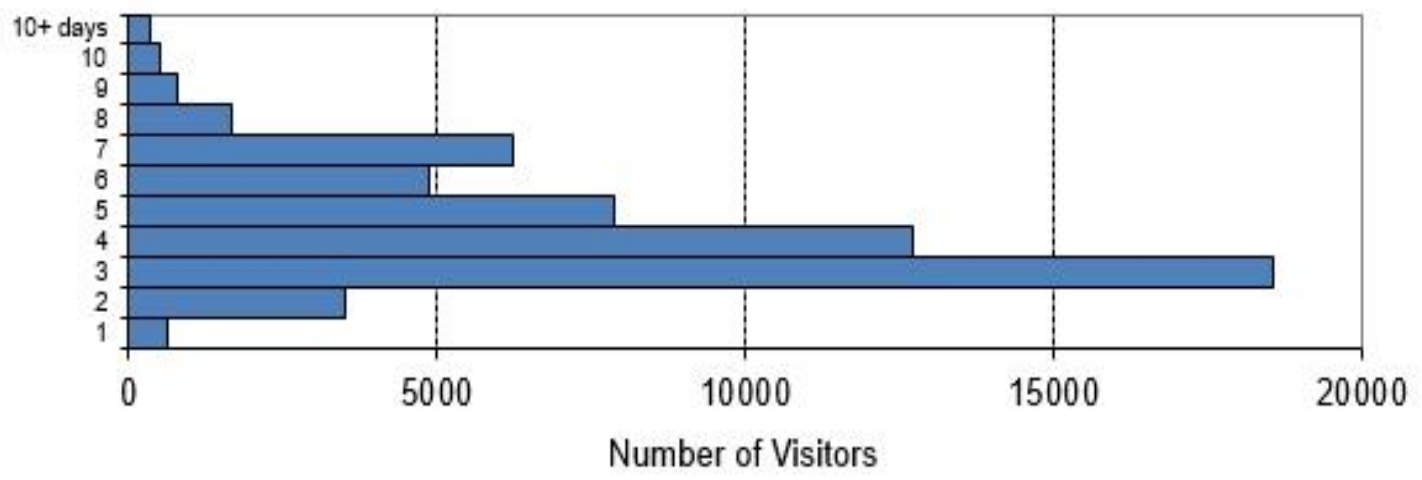

Source: ADEFN, 2012.

\subsection{Importance of capacity management on islands and World Heritage Sites}

A World Heritage Site is considered to be an area of unique and worldwide values and resources that should be preserved and transmitted for future generations (UNESCO World Heritage Centre, 2002). The World Heritage List today includes a total of 936 properties where 725 are cultural heritage, 183 are natural heritage and 28 are both natural and cultural heritages (UNESCO World Heritage List, 2012).

The concept of carrying capacity is well known for the role it plays in mitigating tourism impacts for the sustainable development of destinations. As a consequence, capacity 
management (the use of carrying capacity as way of providing sustainable management to a destination) is of crucial value to the conservation of vulnerable areas, like small islands, national parks and heritage sites as it is in the case of Fernando de Noronha.

As internationally recognised natural and cultural sites, World Heritage Sites are often fragile environments and frequently receive high visitor numbers which results in combined economic, social and environmental impacts for island destinations. As a consequence, lots of attention has been given to their management, including management of visitor capacity. For the inclusion of Natural Properties on the World Heritage List, the place must have:

"natural features consisting of physical and biological
formations or groups of such formations, which are of
outstanding universal value, from the aesthetic or scientific
point of view; geological and physiographical formations and
precisely delineated areas which constitute the habitat of
threatened species of animals and plants of outstanding
universal value from the point of view of science or
conservation; natural sites or precisely delineated natural
areas of outstanding universal value from the point of view of
science, conservation and natural beauty" (UNESCO World
Heritage Centre, 2002, pp.16).

The main idea on the concept of carrying capacity is: “(...) if it can be decided how many tourists an area can accommodate before the volume of visitors begins to cause problems then we may be able to manage tourism so that this number is never exceeded" (Swarbrooke, 1999, pp.261). The need to the creation of limits and placement of carrying capacity plans at destinations are based on the belief on sustainable principles (Butler, 2010).

In the specific case of Fernando de Noronha, there are some important measures regarding the carrying capacity of the destination which mostly influence both businesses selling the destination and tourists deciding to travel to this destination (ADEFN, 2000; PNUD, IBAMA \& elabore, 2007; ADEFN, 2007; Falcão, 2010; Mtur and ABETA, 2011; Fernando de Noronha - Pernambuco Website, 2012; Econoronha, 2013):

- The payment of a conversation fee to gain access to the destination plus the charge to access the marine national park.

- The limited number of regular flights to the island; and consequently regulated number of seats available.

- The restricted number of airlines allowed to provide flights for the island. 
- The controlled number of people that can get to the destination by plane and cruise ships per day.

All these measures have the main object of limiting numbers and managing visitors at the destination in order to keep the natural resources for the future generations.

To date no research has considered how capacity management may be influencing the tourism distribution channels of suppliers in a destination. In addition, only one study on distribution channels has considered a World Heritage Site: the case of Southland in New Zealand where some, but not all, of the destinations studied are a World Heritage Site (Stuart, 2004).

In summary, no study has been made specifically from the perspective of a world natural heritage site which is a considerable conservation unit as in the case of Fernando de Noronha. Hence, what impacts can capacity management have on the distribution channels of suppliers? Can it contribute to the conservation of the natural resources or might it cause a negative effect on demand where tourists might be limited in their ability to book a holiday? What challenges do suppliers face in the distribution of their products?

\subsection{Research aim}

- To investigate how the capacity management of a destination influences the tourism distribution channels of suppliers in the remote and isolated Brazilian island of Fernando de Noronha: a World Heritage Site.

\subsection{Research objectives}

- To identify and present the structures of the tourism distribution channels from a supply-side perspective.

- To analyse the factors that influence the structures revealed, including the capacity management as a factor influencing these structures.

- To evaluate and explain the relationships between the island management and its carrying capacity planning with the supplier's practices in distribution channels.

To accomplish these objectives a total of forty-one in-depth interviews were conducted with suppliers at Fernando de Noronha, intermediaries at Recife and Natal (the gateways to the island) as well as governmental organisations (local, regional and central). The strengths of this research are its supply-side perspective due to stakeholders' involvement on site governance and management as well as the participation of business owners or 
managers of the companies as interviewees. The limitation of the research was the nonparticipation of airlines and impossibility of interviewing virtual distributors and specialized tour operators (focused on luxury and ecotourism) located at São Paulo: the main Brazilian outbound market.

\subsection{Thesis structure}

The thesis is divided into six chapters. This chapter has provided an understanding of the gaps in the literature and an introduction to the case study destination.

Chapter two will present the literature review with special attention to the concepts of marketing and tourism distribution channels: including the presentation of the channel members, the explanation of distribution mix and an overview of the recent studies about tourism distribution channels. After that the emphasis will be on highlighting the research that has already been conducted in Brazil, and particularly the results of a study that took place in Fernando de Noronha on 2011, about the tourism distribution channels. The end of this chapter will point out the gaps in the literature about capacity management and World Heritage Sites, and illustrate the conceptual framework of this study.

Chapter three will outline the methods used to conduct this qualitative research, presenting the number of interviews undertaken, how these people were approached, the three locations the research took place, how the data were analysed and the strengths and limitations of the study.

Chapter four will then reveal the findings of this research by providing five diagrams explaining in detail the tourism distribution channels of the destination from the perspective of private sector: tourism suppliers and intermediaries. And it will then show an overview of the public sectors' roles, views and influences over the way the destination has been placed on the market.

Chapter five will provide a discussion with the main objective of explaining the how and why the capacity management of the island may be influencing supplier's distribution channels.

Chapter six is the concluding chapter which will refer back to the research questions initially proposed, highlighting the implications of the study and areas of future research. 


\section{Chapter 2: Literature review}

\subsection{Introduction}

This chapter will start by presenting the concepts of marketing with a focus on the understanding of distribution channels which is the main subject of this study. The members involved in the distribution channels will be introduced. After that, an explanation about distribution mix will serve as a starting point for presenting the recent studies around the world about tourism distribution channels. Then, special attention will be given to outlining previous research conducted in Brazil and Fernando de Noronha about distribution channels and the tourism area life cycle. Finally, the chapter will discuss some concepts on capacity management and World Heritage Sites and how they have been excluded in the studies of distribution channels to date; which will lead the reader to the research gaps.

\subsection{Marketing and Distribution Channels: the concepts}

Kotler, (et al., 2006, pp.13) defined marketing as: "a social and managerial process by which individuals and groups obtain what they need and want through creating and exchanging products and value with others". To achieve the goal of providing what people need, want and demand, managers make use of a mix of elements called marketing mix which is composed of product, price, place (also known as distribution) and promotion - in order to create effective products or services packages for consumption of the targeted clients. So, first, the product and its characteristics are created, then, the price is set, after that it must be decided how to distribute it and finally opt for the methods of promotion. Above all, it must be understood that marketing must create value and satisfaction for consumers by motivating purchase and fulfilling customer's needs or dreams (Kotler, et al., 2006).

A tourism distribution channel, in short, is what makes products available to consumers; it connects the tourist destination with the tourists. Since tourism products are intangible (they cannot be seen, tasted, felt, heard or smelled before purchase; Kotler, et al., 2006), distribution channels in tourism offer the products/services at the location of potential consumers which is usually far from the destination they may wish to visit.

However, it is important to understand that this connection can be expressed directly or indirectly (via one or more intermediaries such as retailers, wholesalers, inbound and outbound operators etc.) (Kotler, et al., 2006; Schott, 2007, p.260). As explained by 
Middleton and Clarke (2001, pp.293), an intermediary is "any corporate third party or organization between producer and final consumer that facilitates purchases, the transfer or title of the buyer and sales revenue to the producer". Direct distribution is the contact consumers have with producers (suppliers): with the company offering the services they want to enjoy. But direct distribution also involves costs with staff work on handling payments, issuing tickets and taking reservations as argued by Pearce (2007).

According to Stern and El-Ansaray (1982), the focal point of marketing channels is on delivery because it means making products available for consumers. In the same publication (Stern and El-Ansaray, 1982, pp.3-4), marketing channels are defined as:

"... sets of interdependent organizations involved in the process of making a product or service available for use or consumption - not only do marketing channels satisfy demand by supplying goods and services at the right place, quantity, quality and price, but they also stimulate demand... Therefore, the channels should be viewed as an orchestrated network that creates value for the user through the generation of form, possession, time and place utilities."

When Pearce (2010) wrote a review on tourism distribution research, he divided the research done to date into five approaches: structural, behavioural, functional, evaluative and strategic. The first approach - structural - is considered the most common where links are made related to specific factors (particularly to hotels and airlines) or to international markets and destinations (Europe and Asia). In addition, it was identified that many researchers have focused on IT changes and its impact on traditional tourism distribution structures. The second approach concerns the behavioural aspect of different channel members; including their relationships and the underlying factors influencing the behaviours. It was found that most research focusing on intermediaries and suppliers had examined aspects like conflict, control and power or satisfaction, success and trust. Moreover, other studies had focused on tourists' channel-choice behaviour, information search and travel planning behaviour. The third approach is about the functional aspects of tourism distribution, where the majority of research has focused on the role of intermediaries. But special attention must be given to the representation of distribution functions by Pearce (2008a) which shows the functions undertaken by distribution channel members. In short, it recognizes the time, place, possession and form utilities as mentioned in the definition of marketing channels by Stern and El-Ansaray (1982); but this will be expanded on later in section 2.4 . 
A fourth approach relates to evaluating channel performance; where only a few recent studies are making the link between distribution and revenue management. And lastly, the fifth approach presents a strategic point of view analysing issues and implications of tourism distribution channels, with special focus on the effects of new technologies.

For the purpose of this research, structural, behavioural and strategic approaches will be used. The structure of the distribution channels of Fernando de Noronha will be revealed from the suppliers' perspective since they have strong involvement in the destination's governance and management. The behavioural aspects will also be considered with special attention to the factors influencing the structures revealed. And lastly, the influences of the government on the distribution channels of suppliers will be explained with regard to its roles of promoting the island and managing the capacity of the destination.

\subsection{Distribution channels members}

There are three groups of channel members involved in the distribution of tourism: suppliers, intermediaries and consumers. Each member relates to the others in different ways.

\section{Suppliers}

Suppliers are the ones responsible for creating and providing an activity or services to consumers. As a consequence they may be considered the most important channel members because they are the ones who develop tourism in a destination. For this reason this study is undertaking a supply-side approach. Suppliers mainly provide accommodation, transportation, tourist attractions (e.g. scuba diving, boat tour, rappelling, surfing instructions, etc) and restaurants. When selling their services, they may do it directly to consumers or make use of an intermediary who will package it with other services. In Fernando de Noronha, suppliers are small businesses owned by the people from the community or from investors from the continent but without the presence of any big hotel chains (MTur and ABETA, 2011).

\section{Intermediaries}

Intermediaries are only used in indirect distribution. They make this process more efficient by facilitating the sorting and searching processes. However, it is important to note that the main reason for these channel structures is economic. Intermediaries exist because they want to have economic benefits from the services they provide, as explained by Pearce (2007, pp.27), indirect distribution is about transferring functions and the associated costs to other parties and that is why they expect to be remunerated for their function. 
Stern and El-Ansaray (1982) identified that the main functions performed by intermediaries are: (a) sorting out (classifying an heterogeneous supply into divided stocks which can be homogenous), (b) accumulation (which means putting many sources together to create a larger supply), (c) allocation (breaking a homogenous supply into smaller lots) and (d) assorting (organising products to make for use in association with others). In the tourism context these key functions - as explained by Pearce (2007, pp.18) are: (a) Information Provision: having it adequately created and available at the right time and place will stimulate demand, (b) Sorting is about having supplier's products and services selected and classified by intermediaries (especially a tour operator) as well as available in the intermediaries' catalogue, (c) Bundling is the combination of many elements of a travel into a package of travel arrangements and (d) Booking and Purchase is making the booking and purchase of tourist products available.

Since destinations cannot be tangible and transported to other countries or cities, intermediaries play an essential role in trying to convince potential consumers - at the points of sale - to purchase a product that cannot be tested beforehand. As a consequence, providing high-quality and effective information at the point of sale is also another key function of intermediaries. Moreover, Smith (2007a) argues that in the case of events, intermediaries (like ticketing agencies) raise the number and range of purchase channels, facilitate the speed of entry of consumers to the event venue, can deal with large amount of bookings, can lower the costs for distribution and may even attract new type of customers.

Based on Kotler, et al., (2006), Middleton and Clarke (2001), Medlik (2003) and Buhalis and Laws (2001) intermediaries (also known as middleman in the tourism industry) can be:

- Travel agents (retailers) - They sell travel services for a commission on behalf of accommodation providers, transportation companies and tourist attractions but also can provide ancillary services. Essentially, these companies send people abroad or to domestic (within the country) destinations. So, they can also be called outbound or outgoing travel agency.

- Tour operators (wholesalers) - They buy individual travel services from providers like accommodations and airlines with the object of combining them to create a package to sell at a marked-up price via intermediaries or straight to the public. They are actually manufacturers of tourist products. This kind of company can be divided in two subsets as follows: 
○ Inbound tour operators (also called: incoming tour operators, ground operators, destination management companies, inbound agents and land operators) - Are specialized on making all the arrangements for international or domestic tourists to visit the country or destination in which they are based.

○ Outbound operators - Are specialized in sending residents of the country they are based in to travel abroad.

At the same time, it is important to understand that tour operators often can pre-reserve and pre-purchase many services like: transfers at destinations, accommodation rooms and travel seats to set up a single price package where each component's price cannot be identified. Such packages are designed to attract customers. For tour operators, buying bulk services generates discounts and economies of scale. As a consequence, tour operators can become vertically integrated, which means they are incorporating transportation, hospitality and entertainment organisations as well as travel agencies (Buhalis, 2001; Martínez, 2002). In line with this idea of vertical integration, big travel agencies with a tour operator belonging to the same company have another type of intermediary at their office called "switch companies"; also known as consolidators" (Lohmann and Netto, 2012; Medlik, 2003) or "brokers" (Martínez, 2002). The main object of this kind of company in the Brazilian context is to sell flight tickets in large scale to these big travel agencies (Lohmann and Netto, 2012).

Furthermore, there are companies that can be virtual distributors, two-channel distributors or even multi-channel distributors. The first type refers to trading only on the internet without any physical presence. In Brazil, it is common to find virtual distributors for accommodation only (e.g. booking.com) or offering accommodation and flight tickets, car rentals, and cruise ship packages (e.g. decolar.com; submarinoviagens.com.br; hotelurbano.com.br). Two-channel distributors are intermediaries that have the electronic retailing as a major aspect of their businesses or maybe as a minor aspect. Moreover, multi-channels distributors are more established companies offering their services in many different ways such as TV, shops, internet, catalogues and telephone (Cooper, Fletcher, Gilbert, Fyall \& Wanhill, 2005).

\section{Consumers}

Consumers are the potential tourists or visitors who purchase tourist services from suppliers and intermediaries. They belong to different markets (countries, regions or cities), 
have different purchasing power (e.g. backpackers compared to luxury tourists), have different cultures, needs, desires and motivations. Thus, they buy products for different purposes.

\subsection{Distribution mix and recent studies about tourism distribution channels}

Combination of distribution channels is called distribution mix. As a result, it means that companies can make use of many different intermediaries at the same time to sell their products. The best way to illustrate this is by understanding the structure presented by Pearce and Tan (2004) in Figure 5 where different distribution channels are used depending on the market (international or domestic) and also according to the segment targeted (tour group visitors, independent visitors and special interest groups). As this figure shows, sometimes the visitor can make direct contact with the tourist attractions and in many cases they can make use of intermediaries like: visitor information centres, accommodation and transport providers, travel agents, offshore wholesalers, inbound operators and schools and education providers.

Figure 5: Distribution Channels for Heritage and Cultural Attractions in Rotorua and Wellington by Pearce and Tan (source: 2004, pp.230).

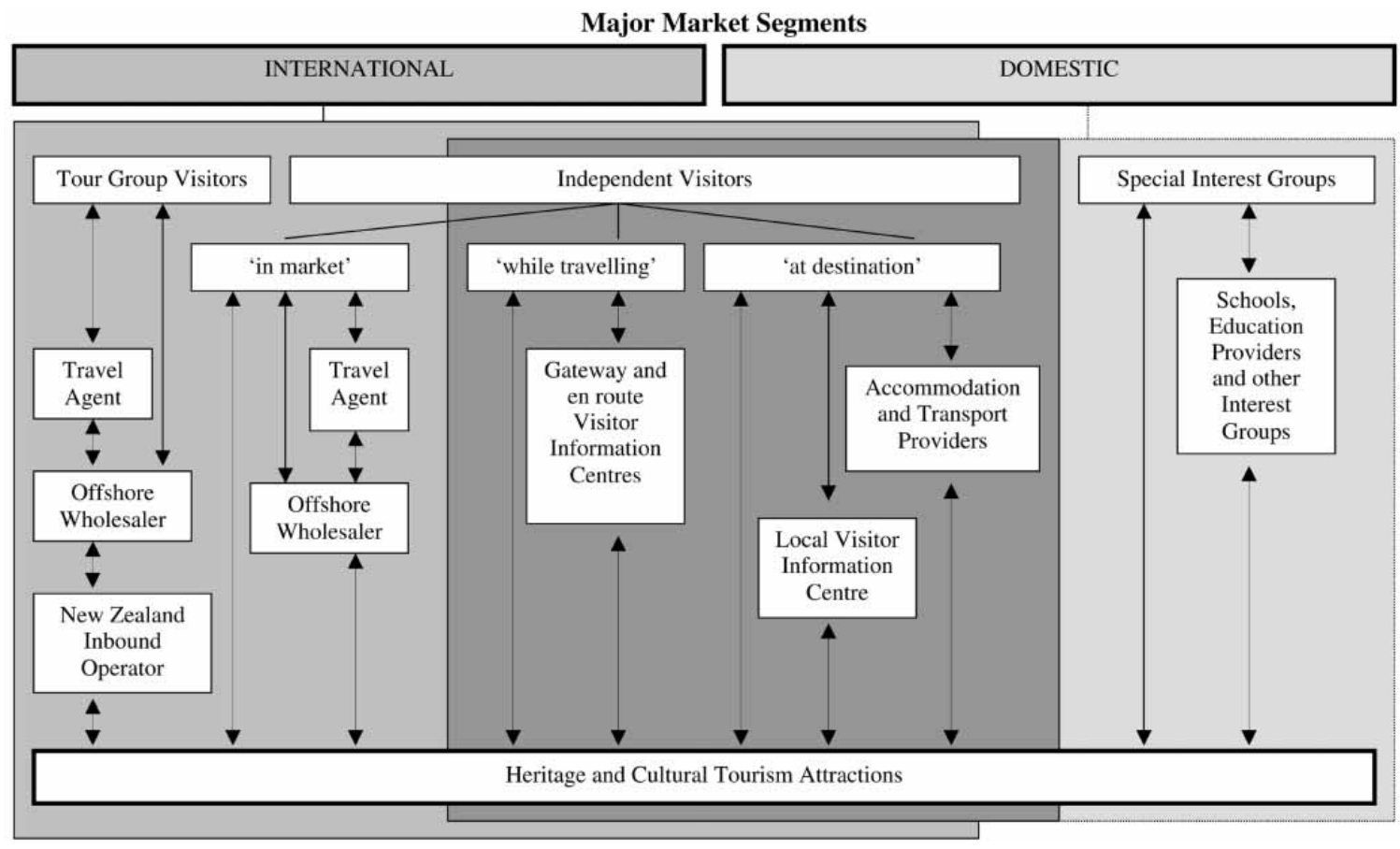

The research conducted in 2004 by Pearce and Tan analysing the structure, functioning and challenges of managing distribution channels for heritage and cultural attractions in Rotorua and Wellington found that the structure of distribution channels varies according to the three different market segments: 'Tour Group Visitors', 'Independent Visitors' and 
'Special Interest Groups'. At the same time, they identified that different channels are used for international and domestic visitors. Consequently, the above structure reflects the differences between distinct segments.

Pearce (2008a and 2010a) depicted the functions involved in the distribution of packaged tours. Figure 6 shows the different functions performed by each of the channel members: travel agency, wholesalers, inbound operator and suppliers. This is crucial to see how these functions vary for each member and understand the relationships among them.

Figure 6: Functions involved in the distribution of packaged tours by Pearce (source: 2008a; pp.159)
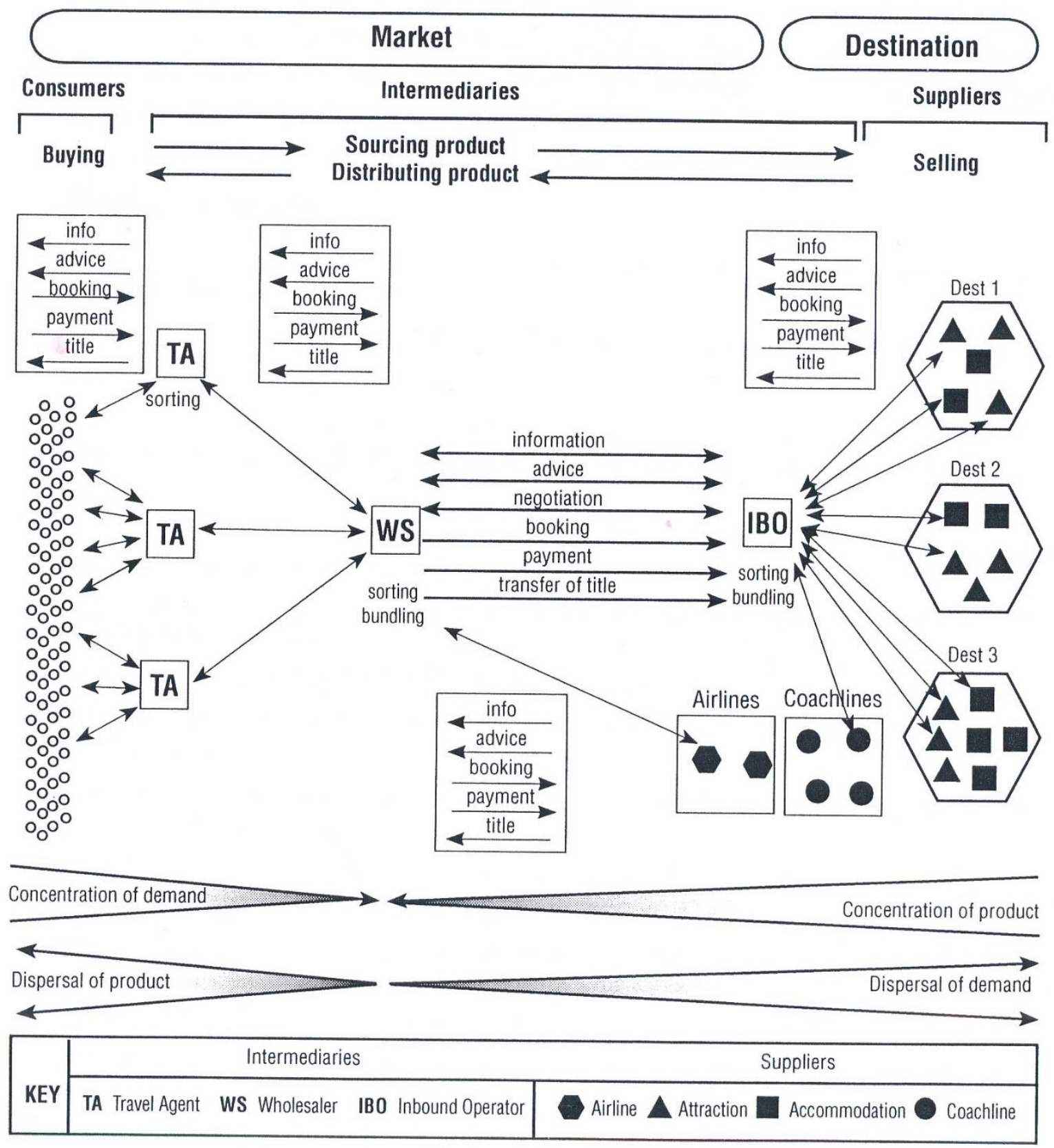
There are many factors influencing channel structures. Schott (2007) investigated the factors underling channels choice of adventure tourism operators in Queenstown and found that these factors are varied and reflect supply characteristics and sector-specific demand.

Pearce and Tan (2004) observed that the factors influencing channels structures are interrelated and were categorized in three main topics: (1) breadth of product appeal, (2) capacity issues and (3) commissionable products.

(1) Breadth of product appeal was strongly related to how some attractions can appeal to some specific segment(s) or all segments. It is about understanding if a tourist attraction is of interest/appeal to anyone who visits the destination, as in the case of the Te Papa museum (representing the history, culture and geography of New Zealand) or the Maori cultural attractions in Rotorua which would be suitable as part of the itinerary of independent travellers, special interest groups as well as group tours. On the other hand, it must be recognized that some attractions may not be valuable to majority of the people because they may be considered more specific to certain groups with special interests.

(2) Capacity issues is about determining the limits to the kind of segments the company will focus on while choosing the distribution channels to work with. In the case of the cultural and heritage attractions studied it means defining "the physical degradation of the property or the diminished enjoyment of visitors" (Pearce and Tan, 2004, pp.233).

(3) Commissionable products refer to understanding the different intermediaries and the tourist attractions' financial interests which determine the nature and extent of the distribution channels chosen. It basically expresses that there is always a commission in play if you want to sell your products via intermediaries; like: visitor information centers, tour operators, and accommodation providers. It is important to note that a tourist attraction that does not pay commission or has a lower commission than other competitive products it may be taken out of the itinerary of a tour operator and accommodation receptionists may not be willing to make reservations for their clients to go there.

Other factors were also identified in terms of choosing to use an intermediary or using direct channels. Some companies stated that the good thing about direct marketing is that you spread your own message about products that many people do not understand much about. Moreover, training staff from a Visitor Center can provide immediate positive effects in the next day (Pearce and Tan, 2004). 
Mkumbo (2010) also investigated the factors influencing channel structures in the northern tourist circuit of Tanzania. In his study he noted that these factors were: distance of companies from their customers, lack of marketing knowledge and formal business knowledge, location of ground operators at a gateway: a close international airport, the inability of companies to handle all functions of distribution channels by themselves, nature of the activity and its appeal, distribution costs, visitor's preference and the cost of promotion.

A more recent identification of the factors influencing the businesses of wine tourism in New Zealand was presented by Liu (2012). She found the following diversity of factors: information cost, commission, businesses' attitudes towards tourism, perceptions of the internet, service diversity, capacity (only regarding vehicle size and cellar door size), accessibility (location), availability, market segments, reputation and nature of intermediaries.

From another perspective Tan (2002) investigated the structure and behavioural explanation of these structures on the distribution channels linking New Zealand and Singapore. The author listed several influences on inbound and outbound operators' choice of counterparts: (1) preference for working with the top 10 wholesalers/retailers to get market penetration; (2) word-of-mouth recommendations (from variety of sources) and reputation; (3) getting to know and learning about other companies in tradeshows; (4) ability to test the reliability and quality of their partners in the initial few years of relationships; (5) according to the product they have available and their costs; (6) based on the gauge of the expertise of suppliers through tourism awards (e.g. Tourism Award winners); (7) in the ability to solve problems or lead-time and (8) to have strategic alliances (for perhaps reaching other markets).

\subsection{Research about distribution channels in Brazil and Fernando de Noronha}

In Brazil, there is very little research about this topic. So far, there are studies done from perspective of the impact of new technologies on travel agencies (Flecha and Costa, 2004; Longhini and Borges, 2005), a case study on the Brazilian adventure capital: Brotas (Filho and Lohmann, 2012), the mapping of distribution channels of rural tourism at Ribeirão Preto region (Lohmann and Nascimento, 2007) and a bibliographic review about tourism distribution channels up to 2005 analysing a total of 43 articles in English and Portuguese (Lohmann, 2006). 
The structure of the distribution channels of rural tourism in Brazil was presented by Lohmann and Nascimento (2007), as may be seen in Figure 7. At the top of the diagram, there are the suppliers: activities and accommodations. While on the bottom consumers are represented by type: families, groups (of young age), couples, corporations, churches, parents, students and individuals. Activity providers have direct distribution (the channel where consumers buy directly at the company or online) or indirect via accommodation or ground operator or travel agency. The accommodations of the region have direct distribution with couples or families. Indirect distribution is more used for corporations, churches and to reach students from schools; in this distribution the intermediaries involved are: sales representatives, travel agencies or schools.

Figure 7: Distribution channel structure for rural tourism at Ribeirão Preto by Lohmann and Nascimento (source: 2007, pp.12, with adaptations)

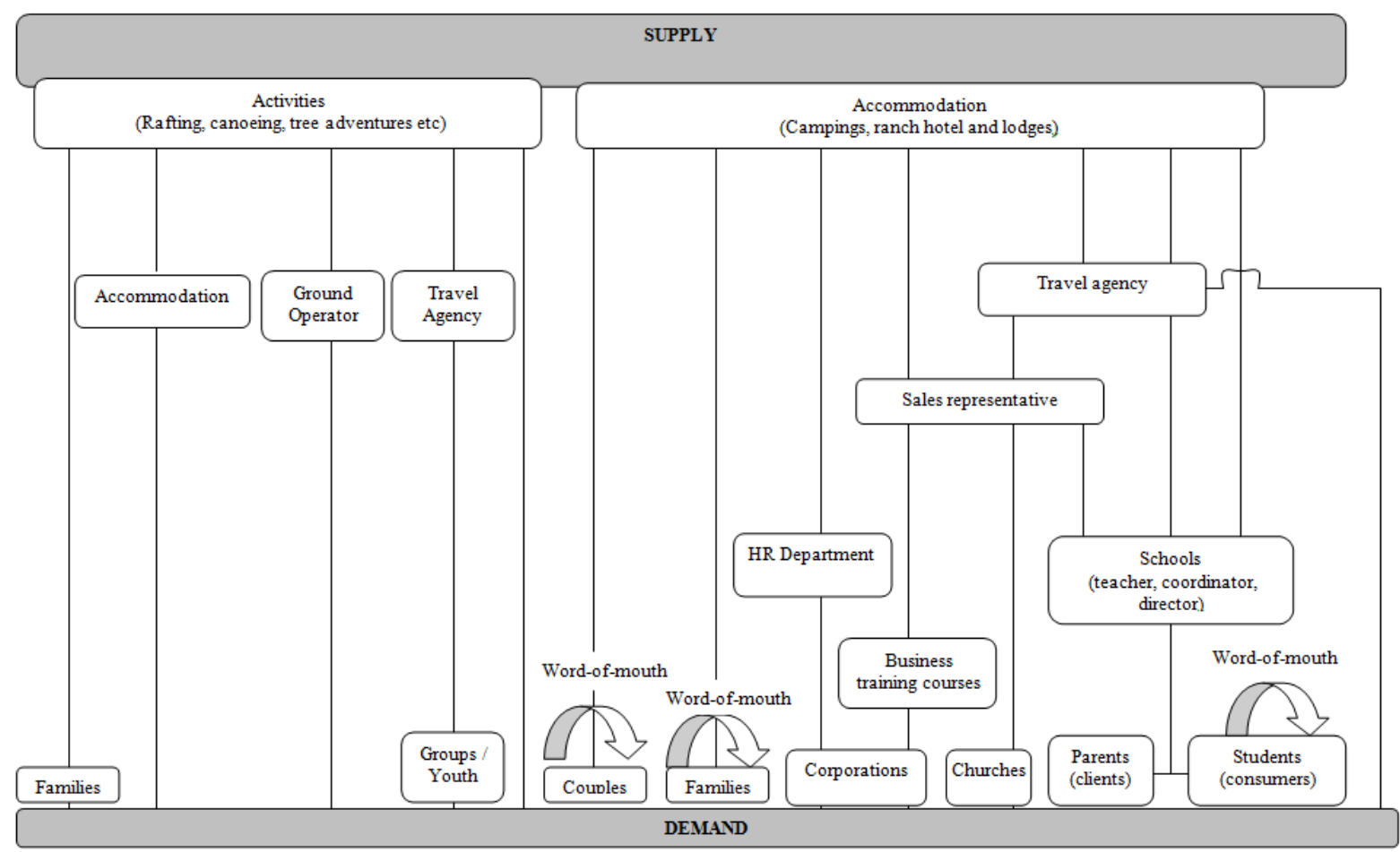

Lohmann and Nascimento's research (2007) has included the distribution of attractions (activities) in the research, as did Pearce and Tan (2004), Schott (2007), Smith (2007b) and Liu (2012) in a New Zealand context. However, according to Pearce (2011) there is still scope for more research to include distribution of attractions since it has been neglected in Brazil (Lohmann, 2006; Pearce, 2011, pp.171) and also because it plays a central role in tourist products of destinations. For this reason, the present research proposes to address this gap in the literature. 
According to Lohmann (2006), there is a scarcity of research on distribution channels in Brazil focusing both on the relationship between the channels and on a case study in a chosen destination. As a consequence, it was recommended that more research could be done trying to reach the following objectives: (1) to establish a detailed analytical structure systematically identifying the different kinds of distribution systems for the main markets of a given destination; (2) to identify the factors that influence the behaviour and motivations of channel members (including tourists) that determine the nature and cohesion of the relationships between them leading to a cooperation and/or conflict in the channel; (3) to evaluate the degree of extension where different structures, practices and relationships of the distribution channel impact on the growth of tourism in a studied destination; and (4) to recommend management practices for the distribution channels of each different market and type of tourism existing in a studied destination (Lohmann, 2006, pp.11). To fill in some of these gaps, this work will present the structure of the different distribution channels at Fernando de Noronha Island and will analyse the factors influencing supplier's distribution choice. Special emphasis will be given to the capacity management of the destination (the use of carrying capacity) as a factor influencing the distribution channels used by suppliers. Such an approach has never been undertaken before in the tourism distribution literature.

\section{Distribution channels in Fernando de Noronha}

A study was created by a marketing consultancy company as part of a bigger project, entitled: "Project to promote the development of tourism in national parks and its surroundings", with the aim of supporting more development of tourism in these conservation units from the perspective of national park as label for the product. This project is organized by the Ministry of Tourism - MTur in partnership with the Brazilian Association of Ecotourism and Adventure Tourism - ABETA (composed only by the private sector) also with the support of: (1) Chico Mendes Institute of Biodiversity Conservation - ICMBio (which is an autarchy of the Ministry of Environment under the special regime of taking care of all federal conservation units in the country and with the power to propose, implement, manage, protect, enforce, do research and monitor these units) and (2) Brazilian Support to the Micro and Small Enterprises - SEBRAE (which covers any industrial or commercial activity including tourism).

This project conducted research in five Brazilian national parks, including Fernando de Noronha. It identified the profiles of the tourists who visit the island. The methodology/approach used by MTur and ABETA (2011) is a bit unclear. Secondary data 
were collected from documents of MTur, Ministry of Environment, ICMBio and ABETA and online research. Primary data were collected with stakeholders via telephone interviews or with the interview questions sent electronically. Interviews with the community and tourists were conducted. In-depth interviews with stakeholders included each interviewee creating a map of the relationships of partnerships and conflicts with other stakeholders as well as presenting tourists' behaviour regarding the channels they use. As well as this, direct and participant observation was undertaken while researchers visited some tourist attractions and participated of the daily activities of the community over ten days.

The tourists of Fernando de Noronha were classified into five categories (relative, cruise tourist, party tourist, adventure/sport tourist and open tourist) according to their characteristics and motivations, (Table 1).

Table 1 - Types of tourists of Fernando de Noronha (source: MTur and ABETA, 2011, pp.47-52, with adaptations)

\begin{tabular}{|c|c|}
\hline Relative & $\begin{array}{l}\text { These tourists only go to Fernando de Noronha to visit their families and they are } \\
\text { originally from Pernambuco State or Rio Grande do Norte State. }\end{array}$ \\
\hline Cruise Tourist & $\begin{array}{l}\text { Generally, the ship leaves the same day; but sometimes the ship may stay one day } \\
\text { and a half. These tourists belong to the middle class. Some of them are considered } \\
\text { as inappropriate tourists to this kind of destination due to their noisy behaviour. } \\
\text { Most of them do not have money to go to the island by plane to spend several days } \\
\text { there. Additionally, they are motivated by status and want to show off that they have } \\
\text { visited the famous paradise. Also, they do not have environmental awareness. } \\
\text { There are about } 600 \text { to } 700 \text { of people on board a the cruise ship so, when they } \\
\text { arrive at the island only half the group is authorized to do activities in land while the } \\
\text { other half may take boat rides or diving activities. Frequently, they also make use of } \\
\text { the following activities/services: taxi, operators and tourist guides, restaurants, } \\
\text { visits to handicraft stores and the handicraft market (specially created and operated } \\
\text { only for cruise tourists) and they rarely go the TAMAR Project store. }\end{array}$ \\
\hline Party Tourist & $\begin{array}{l}\text { Again, also motivated by the idea of the island being a paradise, they look for fun in } \\
\text { parties, are young, from the Southeast region of Brazil, want to meet new people, } \\
\text { may travel alone or with a group of friends and visit the destination on the period of } \\
\text { New Year's Eve. So, usually they stay from the end of December to mid-January but } \\
\text { some people also remain until the end of January. Since they look for interaction } \\
\text { with other tourists, the beaches are the tourist attractions they visit most. }\end{array}$ \\
\hline Adventure / Sport Tourist & $\begin{array}{l}\text { The sports tourist are divided into three groups: } \\
\text { 1. Fishing - They only go for a competition in August. } \\
\text { 2. Regatta - They travel to participate in the sailing regatta in September. } \\
\text { 3. Surfing - Aimed at getting the best tides from January to February and also } \\
\text { participating in a competition during this period. } \\
\text { Adventure tourists look for diving activities from the end of August until October } \\
\text { because it is when the deep sea is more visible. In addition, it was observed that the } \\
\text { above competitions encourage visits by these tourists. The scuba diving companies } \\
\text { design products specifically for them. }\end{array}$ \\
\hline
\end{tabular}




Ohese are categorized as national or international tourists.
National: The majority of them are from the South Region of Brazil looking for
leisure, beach, diving activities and rest/relaxation. Generally it is a couple or a
family (sometimes even with very small children) with a university degree, well
informed and demanding. But they are also motivated by the idea of going to the
Brazilian paradise.
Before visiting the destination, they plan and make reservations through a travel
agency or via Internet. In general, the services used are: accommodation,
restaurants, handicraft shops, TAMAR Project, entertainment activities, rent
transportation as well as making use of the operators and tourist guides.
They are also categorised into two groups:
- Luxury accommodation - These clients are middle or high class. Also looking
for the Brazilian paradise, they are demanding and opinion formers.
Simple accommodation - Also called 'dreamers', because visiting the
destination represents a dream to them. They spend some time saving money to take
the trip, so the trip is planned.
International: Usually, these tourists come from Europe, especially from France,
Spain and Italy. They visit the island in July and August and are motivated by nature,
and for this reason they usually take more trails than other tourists. Their travel is
also purchased through the Internet or a travel agency.

As mentioned the cruise tourist, the party tourist and the national open tourists are all motivated by the idea of paradise. So they are attracted by the destination's images of sun and beach. While the adventure/sport tourist and the international open tourists have different motivations; they look for ecotourism, adventure or sports activities. Regarding the number of tourist arrivals, it can be noted that the cruise ship tourists outnumber those reaching the destination by air per day (since only 246 tourists can arrive at the destination by air in a day, while the cruise ship takes 600 to 700 a day; ADEFN, 2007; MTur and ABETA, 2011).

The types of tourists who usually return to the destination are the party tourists and the adventure/sport tourists (who only visit the island in the specific season which is best for their intended activity; MTur and ABETA, 2011).

The diagram in Figure 8 presents the findings of the research conducted for MTur and ABETA (2011) indicating tourists' purchasing behaviour and the distribution channels used. These are represented with the use of coloured arrows, which show the activities usually enjoyed by these five distinct tourist groups and what means they use for bookings (using travel agency and/or internet). It can be noticed that the cruise tourist is identified by the red arrows, the party tourist is represented by the yellow arrow, the adventure/sport tourist the blue arrow, the open tourist is identified with the green arrow and the relatives that visit the island do not make use of any of the tourist services and activities provided. 
Figure 8: Tourist behaviour at Fernando de Noronha (source: MTur and ABETA, 2010, pp.48, with adaptations)

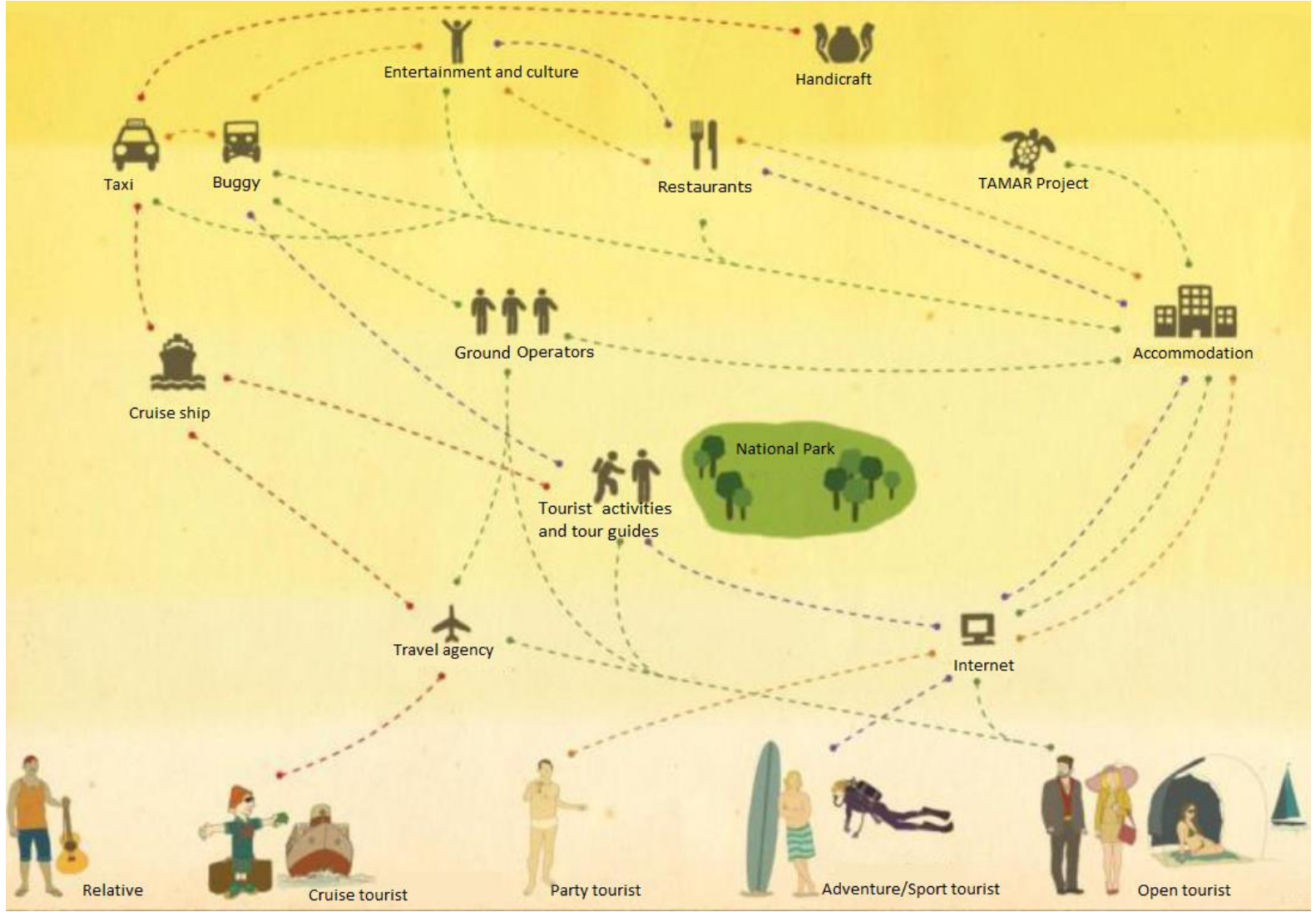

However, the diagram above is very limiting because it involves mainly the suppliers at the destination. Also, it is very confusing for two main reasons: firstly the national park, which means the island, seems to be a separate tourist attraction or type of supplier and secondly this representation does not make use of literature about tourism distribution channels which provides clearer and more precise representations for the understanding of these structures. Furthermore, it does not clearly represent other types of intermediaries; the use of 'internet' as a channel is very vague.

Moreover, in the same study there is an attempt to provide an understanding of the relationships between suppliers as illustrated in Figure 9. 
Figure 9: Relationships between suppliers at Fernando de Noronha (source: MTur and ABETA, 2011, pp.55, with adaptations)

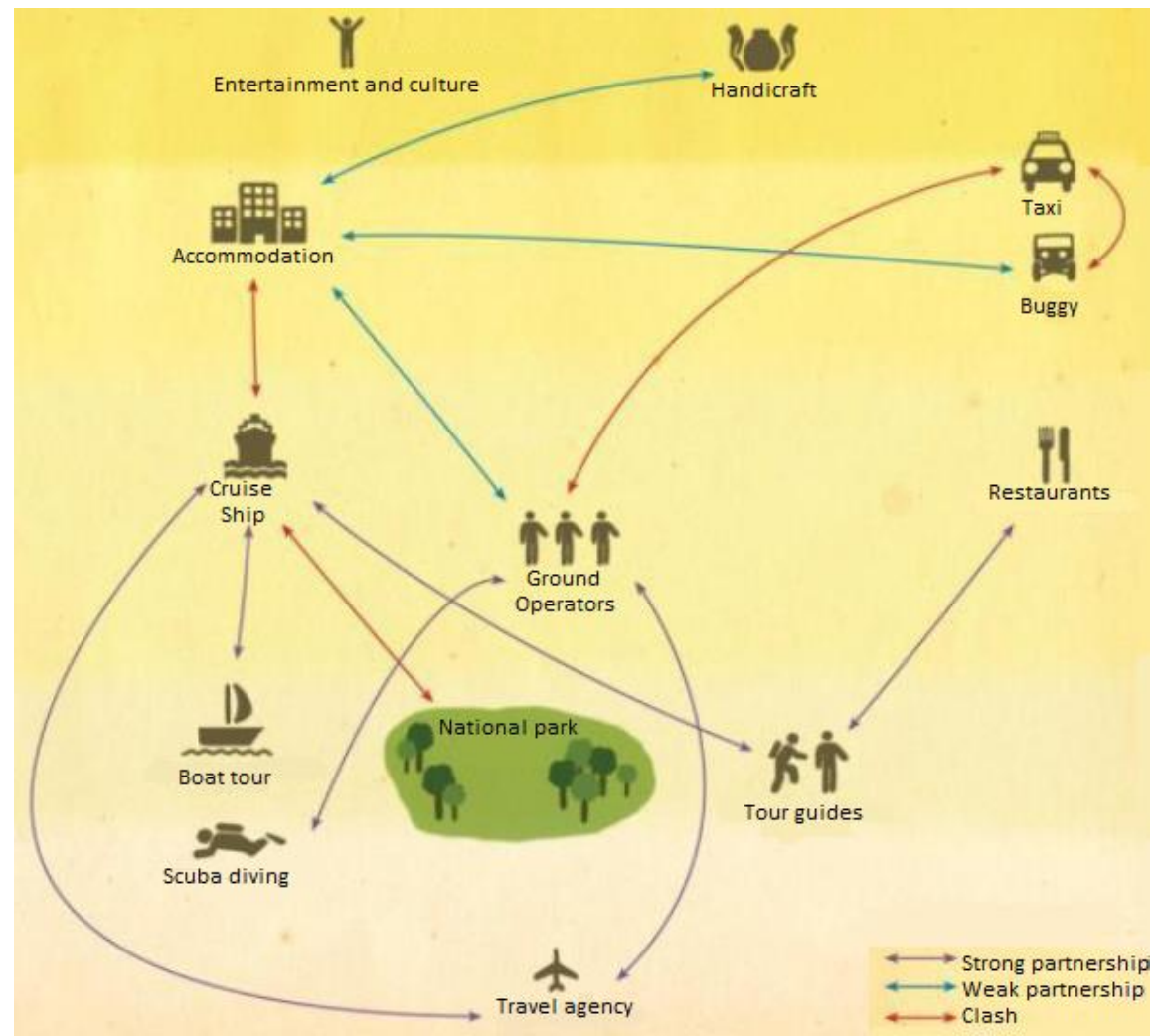

Unfortunately, this representation also failed to provide a deep understanding about these relationships for many reasons. Again, the national park now seems to be a separate tourist attraction when it actually is supposed to be the universe of this diagram. There are a limited number of intermediaries represented in the figure and for this reason it lacks information about tour operators and online reservation websites. It omits the direct channel between consumers and suppliers. It is probably lacking more relationships between these channels as well as among suppliers and intermediaries.

As a consequence of the issues found with both figures 8 and 9, and especially considering that intermediaries outside the island were not interviewed, the present research will address these issues. It includes interviews with a bigger diversity of supply-side participants and based on the holistic approach that has been covered by the latest research (in Portuguese and English) of tourism distribution channels.

\subsection{Capacity management: concepts, distribution channels studies and gaps in the}

\section{literature}

For the purpose of this research, capacity management of a destination is the use of carrying capacity as way of providing sustainable development to destinations (Johnson and Thomas, 1996; Filho, 1996; Swarbrooke, 1999; PNUD, IBAMA \& elabore, 2007; 
Butler, 2010). Capacity management has not yet received attention when related to tourism distribution channels as a factor influencing their structures. Although some previous studies include capacity as a factor, these studies (Pearce and Tan, 2004; Smith, 2007b; Smith, 2007a; Schott, 2007; Smith, 2008; Liu, 2012) actually refer to business capacity: an internal constraint of the company. The difference in the current research is that capacity management is seen as an external limitation imposed by the public sector in order to protect the fragile habitat of the wildlife found in Fernando de Noronha.

Studies taking a business-capacity approach include Schott (2007) where it was mentioned that suppliers of adventure tourism services make their choice of channel and distribution structures based on three factors including capacity issues. In this case, capacity issues are related to service capacity, which is about the size of the business and the number of people that can use the service per day. It was identified that micro and small businesses in Queenstown have low-capacity products due to the highly personalised nature of the product. , As a consequence, only independent travellers are targeted by these businesses and group bookings do not exist. Another approach to capacity is found on the research done by Smith (2007b) where capacity of events depends on the venue, the infrastructure of the destination (particularly considering the accommodation sector) and the experience planned by organisers. In another study, the same author - Smith (2007a) - explores the importance of the distribution of ticketing in events where capacity is a visitor management practice.

In the case of Fernando de Noronha, capacity management is not only dependent on the service capacity of businesses and on the amount of accommodation provided in a destination. It also includes a limited imposed by the government which determines the number of visitors the destination can receive per day. What is proposed here is to analyse how suppliers deal with capacity management on an island which is isolated and remote and has a limited number of tourists permitted to stay or make use of its services.

Tourism distribution channels will be used to build a relationship with the stages of development of the destination based on Butler's tourism area life cycle (TALC) and on Plog's psychographic tourists. This association is relevant because it provides a context to compare the actual development stage with the marketing practices undertaken by stakeholders (Malcolm-Davies, 2006).

A very pertinent piece of research conducted by Falcão (2010) analysed the sustainability of the island based on the TALC approach - proposed by Butler in 1980 - and sustainability 
dimensions. Butler's TALC model shown in Figure 10 is based on the product cycle concept which demonstrates that the sale of a product, in this case the destination, passes through three stages (exploration, involvement and development) before reaching the consolidation and stagnation stages. These two last stages constitute a critical range of elements of capacity which means that with marketing, information dissemination and increased provision of facilities, the destination's popularity will increase so fast that the carrying capacity of the product will be reached (Butler, 2006). For this reason, it is important to research the information provision function of distribution channels (and promotional activities), because it influences the destination image and market coverage. Thus, the channels should be carefully chosen according to the audience and coverage of the intended image the destination wants to have. In addition, it is worth noting that information provision can be performed by both the public and the private sectors.

In the TALC, as a result of the levels of carrying capacity being reached, the destination may experience a decline on its attractiveness and consequently a reduction in visitor numbers. The possible way to avoid this situation would be the creation of a strategic plan composed by measures to lead the destination to other better stages (e.g. rejuvenation).

Figure 10: Hypothetical evolution of a tourist area (source: Butler, 2006, pp.5)

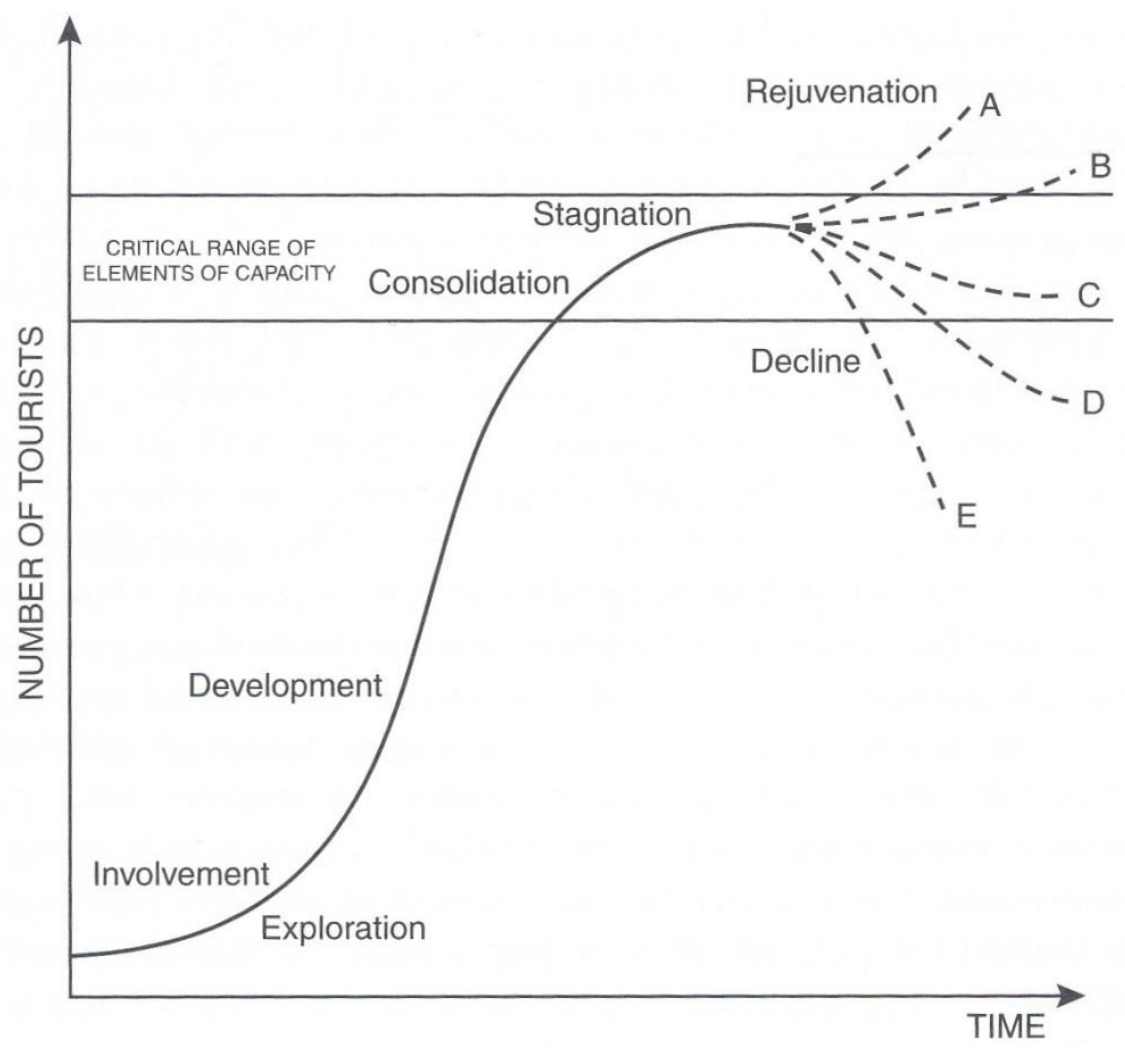


According to Falcão (2010), Fernando de Noronha is at the stages of development and consolidation at the same time due to a lack of clear identification of when a destination moves from one stage to another because it is a gradual process. The development stage means that the destination will have heavy advertising in the place of origin of the biggest outbound markets, changes in the landscape are noted but not enjoyed by the local community, imported labour is used and there will be extensive visitation by 'midcentrics'(as explained further in Figure 12). The consolidation stage is defined by an even higher number of tourists at the destination but with a smaller overall rate of increase; total visitors numbers being higher than the number of residents; the great majority of the local economy depending on tourism; and the marketing and advertising of the destination being broad reaching, with the addition of more efforts to grow visitor's seasonality and markets' coverage (Butler, 2006).

Falcão (2010) also created a TALC timeline for Fernando de Noronha that is useful to provide background on how the island's tourism has developed (Figure 11):

- 1965 - 1974: Exploration phase: The USA military base leaves in 1965. There was the creation of Esmeralda Hotel in 1972 and in 1974 tourism started to occur only for military personnel

- 1975 - 1988: Involvement phase: First telephone services were installed and an extension on the airport runway was made in 1975. The community of the island started to feel satisfied when receiving visitors in 1984. The first TV channel began transmission and the first diving operator began operating in the same year. In 1988, the archipelago came under the management of the State of Pernambuco.

- 1989 - 1997: Development phase: New generators were installed and consequently energy generation capacity arose. The opening of the local economy to investments of entrepreneurs happened around 1998 and that is when the ccreation of new accommodation cycle' started.

- 1998 - 2009: Consolidation phase: Opening of a luxury accommodation in 2003. So, this is the period when the 'opening of luxury accommodation cycle' started. This phase also has registered the highest numbers of tourist arrivals. At the same time, the island began to appear in the strategic tourism plan of Pernambuco State. 
Figure 11: Stages of the tourist area life cycle of Fernando de Noronha (source: Falcão, 2010, pp.106 with adaptations)

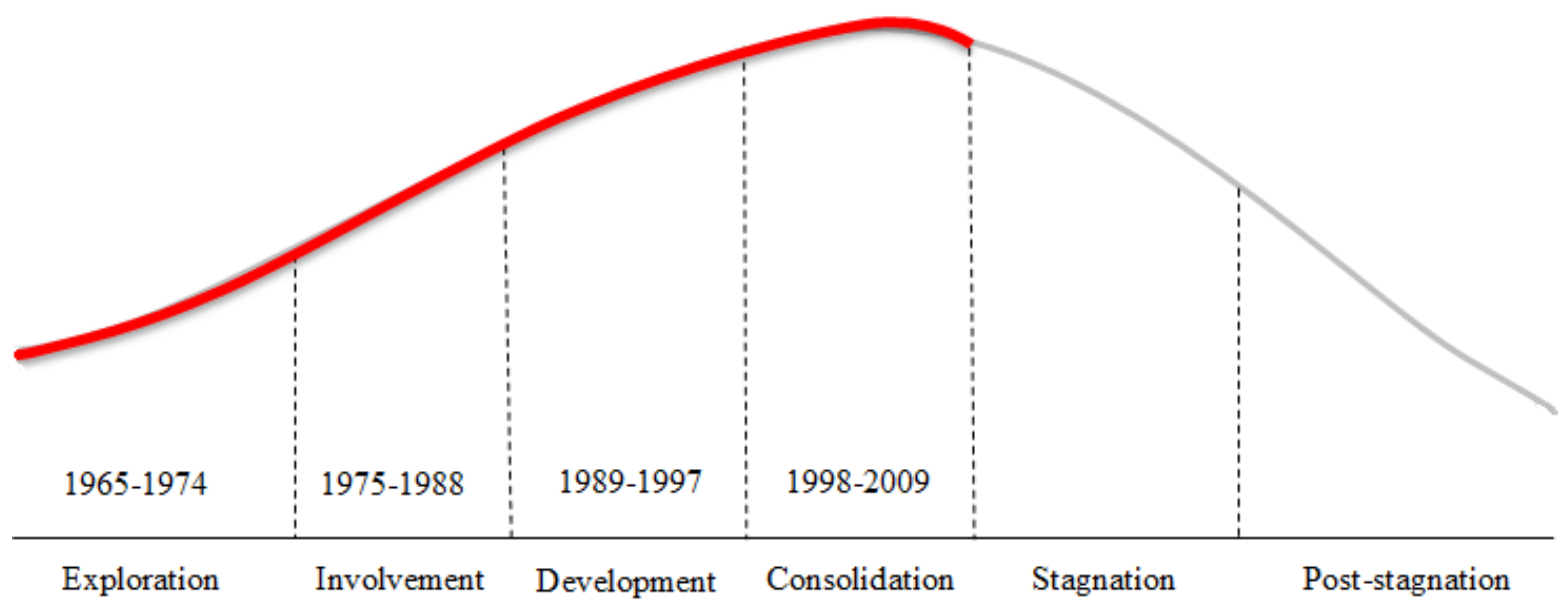

Another perspective on the stages of development of destinations was drawn by Plog (Plog, 1974). In his study the type of tourists destinations get relates to their stage of development. The types of tourists were divided in 5 groups: psychocentric, near psychocentric, midcentric, near allocentric and allocentric. Allocentrics are tourists who enjoy the sense of discovering non-touristy areas, usually fly to destinations, enjoy experiencing lots of activities, like to have flexibility when travelling, enjoy meeting people of foreign culture and the products they choose must offer advantages over other destinations: it must be a novelty or unique. On the other hand, psychocentrics are interested on sun destinations to relax, they do not make use of many activities, prefer familiar atmospheres, strongly rely on scheduled activities and prefer destinations they can drive to.

According to Plog, destinations are initially discovered by allocentrics that promote them via word-of-mouth to near allocentrics (which provides an increased level of visitation to the discovered destination leading to the development of its tourist infrastructure and facilities). When the destination has become much more popular mid-centrics greatly increase the number of tourist visits. This changes the destination to a mature stage of development until it reaches its maximum potential of attracting the broadest audience; as it appears on Figure 12, in which the curve starts from right to left. The author called the attention to the need of planning when destinations receive mid-centric tourists because it means that in the future the destination will suffer lots of negative impacts; consequently leading to the fall of its attractiveness (represented by the descent curve from mid-centric to psychocentric types of tourists received by the declining destination). 
Figure 12: Population curve of psychographic groups by Plog (source: 1974, pp. 56)

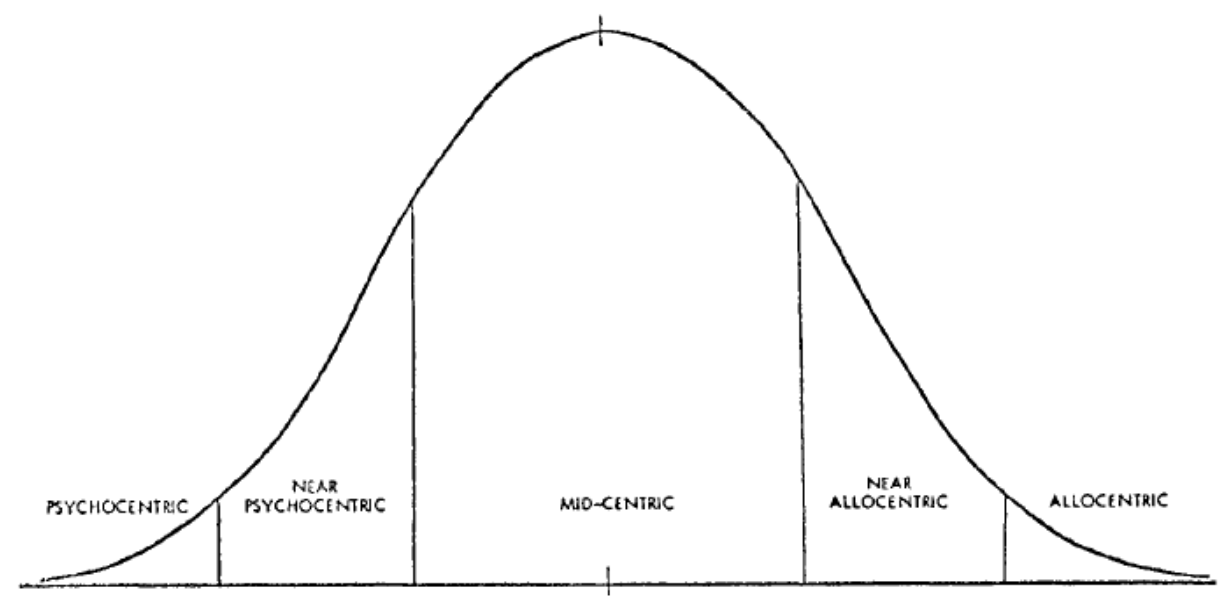

Identifying the stages of development of Fernando de Noronha, according to Butler's TALC model and Plog's psychographic tourists, is important because it provides the opportunity to make a relationship between these stages and the distribution channels currently used during the phases of the destination's development. Likewise, understanding the current most used and less used distribution channels may provide insights to utilise channels of distribution as the most important strategic tool to change the actual development stage of the island. The distribution channel may provide the competitive advantage the island will need to have when avoiding the decline stage.

\subsection{Conceptual framework}

To assist on the concepts under study and on the relationships explored on this research, a conceptual framework was developed. This has helped the researcher to structure the interview questions and to present the results of the objectives of this research in diagrammatic form (Pearce, 2012). Moreover, the conceptual framework is a result of the concepts explored in this literature review.

Since distribution channels may play a crucial role in the development stages of destinations, the conceptual framework in Figure 13 expresses on the left side the distribution channels structure and on the right side the factors influencing these structures (based on the work of Pearce and Tan, 2004). In this framework, it is worth noting that consumers can directly have access to suppliers or make use of up to three intermediaries to book a holiday. The blue column on the right shows examples of factors that can influence the choice of tourism distribution channels used by suppliers. However, it can also be noticed that some factors are exclusively created by the private sector while other factors may be produced by the public sector, such as the capacity management of the 
destination. Hence, the box in blue aims at expressing the main focus of this research: to understand how a governmental management mechanism - the capacity management of destination - is influencing the private sector's distribution channels.

Figure 13: Conceptual framework: factors influencing tourism distribution channels in a capacity controlled destination

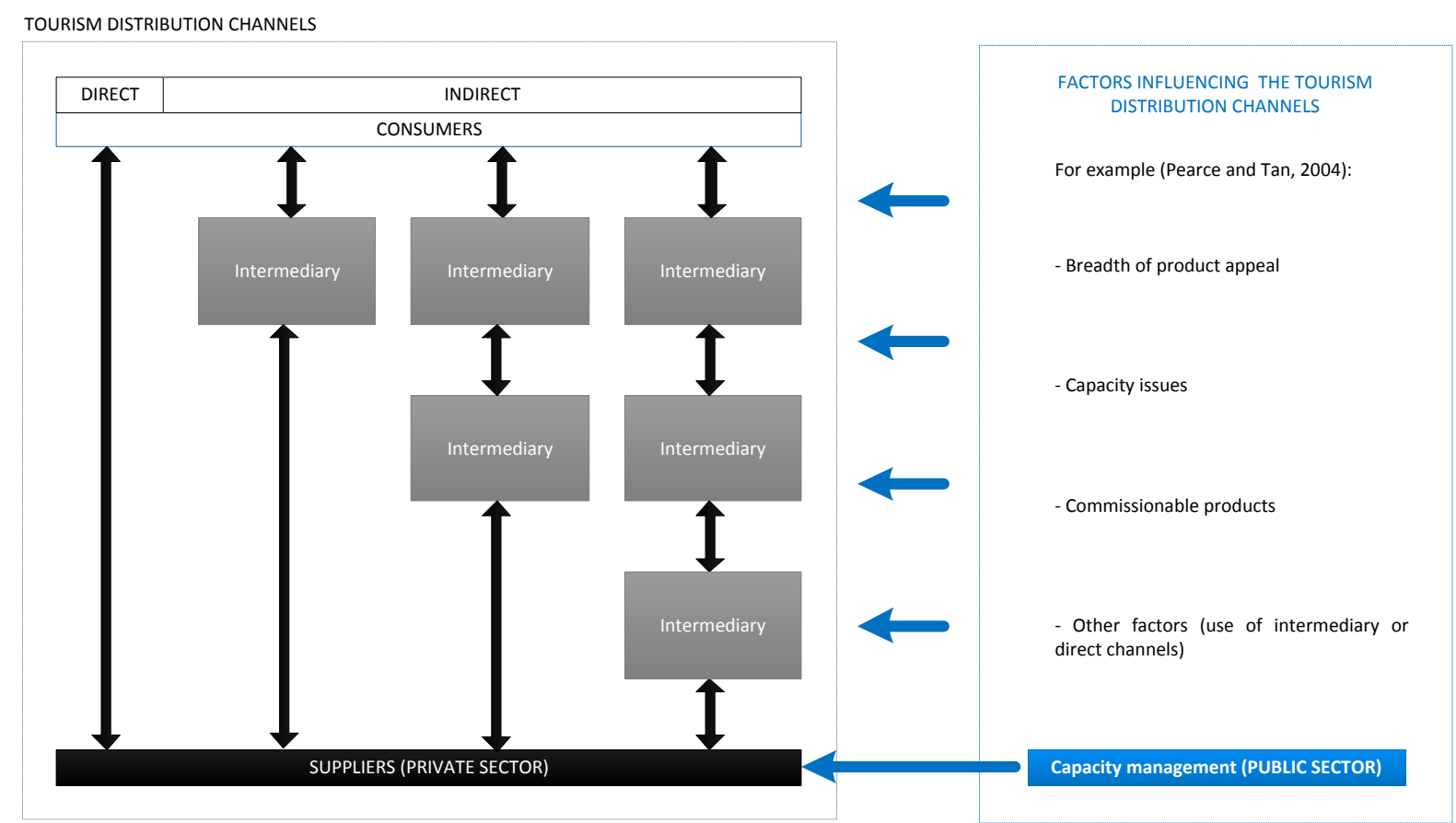

\subsection{Conclusion}

This research is proposing a new perspective on the literature about tourism distribution channels by linking the concept of capacity management of the destination with the practices of suppliers towards the 'place' element of the marketing mix. It also contributes to the incipient research on distribution channels in Brazil.

An overview of the key concepts of this research was highlighted and depicted on the conceptual framework. Moreover, this study will fill in the gap on the literature regarding the need for more research that includes attractions.

In order to identify the structures of distribution channels of Fernando de Noronha, to describe the factors influencing these structures and call attention to capacity management as factor, an analytical framework based on these three aspects will be presented on the next chapter. Secondary data of previous research conducted on the island were outlined in section 2.5. The section 2.6 presented the concept of capacity management and the TALC and psychographic tourists theories. All of these will be considered to add more understanding to the findings during the discussion chapter. 


\section{Chapter 3: Methodology}

\subsection{Introduction}

This chapter will outline the qualitative approach used for data collection based on previous studies on tourism distribution channels both in Brazil and New Zealand. Initially gaps in the literature will be identified followed by a presentation of how previous studies have conducted research on tourism distribution channels. After that, information about the study area will be discussed and the sampling techniques will be described.

To investigate how the capacity management of the destination of Fernando de Noronha is influencing the tourism distribution channels of suppliers, an analytical framework was created based on the three research objectives (see chapter 2). The framework also included the two main sources of data collection: the public and the private sectors.

To conclude the chapter, strengths and limitations will call the attention to the issues regarding the methodology used and it will include some limitations which occurred during fieldwork.

\subsection{Research gaps and methods used in tourism distribution channels' research}

Qualitative methodology is undertaken in this research because it provides a flexible approach where the researcher is interested in emblematic themes that appear during data collection (Veal, 2006; Jennings, 2010). It also aims at exploring social complexities with the objective of understanding interactions, processes and lived experiences of participants (O’Leary, 2010). According to Creswell (2009), this investigative process happens in the natural settings of participants where events occur, it is based on assumptions, the data that emerges are descriptive, that is reported in words. There is an attempt to understand multiple realities by making sense of participant's perceptions and experiences and the main outcome of qualitative research is the process: the understanding of how things occur.

The strategy of inquiry of this research is a case study, by which distribution channels are explored in depth as a process that is being evaluated in a delimited space. The research also makes use of a constructivism approach where participants construct the meanings of a situation. 
According to the previous chapter, research on tourism distribution channels has five different approaches (Pearce, 2010a) but this work will focus on the structural, behavioural and functional approaches in order to present the structure of the tourism distribution channels from the suppliers' viewpoint, as well as analysing the behavioural aspects with special attention to the capacity issues component and its relationship with the capacity management of the island.

The method used to conduct this study is inductive research by which a specific situation is researched and there is an attempt to elicit theories from the data created (Finn, ElliotWhite \& Walton, 2000).According to Pearce (1991, pp.47) an inductive approach: "reviews individual examples and then infers general principles from the case studies which have been considered." This means that explanations of the theories produced will be based on the experience lived by the main participants of this research, in this case tourism suppliers, intermediaries and public sector officials.

Thomas (2006) indicates that besides its convenience, the purposes for using an inductive approach for data analysis are three: "(1) to condense extensive and varied raw text data into a brief, summary format; (2) to establish clear links between the research objectives and the summary findings derived from the raw data and (3) to develop a model or theory about the underlying structure of experiences or processes which are evident in the raw data".

The primary data were collected from semi-structured in-depth interviews with suppliers, intermediaries and governmental organisations. Finn, et al., (2000) explains that the importance of a semi-structured interview is that besides allowing you to compare key questions, it also provides the opportunity of asking for more clarification and elaboration on the responses obtained from interviewees. It is a well-used method with other distribution channels studies using the same technique to collect data (Schott, 2007; Pearce, Tan, and Schott, 2007; Pearce and Tan, 2004; Lohmann and Nascimento, 2007; Mkumbo, 2010; Sharda, 2005). This technique also allowed the researcher to send an email to a couple of respondents to ask for more clarification about an issue uncovered during the representation of the findings.

Secondary sources were also gathered from theses and publications from Brazil about work done in Fernando de Noronha (Falcão, 2010; MTur and ABETA, 2011) as well as about tourism distribution channels in this country (Lohmann, 2006; Lohmann and Nascimento, 2007; Filho and Lohmann, 2012). A specific report from the Ministry of Tourism in 
partnership with the Brazilian Association of Ecotourism and Adventure Tourism (MTur and ABETA, 2011) assisted with the analysis of this thesis because it provided the characteristics and behaviour of the tourists who visit the island as presented in the last chapter in section 2.5. This report also gave background information that helped the researcher be prepared for issues experienced by suppliers that could come out during data collection.

\subsection{The study area}

As already discussed in chapter 1, Fernando de Noronha is an isolated island off the Northeast coast of Brazil. The destination can only be reached by air from Natal (located in the State of Rio Grande do Norte) and Recife (located in the State of Pernambuco). While Recife has two daily flights to and from the island, Natal only has one. Cruise ships also take about six hundred to seven hundred tourists at a time to the destination. There is also the possibility of going to the island in a private boat, but in this case a conservation fee must also be paid in order to anchor the boat. Data were collected on the island and in the two gateway cities (Recife and Natal) in order to identify the structure of the tourism distribution channels to the island. Since Fernando de Noronha is a territory that belongs to the State of Pernambuco, its capital, Recife, was also the location to collect information from the regional tourism organisation (called EMPETUR) and from the State government who is responsible for the management and development of the island (specifically the institution entitled ADEFN). A representative from the Ministry of Environment (ICMBio) responsible for this national park also participated in the research and the interview occurred on the island.

Interviews with suppliers (accommodation, transportation services and activities/attractions) were conducted mostly with owners and general managers, but in a few cases other staff were interviewed. The interviews with intermediaries (mainly travel agencies, tour operators and ground operators; including the travel agencies that sell cruise ship packages) were conducted with managers or with business owners in the case of half of the ground operators interviewed. The interviews with the public sector occurred with managers of the institutions directly involved with the management, tourism, marketing and promotion of the island: EMPETUR, ADEFN and ICMBio.

A checklist of questions was designed according to the two types of interviewees: private sector and public sector. The reasons for this are the different roles played by these stakeholders and the different influences they have at the destination. Since the questions 
varied for different kinds of participants, two checklists were prepared (see Appendices): one for the public sector and two for the private sector (for intermediaries outside the island another version was created without the questions: 12 and 16; so, ground operators had the same questions of suppliers). The questions for private sector respondents covered the structures of the tourism distribution channels used, what factors influence the choice of channel mix and if the capacity management of the island is a factor that influences their choices. The questions to the government aimed at examining how the management plans and practices influence suppliers' tourism distribution channels. However, after collecting data from suppliers a few changes had to be made to the interview questions of one government organization, for example additional questions on specific tourism and conservation project being run by ICMBio.

The research interview questions were approved by the Pipitea Human Ethics Committee (see Appendices). The information sheets and consent forms (see Appendices) were handed to interviewees before the interview started in order to make sure they understood the main idea of the research and formally consented to the interview being recorded. In some cases when the interviewee did not agree to the interview being recorded, notes were taken.

It is worth noting the important role gatekeepers had on this research in order to gain trust when recruiting some participants; especially in a country with the culture of only providing some kind of information if the person has a referral from someone they can trust. However, having an official email address and ID from the university proved to be very good credentials during the recruiting process; the ID (with the researcher's picture) was in many cases used as identification for the researcher. In fewer cases the work experience of the researcher was also considered as an important factor that called the attention of interviewees. A supporting letter from the university was obtained and it allowed the researcher to prove that a trustworthy institution has endorsed the research project. However, this letter only needed to be used once.

Unfortunately, there was no opportunity for the researcher to do pilot interviews to test the interview questions, since the questions were designed for decision makers who could later contact the researcher about the findings. On the other hand, the researcher asked interviewees to comment if they had missed something by the end of the research and no one made any recommendation or criticism. 


\subsection{Sampling}

According to ADEFN, there are about 122 suppliers at Fernando de Noronha (Fernando de Noronha - Pernambuco Website, 2012). However, the real number of suppliers is unknown because the field trip at the Island revealed that there are more suppliers due to the provision of services by some companies operating without a license from the government. This means they do not constitute a company formally recognised by the government and they are informal businesses. The reason for that is to avoid paying taxes and providing lower prices when competing with other companies. At the same time the researcher noticed that there is no initiative from the government to avoid or remedy this situation.

Additionally, the researcher checked the local telephone directory to see if it could help reveal the universe of suppliers but it has not been updated since 2006. As a consequence, the universe of suppliers on the island is hard to establish accurately. For the same reason, identifying all the diversity of tourist activities being offered was only possible once the researcher arrived at the destination (despite the online research made beforehand). Once at the destination, three additional different types of activities (suppliers) were identified and included in the research: adventure activities (surfing, rappelling, slacklining and rock climbing), horse riding tours and underwater photo and video service.

The variety of suppliers and tourist services provided on the island are: accommodation, guided tours, transport provision, adventure activities (surfing, rappelling, slacklining and rock climbing), horse riding tours, event organisation, diving activities, fishing activities, restaurants, shop stores (of handcraft and rental of equipment: for snorkelling, surfing, waterproof camera and biking), boat tours and underwater photo and video services. Ground operators, as previously explained on chapter two, are intermediaries located at the destination and they were also interviewed.

For the purpose of this research, restaurants and shops were not considered. The type of product they provide is not relevant for a tourism distribution channels analysis since they do not need to sell or promote their products before the tourist arrive at the destination.; This also means that there is no pre-purchase of these services/products and consequently they do no build any relationship directly with consumers before consumption.

Additionally, it was expected that the information gathered from suppliers would vary according to the markets they work with (whether the company receives mainly national or international tourists, or both), depending on the ownership of the company (whether it is 
owned by a local without higher education or by non-local business people with a university degree) and the type of tourists they receive (a luxury tourist has different expectations and needs compared to backpackers for example).

The selection for the interview with suppliers was 'stratified purposeful', which means, based on the criteria that the subsector of the company was considered. The aim was to interview as many different subsectors of companies as possible to represent all distinct services provided by suppliers. In addition, 'purposeful sample' included the following considerations:

1. The type of tourists received as clients and product appeal/price (luxury tourists differ from 'Party Tourists' and luxury products differ from more simple and cheaper products);

2. The location of the accommodations (they are distributed in seven villages, as it can be noticed on the map in Figurer 14 below) and of the tourist activities providers.

Figure 14: Map of the villages with businesses at Fernando de Noronha

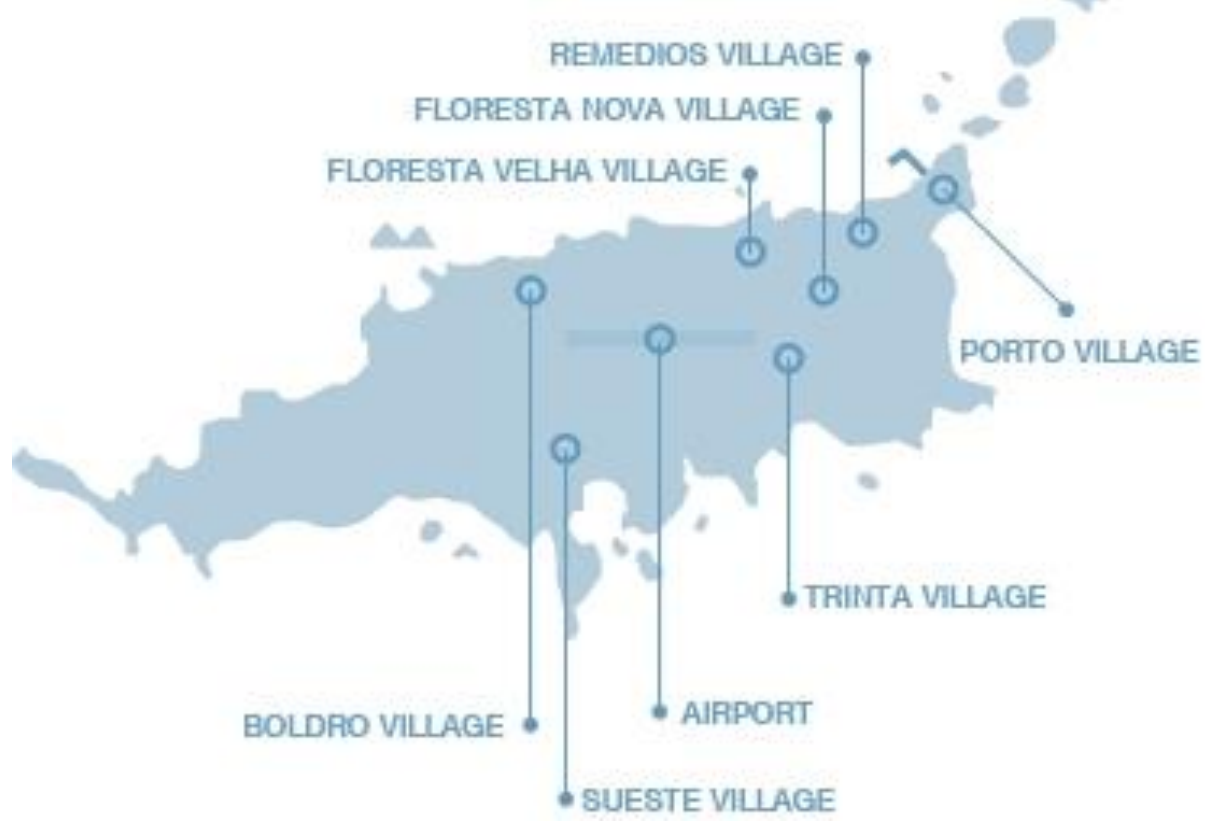

Source: www.ilhadenoronha.com.br (with adaptations)

Initially, many interviewees were contacted via an email which contained information about the project as well as an invitation to participate in the research. They were asked to provide a suitable date and time for the interview. But as many companies did not reply to the email, a follow-up phone call was made after one or two days. In the case of the 
businesses located at Fernando de Noronha, the researcher also was able to visit in person the businesses previously selected to make an appointment when the contact by phone did not succeed or when the researcher was coincidentally passing the company's premises. Another good place used to meet gatekeepers and recruit interviewees was at the TAMAR Project's theatre, where there is a daily hour-long informative presentation for tourists about the island's attractions and on-going conservation projects, e.g. dolphins, sea turtles, sharks, native plants, flowers and bushes etc. So, it was possible to meet some suppliers or get information about others there.

In order to identify the intermediaries to be interviewed in Recife and Natal as well as to know which companies own and sell packages to the cruise ships, the 'snowball technique' was occasionally used in order to get referrals from interviewees to recruit these targeted companies. However, in most of the interviews with suppliers these companies were mentioned incidentally without any input from the researcher. The researcher also contacted some gatekeepers to get contact details of decision makers (business owners and managers) in the companies interviewed (for both suppliers and intermediaries).

Multi-distributors were interviewed and they represent some of the biggest intermediaries in the country regarding the number of stores distributed in the country and revenue obtained. Although their headquarters are located in São Paulo State and the researcher was unable to include a trip to that State, it was possible to interview the regional managers who are the main contacts of the companies in the Northeast region of Brazil or in the State of Pernambuco.

The data from the interviews is presented as non-attributable where respondents were identified by broad categories, which are: accommodation, tourist attraction/activity, transport provider, intermediary and government body. It was expected that about 30-40 interviews would be undertaken and a total of 41 valid interviews were conducted. One interview with an intermediary was discarded because the employee who was designated by to do the interview was not able to answer most of the questions, and the company did not have someone from a higher position available. Since tour guides were difficult to reach, the president of the association of tour guides in Fernando de Noronha (ACITUR) was interviewed.

Only 4 companies declined to participate on the research. Of these, 2 were airlines, 1 was a supplier and 1 a cruise ship operator. As cruise ships have been visiting the island since 1990 (Viver Noronha, 2012), this service was included as one of the transport providers to 
be researched. However the tour operator that has permission to carry cruise passengers to the island cancelled the service in 2012 and the reasons for the cancellation were discovered in an interview. During the fieldtrip it was hard to contact the company especially because of the doubt whether the company would be still providing this service in the future. After returning from Brazil the researcher finally got in touch with the business owner who did not want to participate of the research.

The sample sizes of the interview groups from both the public and private sectors are shown in the Table 2 below.

Table 2 - Types of organisations interviewed and sample size

\begin{tabular}{|c|c|c|c|}
\hline & Broad Categories & Subsector & Sample \\
\hline \multirow{12}{*}{ Suppliers } & \multirow{3}{*}{ Accommodation } & Accommodation classified as & 4 \\
\hline & & Accommodation classified as & 3 \\
\hline & & $\begin{array}{l}\text { Accommodation classified as } \\
\text { (luxury accommodation) }\end{array}$ & 2 \\
\hline & \multirow{8}{*}{$\begin{array}{l}\text { Tourist } \\
\text { Attraction/Activities }\end{array}$} & Event organiser (weddings) & 1 \\
\hline & & Horse riding tours & 1 \\
\hline & & Tour guides (offer guided trails) & 2 \\
\hline & & Underwater photo and video service & 1 \\
\hline & & $\begin{array}{l}\text { Adventure } \\
\text { rappelling, } \\
\text { climbing) }\end{array} \quad$ slacklinities $\quad \begin{array}{r}\text { (surfing, } \\
\text { and rock }\end{array}$ & 1 \\
\hline & & Scuba Diving operators & 3 \\
\hline & & Boat tours & 3 \\
\hline & & Fishing operators & 2 \\
\hline & Transport provider & $\begin{array}{l}\text { Buggy and motorcycle rentals and taxi } \\
\text { drivers }\end{array}$ & 3 \\
\hline Intermediaries & Intermediary & $\begin{array}{l}\text { Tourism operators, travel agencies and } \\
\text { ground operators }\end{array}$ & 12 \\
\hline \multirow[t]{2}{*}{ Public Sector } & Government body & Local, regional and central & 3 \\
\hline & TOTAL: & \multicolumn{2}{|l|}{$\begin{array}{llll} & 0\end{array}$} \\
\hline
\end{tabular}

Among the companies interviewed, purposeful sampling was also applied based on differences of price and service/product appeal and quality. Within each subsector of suppliers, a range of businesses were chosen bearing in mid these two distinctions (e.g. some buggy rental companies have extremely different prices and quality: high and low, so both options were included on the interviews).

The sample size of companies and organizations interviewed represents all the different kinds of tourist activities provided by suppliers at the island. It also includes the big, small 
and medium sized intermediaries that sell the destination in the main outbound markets for the island (according to information gathered during the interviews and from all main government institutions that directly influence tourist activity in the location).

\subsection{Data analysis (content analysis / textual material)}

The data were analysed by making verbatim transcriptions of every interview and after that NVIVO was used to help in the process of coding since there was a considerable number of interviews.

The data were analysed using the analytical framework below (Figure 15). It shows that all information gathered from the in-depth interviews with the public sector as well as with the private sector - represented by suppliers and intermediaries - was analysed following this order:

1. To reveal the structure of the tourism distribution channels in Fernando de Noronha;

2. To identify all the factors influencing the structures revealed;

3. To analyse the influence capacity management has on the tourism distribution channels of the island;

4. And finally, to assess the relationships between capacity management and the tourism distribution channels.

Figure 15 - Analytical Framework

\begin{tabular}{|c|c|c|c|}
\cline { 2 - 4 } \multicolumn{1}{c|}{} & $\begin{array}{c}\text { Structure of the } \\
\text { tourism distribution } \\
\text { channels in Fernando } \\
\text { de Noronha }\end{array}$ & $\begin{array}{c}\text { Factors influencing } \\
\text { the structures } \\
\text { revealed }\end{array}$ & $\begin{array}{c}\text { Capacity } \\
\text { management as a } \\
\text { factor influencing } \\
\text { the distribution } \\
\text { channels }\end{array}$ \\
\hline $\begin{array}{c}\text { Private sector } \\
\text { (suppliers and } \\
\text { intermediaries) }\end{array}$ & & & \\
\hline $\begin{array}{c}\text { Public sector (local, } \\
\text { regional and central } \\
\text { government) }\end{array}$ & & & \\
\hline & \multicolumn{2}{|c|}{ Relationships between capacity management and the distribution } \\
channels
\end{tabular}

During data analysis several themes were identified; some were similar to the literature but new themes also emerged (e.g. the provision of payment ease for consumers as a factor 
influencing the use of intermediaries by suppliers). Findings are reported using quotations as well as by the creation of diagrams to better illustrate the distribution channel structures.

\subsection{Strengths and limitations}

Although it was hard to establish the exact number of suppliers on the island, the sample appears to be representative because it includes almost all the different types of activities/services (tourist attractions) the destination offers; with the exception of those services focused only on 'at destination' distribution (e.g. restaurants). Since the population involved more than one supplier for most types of supplier present on the island, it was possible to achieve saturation: no new insights were gained and there was only a redundancy of information after the second interview in a particular supplier group in the great majority of cases (O'Leary, 2010; Jennings, 2010). Consequently, broad representation was obtained because the representation of the population is wide enough to ensure that the phenomenon may be spoken about with confidence (O'Leary, 2010). Moreover, it may be said that the researcher also had a prolonged engagement with the community by spending a total of eighteen days on the Island (more than the ten days spent by the researchers from of MTur and ABETA's study, 2011). This was sufficient time to build trust and rapport with participants which was especially easily because the researcher comes from the same city of origin as most of the island's population: Recife, which means that researcher and participants share the same culture (O'Leary, 2010). All interviews were conducted in Portuguese which emphasized this shared culture and encouraged respondents to talk freely.

In addition, getting this broad diversity of services (different subsectors of suppliers) provided the opportunity to find more information and details not previously covered by the research of MTur and ABETA (2011) and it also allowed the researcher to fill the gap noted by Lohmann (2006) and Pearce (2011), which was to have more research on distribution channels with attractions and activities.

In addition, other strengths of the methods used include:

- The use of gatekeepers supports the research in building a trust relationship between the researcher and participants.

- The use of semi-structured interviews provides the possibility of comparison between key questions as well as giving an opportunity for the researcher to ask for more clarification and elaboration on interviewee's responses when necessary. 
- The use of open-ended questions enabled interviewees to say what they do (about the topic under research) and give practical examples. Moreover, the interviews were conducted at participant's workplace where the issues related to this research are fresh in mind.

- Face-to-face interviews may open the opportunity for interviewees to provide historical information that influenced in the topic studied. They also make participants focus on the questions, rather than talking about unrelated issues.

- The protection of participants' identity increases the relationship of trust between the researcher and interviewees.

- A holistic approach was undertaken since a number of the stakeholders were interviewed (suppliers, intermediaries and governmental organisations).

There were also limitations to this research. Although it was not possible to interview tourists to get the perspectives from the demand-side, this research could make use of the previous study from MTur and ABETA (2011) since they had interviewed tourists. However, further research could be conducted with tourists in order to analyse how the capacity management of the destinations is affecting their purchasing behaviour.

One challenge faced during fieldwork was making people unfamiliar with the concept of distribution channels to think about it and elaborate more on the topic; especially because most of suppliers did not have marketing plans for their businesses. Another challenge was convincing decision makers, owners, commercial directors/managers and marketing directors of intermediaries and airlines to participate in the research.

Some of the data obtained was limited by the level of education of the interviewees which is also related to the history of development of the destination. Consequently, some interviewees did not provide reasonable responses and explanations for the more complex questions (which had to be explained in a more simple and operational way) even when more clarification was asked by the researcher, leaving the researcher with the task of trying to understand confusing ideas. This fact also reflects the lack of knowledge that some interviewees have about distribution channels, marketing and capacity management.

Information about body posture and movements could not be collected because participants were uncomfortable when the researcher lost eye contact by taking notes while they spoke. 
It was not possible to interview virtual distributors (e.g. Decolar, Booking.com), airlines and tour operators specializing in luxury, cruise ship travels, ecotourism and adventure because the researcher lacked the resources and time to visit the three or four cities in Sao Paulo State where the headquarters of these companies are based. Although some managers of the airlines offices in Recife were contacted to take part on the research, they declined to participate.

The Ministry of Tourism also plays a role in the tourism distribution channels due to its role of marketing and promoting destinations for the domestic market and abroad via the Brazilian destination marketing organization (EMBRATUR - Brazilian Tourism Board). Bearing this in mind, these two organizations were also contacted by telephone (since they are located in the capital of Brazil: Brasilia, in the Centre-West region) but their marketing directors and substitutes were not available.

\subsection{Conclusion}

This chapter has presented the methodology used in this qualitative research exploring the relationships between distribution channels and capacity management of a destination. The research gaps have been revisited, more information has been provided about the study area and the sampling techniques have been outlined. In order to reach the three main objectives of the research, an analytical framework was created. This research achieved saturation and a broad representation of the population of suppliers interviewed. This allowed the researcher to get a lot of detailed information which is detailed in the following chapter of findings. 
Chapter 4: Tourism distribution channels structures, factors and challenges at Fernando de Noronha

\subsection{Introduction}

This chapter is structured according to the analytical framework of this research (Figure 15). To show the relationships between capacity management and the tourism distribution channels of suppliers, this chapter will first present the distribution channels structures and explain how these function, secondly highlight the factors influencing these structures, thirdly analyse capacity management as a factor influencing the structures revealed, and finally cover the challenges suppliers and intermediaries experience in their distribution channels.

In order to explain the tourism distribution channels structures of Fernando de Noronha from a supply-side perspective, these structures were divided in four categories: accommodation (non-luxury), luxury accommodation, scuba diving and other activities. These categories represent the most distinct and strong products of the destination as well as the most important service used by tourists: the accommodation.

In a destination with limited capacity, accommodation providers play a significant role for tourists when deciding to go to the destination. Having a place to stay once at the destination and buying the airline ticket to get there are the most important basic things a traveller takes care of. Based on quality, accommodation providers were divided in two categories: luxury and non-luxury accommodations; but also because there are some distinctions on the distribution channels of these two products. In the high season, from December to February and during the events season, most of the tourists to Fernando de Noronha focus on sunbathing at the beach, meeting new people at the end of year's parties or in participating in sports competitions. As a consequence the 'Sun and Beach tourists' do not make much use of the other services and activities offered on the island. The interviews with suppliers identified this kind of tourist usually makes more use of restaurants and non-luxury accommodations. 'Luxury Accommodation' is a different product that competes in the international market and as such has some differences to other accommodations.

Activities were also analysed in two product types: 'Scuba Diving' and 'Other Activities'. In the case of the 'Scuba Diving', this is a distinct product offered at the island and scuba diving suppliers compete internationally. As a consequence, many tourists visit and return 
to the island only focused on this activity. All other tourism services were categorised as 'Other Activities' because they have similarities in the distribution channels. This group includes: horse riding tours, event organizers, tour guides, adventure activities (surfing, rappelling, slacklining and rock climbing), boat rides, transport providers (taxi as well as buggy and motorcycle rentals) fishing operators and ground operators.

The tourism distribution channels' structures presented below are based on the conceptual framework (Figure 13), where customers are represented at the top of the diagrams and the type of suppliers under investigation are located at the bottom. The distribution channels are ordered from left to right according to the complexity of structures, starting with direct channels. After that, indirect channels to reach consumers will be portrayed according to the number of intermediaries involved: from few to a larger number and hence more complexity. In addition, the colours of the boxes representing intermediaries will express the source of the information obtained to represent that structure: grey represents information from the interviews with intermediaries and black is used for suppliers. This difference is important to notice in order to understand that the knowledge about distribution channels in a destination comes from information accumulated from both sources: intermediaries and suppliers because each participant cannot have full information about how their business partners (other channels) operate.

\subsection{Dominant distribution channels structures for intermediaries and ground operators}

Despite the division of suppliers into four different categories ('Accommodation', 'Luxury Accommodation', 'Scuba Diving' and 'Other Activities'), there is a set of traditional common structures in the distribution channels in Brazil and this is evident in Fernando de Noronha. These common channels are composed of 'in market' intermediaries and ground operators. Most of these channels are common to all the four suppliers' categories. Figure 16 below presents all the three dominant distribution channels structures and these are discussed first before presenting each of the four categories and their distinct channels. 
Figure 16: Dominant distribution channels structure at Fernando de Noronha
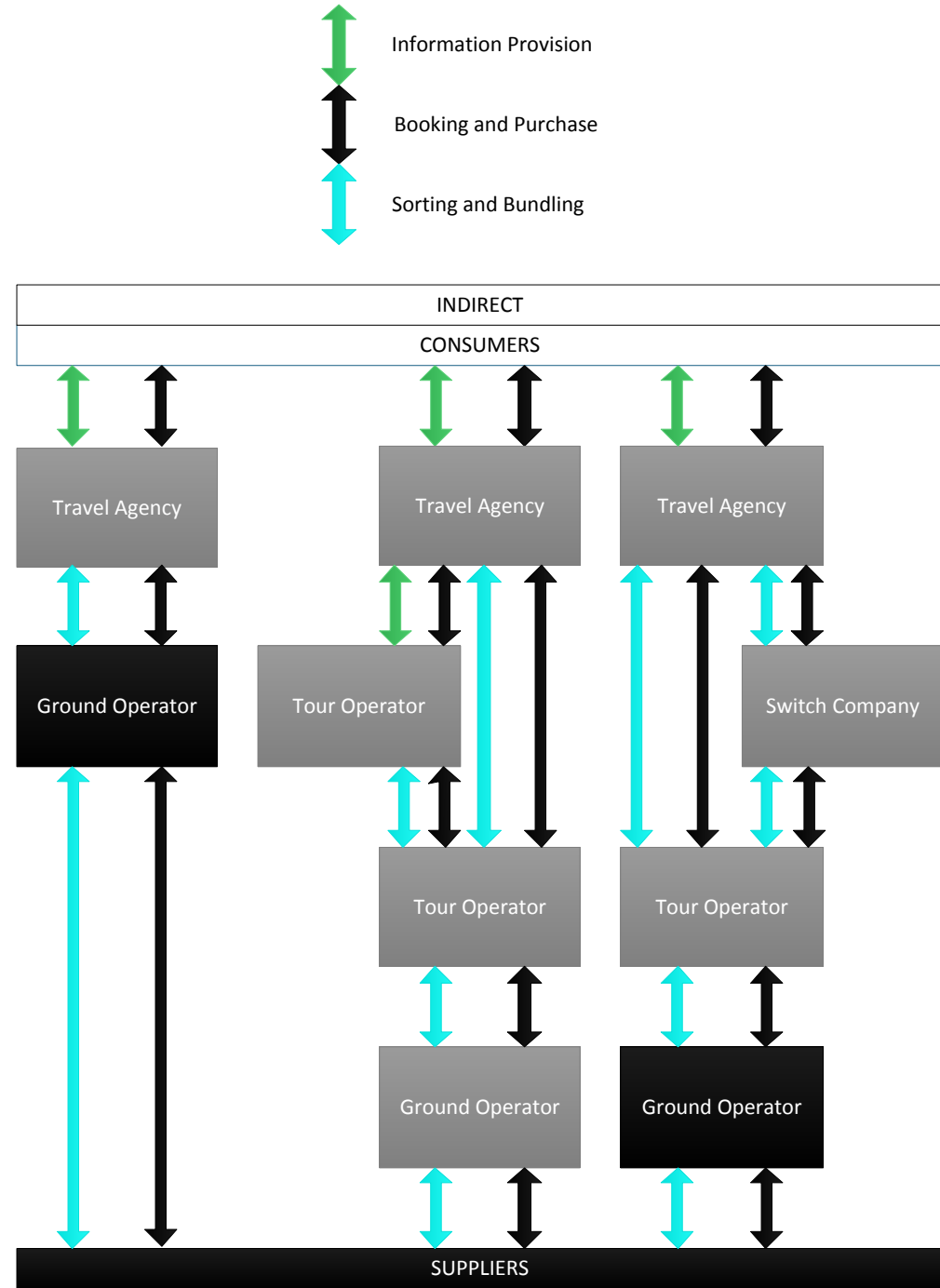

Starting from left to right, the first common structure found was when consumers contact travel agencies to purchase a product and get more information about destinations. Travel agents then contact ground operators to get information, book and purchase accommodation and activities according to clients' needs. Hence, ground operators are intermediaries located and operating at the destination; they sell all activities, provide land transportation and make accommodation reservations:

"The ground operators, we have constant contact with them." (intermediary B)

The second common and very traditional way of distribution among intermediaries is when a tour operator transmits their products to be sold through travel agencies. But before that, they do the sorting, bundling, booking and purchasing with ground operators at the destination. As an example, a respondent communicated that: 
"Our objective is to distribute to travel agencies. We do not work directly with consumers. We work with the travel agencies at a national level. So, we create packages, with the airline ticket, with ground operators at Fernando de Noronha and accommodations at the island and then we send our prices to the travel agencies to sell to consumers. " (intermediary D)

It was found that sometimes there is also a possibility of a tour operator selling to another tour operator located in another region of Brazil:

"Sometimes there is a tour operator in another state, I send them the net rate, they add a markup and then they distribute the same product to a travel agency. After that I don't participate in this relationship anymore because the tour operator is already doing what I was supposed to. This case is an example of a relationship between tour operators. But when I work directly with a travel agency, I get commission." (intermediary D)

The third indirect structure is very classic in Brazil. It happens when consumers buy a package at a travel agency (and this could include an online travel agency). This travel agency makes use of a tour operator - which in some cases can be the same company (vertical integration) - to make the bookings and purchase the accommodation and air ticket. So, the tour operator is responsible for making this booking and purchase with ground operators and airlines. Travel agencies' packages only include the return flight, accommodation reservations as well as one activity (usually a kind of city tour. In the case of the island this is called 'Ilhatur' which means 'island tour' and it refers to a whole day tour by car taking tourists to have a quick glimpse at the main tourist attractions, specifically the beaches). But some travel agencies are also able to offer more activities before this client arrives at the destination (depending on the client's request). Ground operators will then, be the ones to sell all possible activities offered at Fernando de Noronha to the travel agent's consumer once they get to the destination.

It is worth noting that the destination has two online travel agencies focused on selling Fernando de Noronha, both of which have the name 'Noronha' in their company's name in order to attract customers online (via a simple Google search, for example). It means that the great majority of their clients are recruited online and the customer is able to get information and purchase a package without the need to go to the company's stores. Intermediaries interviewed in this research informed that a few clients visit their office either to get more information, make booking and purchase; some just visit the office to check if the company really exists and is trustworthy. With the increasing use of internet facilities and technological gadgets like tablets and smartphones there is a growing trend toward online purchase of products, including tourism products. 
Another interesting aspect of the relationship and ownership between travel agency and tour operator is that one participant reported the need to be both kind of company, saying that to sell their services:

"I had to go online. Everyone [travel agencies] became a tour operator! The distinct concept between travel agency and tour operator did not exist anymore! So I had to do the same otherwise I would have gone bankrupt." (intermediary A)

Half of the intermediaries interviewed (four out of eight participants) were shown to have this vertical integration.

Some intermediaries interviewed work with different kind of demand segments, which are: leisure, corporate, incentive groups and business. In these cases, the companies were classified as medium or big size and working as both an inbound and outbound operator. The data collected also showed that they have a switch company at their office responsible for buying in large numbers of air tickets from the airlines. A participant reported that:

"Our company works with the corporation segment. We also assist travel agencies, issuing tickets. We have franchising all over the country and it has also expanded to other countries as well. We have a tour operator and GSA [general sales agent]." (intermediary E)

\subsubsection{Intermediaries' information provision to consumers}

Concerning the information provision function of distribution channels, intermediaries reported using many promotional techniques to reach customers.

Website of the company and email marketing - sent to business partners or consumers that have already purchased products at the company - are probably the most classic way to reach customers nowadays. Some businesses also advertise on Google to better get results from this channel as well as linking to their social media page, Instagram and/or Blog.

Office location was shown to be another important aspect for intermediaries when reaching consumers. Some companies interviewed are large or medium sized and they own branches all over the country, including at Recife International Airport. Other companies only have someone representing the company elsewhere (in another city), while some also offer franchising opportunities to spread the company into a larger geographical location.

Word-of-mouth was also reported to help intermediaries promote their businesses. It usually happens when someone has already experienced the services of a company and 
recommends it to others. In Brazil this is important since the community has a culture of asking for recommendations from others when hiring any kind of services.

In the case of tour operators, a regular visit to business partners' offices is the most effective way of selling their products. Tourist information centres play a role in helping a huge audience of potential customers to locate intermediaries along with advertisements in magazines and newspapers, on billboards, and huge banners with the picture of Fernando de Noronha in front of the office of intermediaries. National and international events focused on tourism are also used as a tool to promote companies, to find consumers or even new business partners.

It was also identified that the places used by intermediaries to provide information via brochure distribution in order to attract new customers are diverse. They included handcraft fairs, accommodations, pharmacies, fitness studios, via taxi drivers, dry-cleaning stores and at the streets when cars stop in front of traffic lights. Likewise tourism associations also have the function of supporting businesses promotion.

\subsection{Distribution channels structure of suppliers at Fernando de Noronha}

This section will present in diagrams the distribution channels structures of suppliers located at Fernando de Noronha. Different figures will explain the structures based on four distinguish figures divided in the following categories: luxury accommodations (section 4.3.1), non-luxury accommodations (section 4.3.2), scuba diving (section 4.3.3) and other activities (section 4.3.4).

\subsubsection{Distribution channels structure of luxury accommodations}

With four luxury accommodations, Fernando de Noronha has facilities to receive tourists belonging to the highest social classes, who have strong purchasing power and demand personalized services of the finest quality. Managers of two of the four luxury accommodations were interviewed.

Figure 17 below shows the distribution channels structure for luxury accommodations. From the left to the right, the diagram presents the direct and indirect channels for this type of supplier. 
Figure 17: Distribution channels structure of luxury accommodations

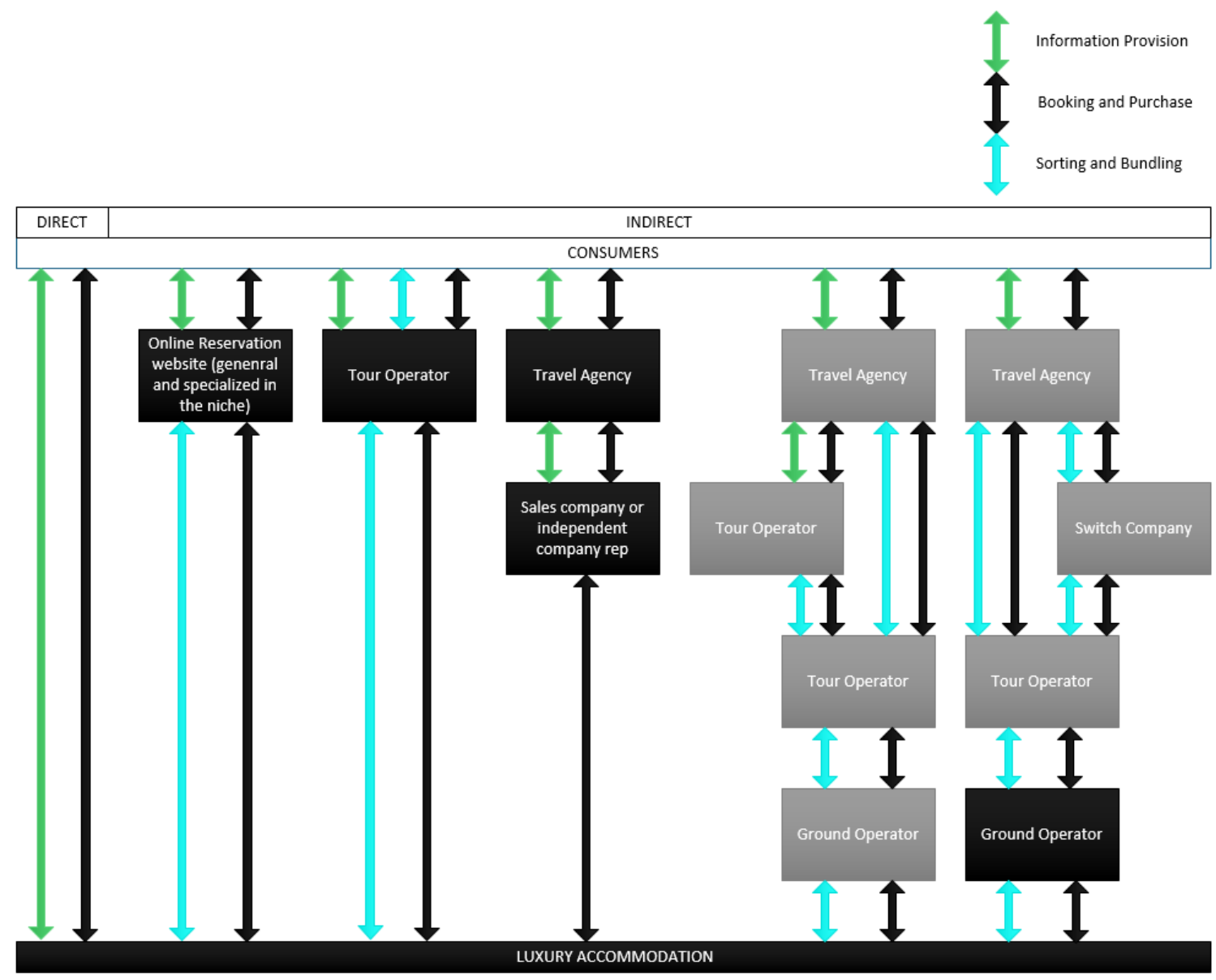

The direct distribution channels interviewees identified they used are related to the following promotional techniques (with the function of information provision): company's website, word of mouth, advertisement in magazines (both general magazines and specialized in luxury travel), specialized books of luxury products (e.g. Rolls Royce book), promotion of the company after cultural events and via publications. For example, a partnership with banks/credit card companies to advertise in a brochures specific for clients belonging to a selected group with high purchasing power.

The promotional activities that suppliers participated in to establish more business partners, i.e. intermediaries were: taking part in niche associations (e.g. Brazilian Luxury Travel Association) and participating in tourism fairs which are specialized in luxury travel as well as general travel fairs.

Online reservation websites are the first and simplest indirect distribution channel for luxury accommodations. These websites include intermediaries that are specialized in the luxury niche but there are also other websites that sell many destinations. Online 
reservation companies do not have an office to receive customers, they are online retailers. Suppliers give them a net rate (discounted rate) for selling their products and they sell it to consumers for a marked up price; in other cases they get a commission. Participants mentioned:

"We look for distribution channels that are focused on our market niche. For example, a commissioned website we work with is one that only works with accommodations that have a great view from all rooms." (accommodation F)

Secondly, tour operators specialized in creating small private groups for domestic and international luxury travellers are another channel to receive luxury tourists because their customers are corporations like multi-nationals that look for customized and special packages for their incentive tours, board meetings and corporate retreats. Consequently, suppliers choose intermediaries with expertise in the markets:

"We also work with intermediaries that only work with the luxury segment, and have clients of this category." (intermediary F)

Thirdly, participants mentioned they make use of a sales company and some independent representatives to help achieve the target of more travel agencies (in a wider geographical area) selling their accommodation.

"We have hired a company that represents us and visit travel agencies all over the country." (intermediary F)

"We also have people representing us at other states." (intermediary I)

Lastly, the two following structures have already been explained in section 4.2: the use of travel agencies buying products from tour operators who make use of ground operators; and the use of travel agencies with vertical integration having a switch company at their office and its tour operator making use of a ground operator at the destination. However, when the ground operator is involved, its function is only for providing the transportation from the airport to the client's luxury accommodation (some luxury accommodations have their own transportation and others do not). Then, when they arrive at the accommodation there is a special reception where a staff member presents all the options of activities to enjoy at the destination. In this case, the activity providers have had their products previously tested by the luxury accommodation to make sure they have great quality to provide for their luxury tourists. So, only a selected group of suppliers will have their services being offered at luxury accommodations (which plays the role of sorting in this situation). 


\subsubsection{Distribution channels structure of non-luxury accommodations}

The structure of distribution channels from non-luxury accommodations are represented in the Figure 18 hereafter. A total of seven companies were interviewed.

Figure 18: Distribution channels structure of non-luxury accommodations

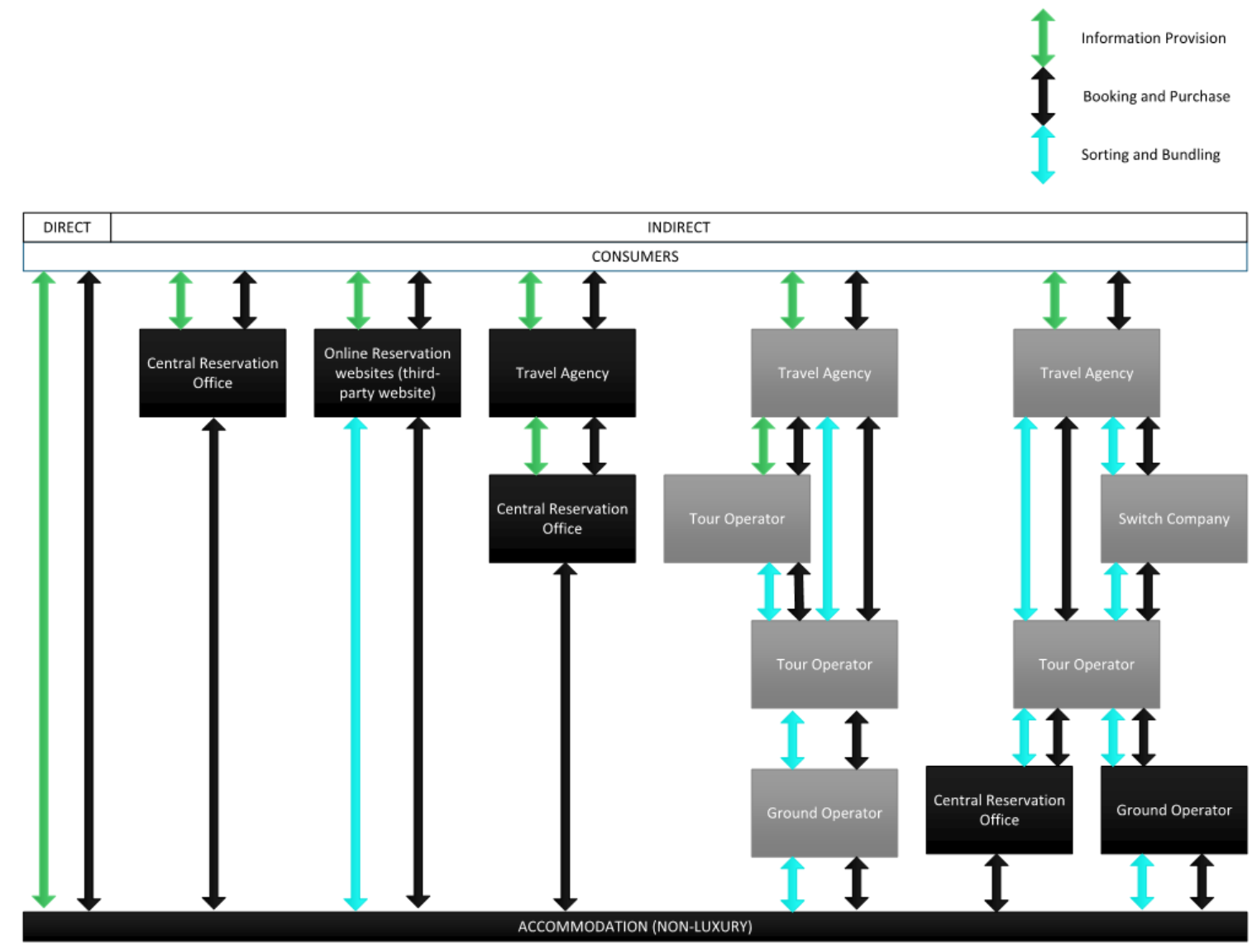

A comparison between this diagram and the one on Figure 17, shows that luxury accommodations have similar distribution channels structures to the non-luxury accommodations. These commonalities are composed of the use of online reservation websites and the two dominant distribution channels already explained in section 4.2: the use of travel agencies buying products from tour operators whose make use of ground operators and the use of travel agencies with vertical integration having a switch company at their office and its tour operator making use of a ground operator at the destination.

Nevertheless, there are some few distinctions between these two categories of suppliers. As it can be noticed in the last dominant distribution channel structure above, rather than having a ground operator helping the tour operator with the information provision, booking and purchasing of a non-luxury accommodation, sometimes a central reservation office plays this role. 
Also, there are some slight changes regarding the direct distribution channels used by nonluxury accommodations. Participants stated that independent travellers make direct contact with them after accessing their websites, their social media page or getting information from: guidebooks, advertisements in magazines, brochures at tourism fairs, travellers' review websites (like Trip Advisor), via word of mouth and in the brochure distributed by the Association of Accommodation providers at Fernando de Noronha.

Concerning the indirect distribution channels, looking from left to right the diagram in Figure 18, initially some suppliers mentioned they make use of a central reservation office to manage their information provision, booking and purchases (with both consumers and intermediaries):

"Instead of paying an employee to take care of my reservations, I have a company that works for me with my bookings" (accommodation B)

The reason for the use of a central reservation office is that a total of six non-luxury accommodations in the island are leased by one person who also owns other businesses at the destination and prefers to have a company taking care of these accommodations for the purpose of convenience when managing all the businesses owned. Secondly, there are some online reservation websites which deal with consumers to provide the same functions as the central reservation office. Thirdly, because some companies have a central reservation office (located in Recife), travel agencies interested in these accommodations will get in touch with the office that manages the reservations.

\subsubsection{Distribution channels structure of scuba diving}

Scuba diving is a strong product at Fernando de Noronha because there are twenty-four spots all around the island (see Figure 19) for different skill levels, from beginners to advanced scuba divers. The destination only has three companies providing scuba diving and all of them participated in the research. 
Figure 19: Spots for scuba diving at Fernando de Noronha

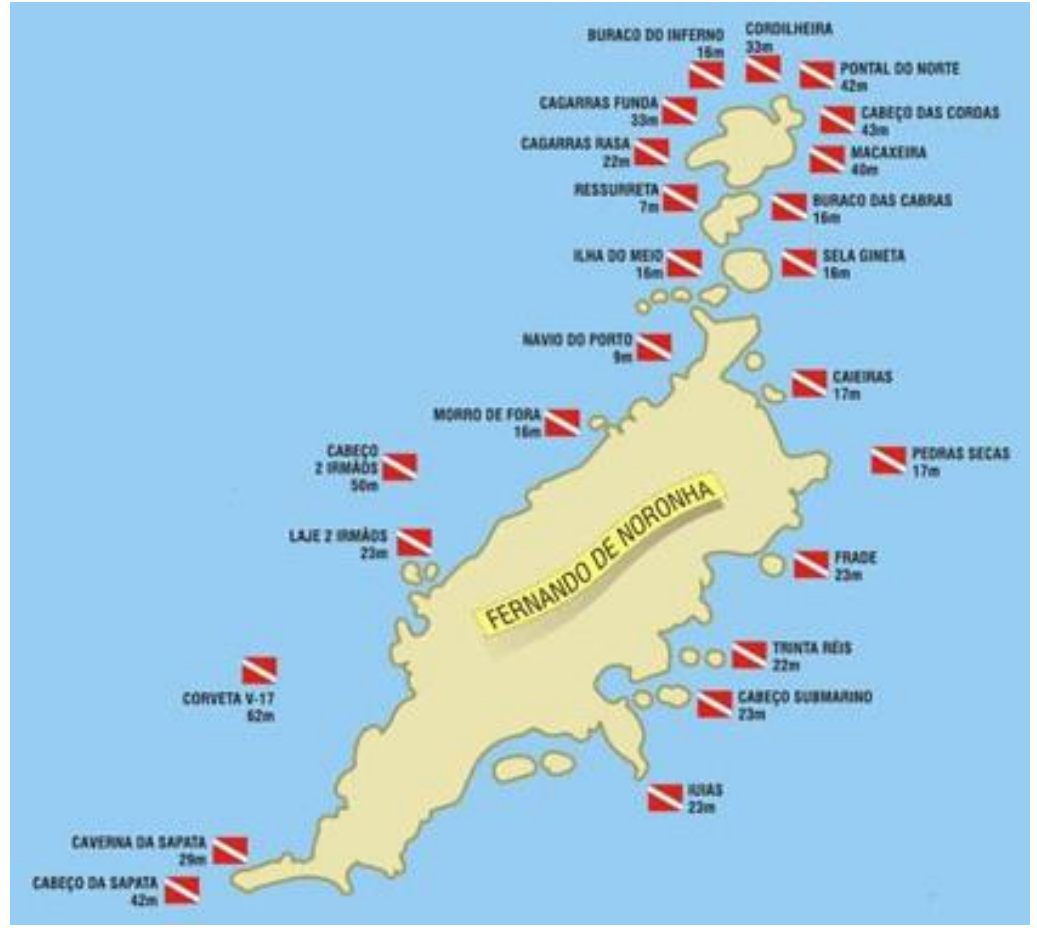

Source: www.atlantisdivers.com.br (with adaptations)

Tourists access the scuba diving suppliers via both direct and indirect channels. Some suppliers experience having more independent travellers while other suppliers reported receiving more tour groups via intermediaries. The two examples below illustrate these contrasting points:

\footnotetext{
"We receive both [independent travellers and tour group visitors] but the majority of our clients are independent travellers." (tourist activity Q)

"We receive very few amount of independent travellers. The majority [of our customers] I consider to be tour group visitors because they buy packages in a travel agency". (tourist activity $\mathrm{P}$ )
}

The Figure 20 below represents the distribution channels structure for scuba diving. 
Figure 20: Distribution channels structure of scuba diving

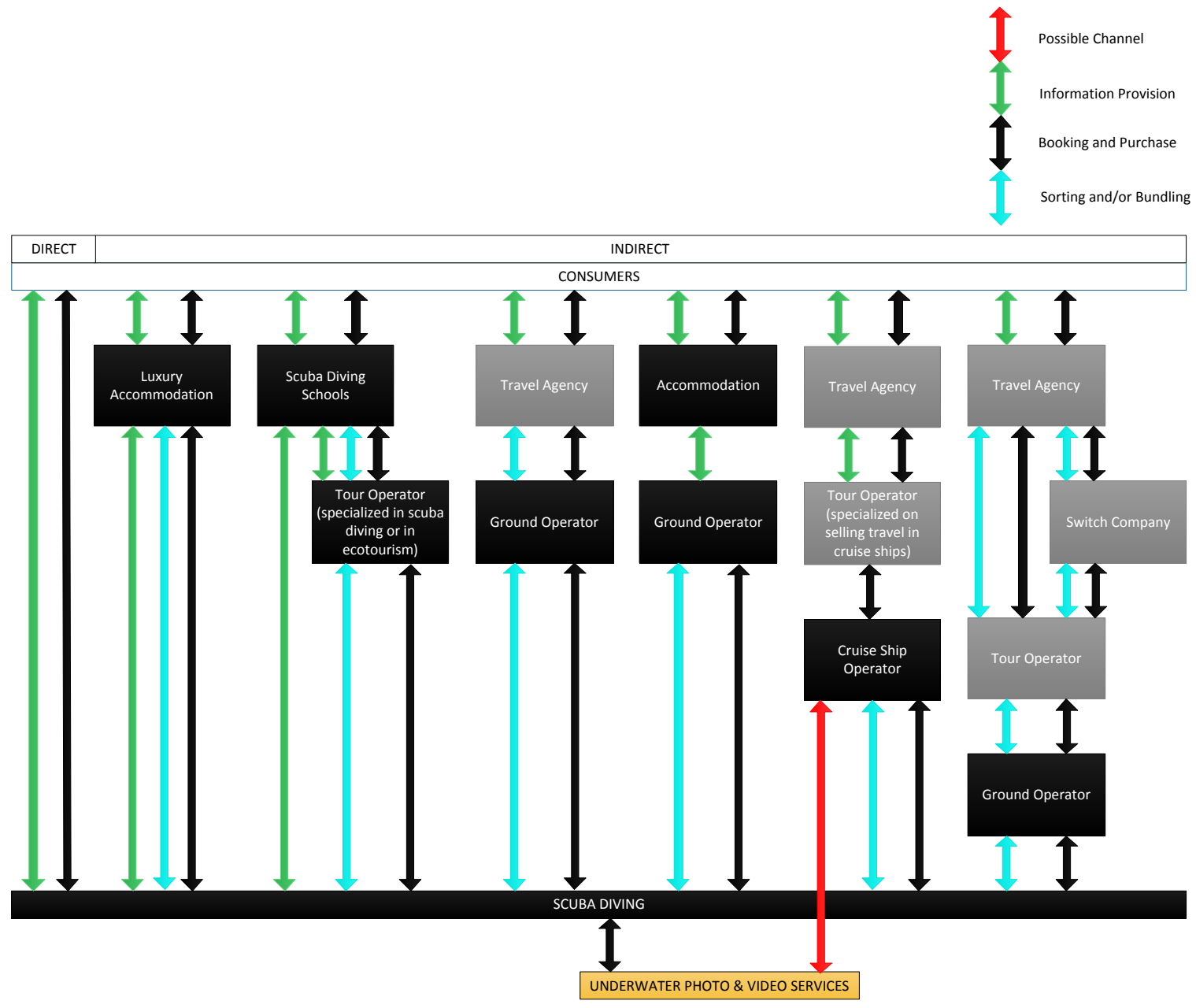

Direct channels used by suppliers to reach travellers were revealed to be very diverse. Independent travellers can get to know scuba diving suppliers via many promotional techniques that provide information to consumers. Companies' websites and social media (usually Facebook) are the online channels most utilised. Advertising in specialist scuba diving magazines is taken as a must by some companies:

"We invest and advertise a lot in all magazines specializing in scuba diving”. (tourist activity Q)

Mention of the company in travel guidebooks was also reported by suppliers, although this is something that the company cannot control because these publications are independent (not advertisement based). Tourism fairs, both national and international, are also included on suppliers' agenda but they must specialize in scuba diving, sports, adventure or ecotourism.

"[We go to the] scuba diving events, all that exist in Brazil as well as some abroad too. And in general tourism fairs, but mainly those that specialize in scuba diving." (tourist activity $\mathrm{S}$ ) 
At these events suppliers look for travellers but mostly for more intermediaries to work with:

"We also go to fairs. Nowadays, the specialized tourism trade fairs are also opening for the public. But when we go, we focus at the diving schools and specialized travel agencies. We used to attract consumers with advertising in magazines or via our website. However, in the fairs we look for partnerships." (tourist activity Q)

Regarding brochure distribution, these are distributed in the accommodations at the destination and in events.

"We distribute [brochures] at international fairs specialized in tourism, adventure as well as specialized in scuba diving." (tourist activity S)

Tourist information centres and associations (of ecotourism, adventure tourism or specific of scuba diving) also play a minor role in information provision for companies.

"We participate in some associations, where everyone promotes themselves; so it also helps on my business promotion." (tourist activity S)

Word-of-mouth can happen in two different ways: via clients that have already experienced the services of a given supplier or at the destination via recommendations from: tourist guides, transport providers, accommodations or any person in the community that takes the tourist to the scuba diving company or calls to make a booking; however, the former is a spontaneous recommendation while in the latter case the recommendation is made under the payment of a commission.

"The word-of-mouth [from people that have already experienced our services] is good for us. But I perceive that if something goes wrong the word-of-mouth can be negative too." (tourist activity $\mathrm{P}$ )

"Nowadays, everyone works under a commission. Actually, all around the world people only recommend you to get a commission; no one recommends you because he or she is your friend anymore." (tourist activity $\mathrm{S}$ )

Regarding the indirect channels, firstly it was identified that luxury accommodations act as intermediaries for the scuba diving suppliers. When the luxury tourist arrives at their accommodation a special reception is prepared and at this occasion all options of activities to experience at the destination are offered, including the possibility of scuba diving. Not all scuba diving companies are included in this channel. These accommodations play the function of sorting, which means that they only work with the scuba diving companies that meet their need for high quality standards. 
Secondly, the scuba diving schools not only in Brazil but around the globe are another source of clients for this type of suppliers. The clients of scuba diving schools are people that have this activity as a hobby and great purchasing power, use to travel once or twice a year with the main objective to scuba dive. There are also some people who are fanatical about scuba diving, who do it on the weekends, travelling regularly to other countries always looking for the greatest locations for scuba diving. These are very demanding clients who ask the companies about security measures, innovation (at the company and also concerning new activities to do at the destination) and ultimate high-tech equipment. So, the scuba diving schools get commissioned by suppliers to sell their services to travellers who can make the booking and purchase with the school. But they also get commission if they recommend a supplier for their students who later may purchase products from a scuba diving company directly at the destination. Consequently, the scuba diving schools also promote the scuba diving companies at their website, via their newsletter sent to their mailing list of students and distributing brochures at the school; so, they also perform the function of information provision for the suppliers they work with.

Furthermore, some scuba diving companies at Fernando de Noronha are also operating as intermediaries, and are essentially a travel agency specialized in scuba diving. In this case they sell their services to a group of students at a scuba diving school. So, the scuba diving travel agency sells a package specific for them including air tickets, accommodation and the dive. But this kind of package is also offered by tour operators specializing in ecotourism or scuba diving (in the case of international markets) selling their products also to scuba diving schools. As a consequence, when these suppliers have vertical integration working also as intermediaries they compete with their business partners: the specialized tour operators.

The third structure refers to a dominant distribution channel covered by section 4.2 : it is when travel agencies buy the services of ground operators and the ground operator is responsible for making contact with suppliers.

The fourth structure is about the relationship between accommodations and ground operators. Some participants informed that working with ground operators is the key channel they have to reach customers to do the 'Baptism': the name given to consumers that experience scuba diving for the first time in their lives. The recruiting of this type of clients happens when they arrive at the island. Every traveller that goes to the island and has bought a package in a travel agency or third-party website or had only booked 
accommodation directly will have free transportation included in the purchase to go to the accommodation upon arrival at Fernando de Noronha airport. When the transportation is provided by ground operators (which is something that happens with the great majority of the tourists, except a few luxury accommodations that have their own transportation), tourists receive information of some activities to do in the island. This can happen in? the transportation when they are heading to their accommodation (some scuba diving suppliers provide a representative from the company only to talk about their services as well as informing about how unique is the sea life there) or in some cases, the ground operator can take these people to their office where there is a small presentation (including videos) about all tourist attractions the island has to offer. Consequently, having a partnership with ground operators is the most important distribution channel a scuba diving supplier can have because it is the one that provides more new customers and potential returning clients.

"We do a hard work at the destination with tourists that went there thinking of ecotourism, beaches and do not have a clue on what scuba diving is about. So, we have to insist on telling them how cool it is to scuba dive. (...) To receive these people is very good for us because we have the objective of making them become a frequent scuba diver. After the first time it is explained to them that we also offer some courses to get an accreditation which means that they will be able to do this activity in any other place around the world. And it happens that the next trip this person makes is to a place where they can scuba dive. That is great because one day the same person will also return to Fernando de Noronha". (tourist activity Q)

Additionally, it is worth noting that in the case when previous customers return to the island to scuba dive again rather than using an intermediary they go as independent travellers and will probably contact scuba diving suppliers directly. This means repeat visitors use different channels.

The fifth structure shows the presence of a cruise ship operator. Online sources and some interviews provided information that the cruise ship operator partners with another tour operator (which is an international company specializing in this kind of product) that sells the cruise ship tours to travel agencies. Additionally, the interviews with suppliers showed that the cruise ship operator performs the sorting and bundling functions with suppliers. Moreover, the cruise ship tourists buy suppliers' services while en route and make the payment to the cruise ship operator which adds a mark up on the services sold. Later the cruise ship operator makes the payment to suppliers. 
And finally the sixth structure has already been explained in section 4.2: it refers to tour operators and travel agencies being vertically integrated, having a switch company at their office and making use of ground operators to reach suppliers.

\section{Underwater photo and videos services}

The underwater photo and video services are a specific kind of service that completely depends on the scuba diving activity. As a consequence, this kind of supplier has the scuba diving operators as their main distribution channel. There is a partnership between them and the scuba diving companies in order to allow these services to be offered for their customers.

"I do not need to make major efforts to have clients, when people purchase the scuba diving activity I can easily offer my services to these companies". (tourist activity R)

The cruise ship tourists are also another target for this company. When the cruise ship anchors at the destination, one staff member gets into scuba diving boats and can directly sell their services to consumers.

"The cruise ships influence my sales a lot because we sell at the scuba diving boats right after the people receive instructions about the activity. So we sell a lot! Specially the video service. These tourists spend little time [at the island]; consequently they try to enjoy the most! These cruise chips are very positive for me". (tourist activity R)

Figure 20 shows a possible channel between this supplier and the cruise ship operator. This unconfirmed information is due to not being able to interview a cruise ship operator. So, in this situation it is not clear if this supplier receives the payment of the cruise ship tourists from the scuba diving companies or from the cruise ship operator.

Physically, the company's office is located between two scuba diving operators which helps in the commercialization of their services. This factor may explain why some tourists contact this company directly, sometimes even before purchasing their scuba diving experience.

When questioned if they also get clients that contact them directly the answer was positive. As mentioned below, they end up acting like a distribution channel for the two dive companies they work with; but without any commission involved they only provide information.

"Yes [it happens], in this case we recommend them to the [scuba diving] operators". (tourist activity R) 
The services provided for the scuba diving companies vary according to the business because one of the dive companies already has a team that provides a photo service. So, they only require the video service. While the other company makes use of both underwater services: video and photo shootings.

"We pay a commission to the scuba diving operators to able to board their boats and provide our services to their clients." (tourist activity R)

\subsubsection{Distribution channels structure of the other activities}

The 'other activities' category involves the following: horse riding tours, event organizers, tour guides, adventure activities (surfing, rappelling, slacklining and rock climbing), boat rides, transport providers (taxi as well as buggy and motorcycles rentals) fishing operators and ground operators. To be able to encompass all this different kind of activities, a total of seventeen companies took part on the research.

The Figure 21 presents the structures of the distribution channels for 'Other Activities'.

Figure 21: Distribution channels structure of the other activities

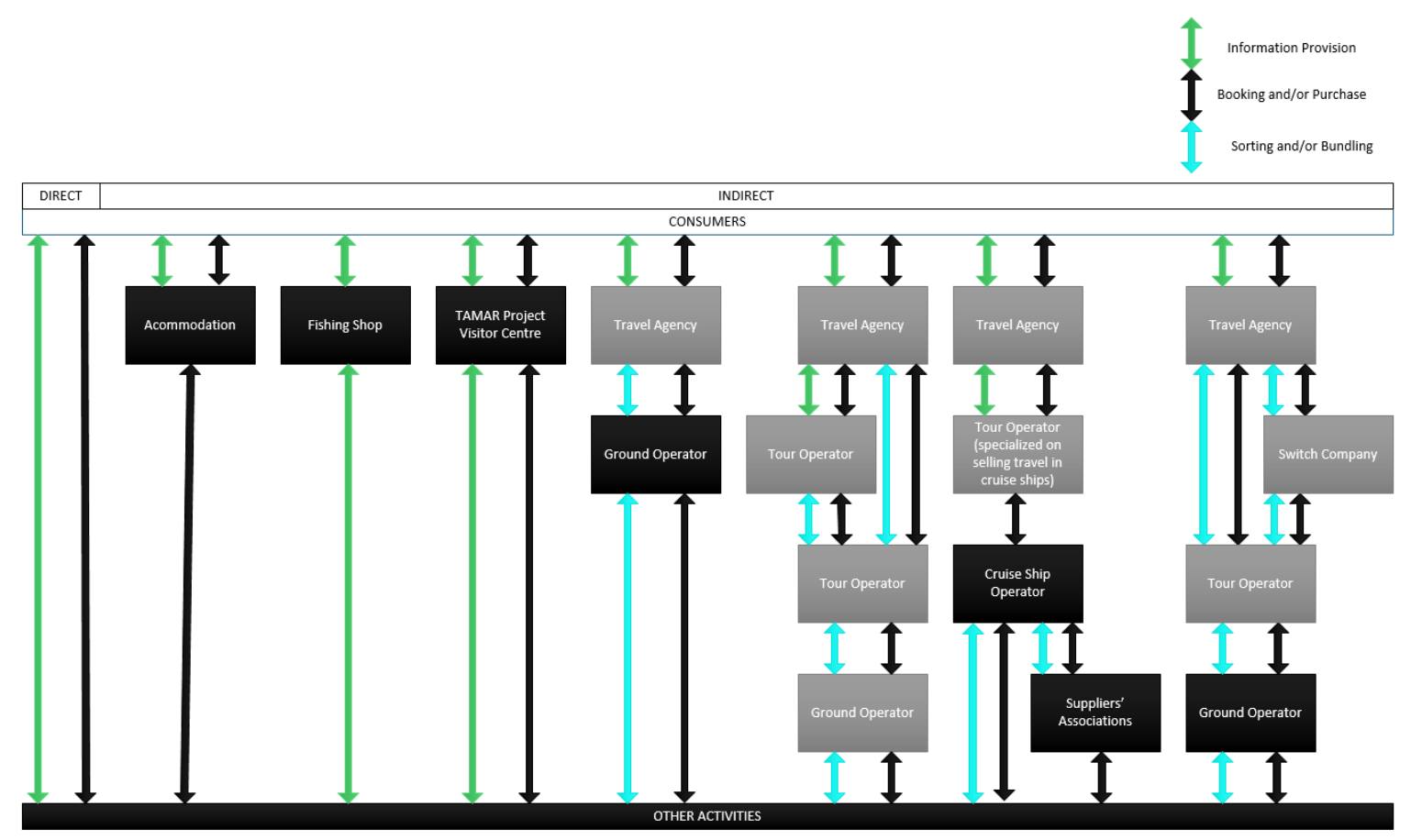

There are several direct channels used for information and advertising by all other different kind of suppliers on the island. These channels are: company's website, advertising in telephone directory, social media (usually Facebook), blog, visible location of the company (in the case of tourist guides, the association has a booth well located at the TAMAR Project's visitor centre to help them sell their services), signs, business card distributed to 
consumers, brochure distribution in tourism fairs (produced by the company or by a local association), brochures distributed at accommodation, restaurants and at transport providers offices, the appearance of their companies at independent guidebooks and on travellers' review websites and finally brochures and business cards distributed at the tourist information centre of the destination.

It is worth noting that some taxi drivers are also tourist guides which facilitates the promotion of the 'Island Tour' they offer. Many tourist guides also directly approach tourists at the hallways of the TAMAR Project visitor centre. Furthermore, many suppliers reported that a commission is paid to tourist guides, accommodations or any person in the community that takes the tourist to a supplier's office or makes a booking call on behalf of a customer.

In Figure 21, starting from left to right, the first three indirect channels presented involve: accommodation, fishing shop and the TAMAR Project Visitor Centre. Some participants explained:

"It is part of the selling process of our products. The accommodation providers recommend us to tourists and for that we pay a commission precisely to have something in return [more customers]." (tourist activity I)

"There are some fishing shops for whom we are clients and because of that they recommend customers to us a lot, that's an interesting partnership." (tourist activity K)

"We have this booth at TAMAR Project Visitor Centre which is a great location to get clients." (tourist activity A)

The following fourth, fifth and seventh structures presented have already been explained in the section 4.2. They are about the use of travel agencies buying products from ground operator or tour operators whose then make use of ground operators and the use of travel agencies with vertical integration having a switch company at their office and its tour operator making use of a ground operator at the destination.

Although most of the sixth structure has already been captured at the 'Scuba Diving' distribution structure (Figure 20), in this case it has a novelty: the participation of "Suppliers' Association". Such associations are responsible for paying the associates that worked with the cruise ship tourists (which is specifically the case of taxi drivers and tour guides). Participants reported that: 
"The company that sells the activities at the boat gets paid by their customers and they pay us [the association] the amount we charge them for providing the activity we offer. As a consequence, the association distributes the money among those that worked for them." (transport provider $\mathrm{O}$ )

So it means that sometimes the cruise ship operators directly pays the suppliers they work with and sometimes suppliers get paid by the association they are part of (like in the case of tourist guides, for example).

The creation of the structure with the presence of a cruise ship operator was only possible via online sources and from the information of some interviews with suppliers, intermediaries and the government. After gathering together all information, it was identified that the cruise ship operator partners with another specialized tour operator (which is an international company specializing in this kind of product) that sells the cruise ship tours to travel agencies. Interviews with suppliers revealed that the cruise ship operator performs the sorting and bundling functions with suppliers. Also, consumers buy suppliers' products at the ship from the cruise ship operator for a marked up price. Then, suppliers are paid by the cruise ship operator for a previously agreed price.

\subsection{Factors and challenges influencing the tourism distribution channels of Fernando de Noronha tourism products}

Having explained the structure of distribution, this section concerns the factors and challenges which influence the tourism distribution channels of suppliers at Fernando de Noronha and intermediaries that sell this destination. Most of the factors represent the advantages and disadvantages of the channels chosen. As it can be noticed in the distribution channels structure of the four categories above, some channels only apply to some products. As a result, some of the factors also show some particularities of the services offered and represent the need of using a channel mix. On the other hand the challenges show some amount of distinct issues.

\subsubsection{Factors influencing the tourism distribution channels of Fernando de Noronha tourism products}

Based on the data, the factors influencing suppliers' choice for a mix of different channels are very diverse. Initially general factors influencing their decision will be presented and after that the factors will outline why they have chosen to have direct and indirect channels.

The general factors influencing suppliers' decision for channels' mix are: market opportunity, need to match targeted consumers with the channels used by them, partnership 
issues, price for using some channels, product characteristics, lack of study about scuba diving in Brazil, reputation of the channel, desire to be known as much as possible, infrastructure, business capacity, experience and flexibility.

The factors influencing their use of direct distribution are: higher profitability, following market trends and matching expectations of consumers with the price paid as well as the ease and good results of a particular channel.

While the factors influencing the choice for indirect distributions are: to get higher customer numbers, to increase business promotion, to provide payment ease for consumers, to support the selling of their products and because of the high costs of information provision.

\section{General factors influencing distribution}

For intermediaries and suppliers, matching targeted consumers with the channels these consumers use is an important factor.

"Our use of billboards has the objective to reach a huge mass of potential clients." (intermediary F)

"Since my product is not cheap, it is worthless to distribute my promotional materials in the accommodations with low room rate. I really need to work with accommodations that receive customers with the purchasing power to buy my services. " (tourist activity K)

"We also work with a lot of intermediaries that have clients with many different purchasing powers. They also have clients that travel many times in a year. And these people have a strong relationship with a travel agent." (luxury accommodation $\mathrm{F}$ )

An intermediary stated that market opportunity to reach clients is another factor influencing the distribution channels they use.

\footnotetext{
"We saw that other companies did not have this kind of partnership with other organizations in the neighbourhood that receive people with the profile of our customers. So, we saw this as a market opportunity to be explored. A small handcraft fair has craftsmen without any information available for tourists or the local community. And because of that many times they ask taxi drivers to help them, which again are not prepared to talk about travel. We also identified that some fitness studios and companies that provide laundry services receive customers with good purchasing power." (intermediary B)
}

Moreover, intermediaries and suppliers explained that the distribution channels they use also reflect partnership issues. These issues involve difficulties in establishing and keeping 
partnerships, the need to have more harmonious partnerships and getting a fair deal on the price of commissions.

Some intermediaries mentioned that as the market is ruled by commission interest, it was hard to keep a relationship with travel agencies:

"The problem with travel agencies is because they change their business partners for 20 cents, 1, 2 or 3 reais. I had to focus on the internet and specially on Google which is the best search engine. When I started to focus on advertising on Google and got a lot of clients and I started to forget about working with travel agencies and begun to focus directly on consumers. I only started advertising on the internet because I could not find a good partnership with travel agencies. And now I get a client at least one booking every day." (intermediary A)

A supplier mentioned that the discounted rates they give to intermediaries is to make them sell their product for a determined price However, intermediaries are not keeping to the price agreed and are taking advantage of the situation to get more commission than expected:

"I sell online for a better price. While some travel agencies always diminish my payment a lot and try to get as much as they can from tourists." (accommodation G)

Other suppliers demonstrated that they could not use ground operators as a channel because they have not reached a fair deal on the percentage of commission:

"My service is not cheap and I also do not have a high demand of clients because it is a market niche. The percentage of commission asked by ground operators makes my operation unfeasible. So, I cannot use this channel." (tourist activity K)

Although some suppliers showed an interest in working with only one company as a channel, this situation is not working right for them and for this reason they are seeing the need to look for more partnerships:

"I cannot work with only one travel agency because of the approach they use. They arrive here saying how much they want to pay and how they want to do it. That is not how things work. I have expenses, I have some planning regarding the maintenance and sometimes I am unable to do things because of this unfair partnership. We should have a partnership where both sides win. And now only one side is winning." (accommodation $\mathrm{H}$ )

Price for using some channels is also a factor influencing both suppliers and intermediaries when selecting distribution channels. 
"Online newsletters are useful to maintain a relationship with our customers. But it is also important because there is no cost to produce them. We always go for the channels that offer more value for money." (intermediary F)

"We try to use word-of-mouth more because it is for free. When we are recommended by restaurants or accommodations we are asked to pay a commission. Price is what influences us most." (tourist activity A)

"At the beginning we did not have enough budget to leave the island [and look for more business partners]. But now with the association of accommodation providers we are expanding our partnerships. Recently we formed a group and went to São Paulo looking for the big tour operators." (accommodation $\mathrm{H})$

The characteristics of suppliers' products can be a limiting factor when choosing the distribution channels to work with.

Product's characteristics usually reflected in price and quality, may determine the target market and consequently the channels used by these markets. If you have a luxury product, it is expected that your clients use the specific channels for this niche; which are mostly different from the channels used by the general public and the middle class. And it differs a lot to the channels used by scuba divers or backpackers for example.

"We look for distribution channels that are focused on our market niche. For example, a commissioned website we work with is one that only works with accommodations that have a great view from all rooms." (luxury accommodation F)

"We focus on our market niche. As an example we advertised on a brochure to the American Express 'Platinum' clients. . So, it is a market niche, it is the type of client, it is this social class." (luxury accommodation F)

In addition, an activity that completely depends on environmental conditions for its visibility and operation may feel reluctant to work with tour operators and travel agencies. In this situation, if you decide to allow advance bookings and purchases, you may expect a lot of work resulting from the many cancellations you may get when the weather is not good. Besides, cancellations usually affect businesses' image:

"As our activity is in the ocean, we depend on environmental parameters and many times it is not possible to operate the activity. So, if you sell it in a package it means that the client will pay for an activity that may not happen. This creates conflicts that are not easy to manage. Consequently, at this moment, we chose to only work with ground operators; because it is easier to deal with them since they are located at the island. That is why we do not work with tour operators and travel agencies. In addition, we do not make any effort to work with bookings. This is a limiting factor, 
but it is true. It is due to the product's characteristics and because we only have one boat. If we make a booking and do not actually sell it, we take the risk of not getting the product sold in the future." (tourist activity M)

Another aspect of products' characteristics is when your services completely depend on other companies' services, as in the case of the underwater photo and video services. The channels may be narrowed because the product you depend on (in this case scuba diving) must be sold first.

"Scuba diving is very limiting here. You cannot come and dive by yourself without a scuba diving company. That is why I totally depend on them." (tourist activity R)

Moreover, the characteristics of the product you have also reflect a lot on your choice of suppliers. In the case of luxury accommodations, which commonly also act like a ground operator for their clients at the destination, choosing suppliers meeting the same high standards is essential to their business. In remote destinations luxury accommodations have two choices to entertain their customers: act like a supplier offering many different activities or select suppliers that meet their quality standards. In the case of Fernando de Noronha, they chose the second option because it seems to be more convenient since the destination does already have many suppliers offering a variety of activities.

"We offer tourist activities to our clients at the moment of their check-in. We check and try out all of our suppliers to make sure they have quality standards very similar to ours when delivering their services. We offer all the activities the island has to offer, we recommend other restaurants that we also check and try out their quality standards." (luxury accommodation F)

"We tried to find business partners that could meet the quality standards of the clients we receive." (luxury accommodation I)

A participant reported that the lack of a study about scuba diving in Brazil made them discover for themselves which the distribution channels work for their niche market.

"There is no data and information about scuba diving and its consumers in Brazil. What we have is about the North American market. So, since we do not have a source of information to guide our decisions, we end up learning by doing. So, we try some channels and if one does not bring results we do not invest in it again." (tourist activity Q)

Reputation of the channel can also influence the company's decision to work with some channels. 
"There is an online reservation website that always tried to make me work with them. But I did not want to do this because a friend of mine, who has also owned an accommodation here for about 19 years, told me that they have a lot of cancellations and it is annoying." (accommodation E)

To be known, seen and remembered as much as possible is the main goal of some participants in choosing a channel. Some interviewees believe that the more distribution channels they have, the better it is for the company's image and promotion.

"The factor is the same of that saying: 'Who is not seen is not remembered', so, that's the idea; to make the company become known all around the globe" (tourist activity Q)

"The main object is always to get the most exposure possible. We always look for points of sale that call the attention of clients to see our packages." (intermediary $G$ )

"Actually we did not make a choice [of distribution channels], we tried our best to be everywhere. We promoted the company at many points of sale; some were effective while others did not. However, we keep distributing our brochures at these places which were not effective because at some point it may work." (tourist activity C)

Infrastructure was also a factor and many participants expressed having limitations on expanding their presence online due to the poor and expensive infrastructure for accessing internet at the destination. So, in this case working with intermediaries is quite useful when online communication is not working because they can afford to contact suppliers by phone.

"I would like to make more use of internet as a channel but broadband internet is very expensive for a small business like mine. The free internet provided by the government is terrible, sometimes you cannot do anything." (accommodation $\mathrm{H}$ )

"My clients ask me a lot to have a Facebook account. But in reality we have a huge problem with the internet on the island. I do already spend a lot of time on the internet to solve other problems. Also, social media still does not attract me, I am not sure about its effectiveness. However, I have got an offer to have broadband. If it works, maybe I will improve my online presence." (tourist activity $\mathrm{K}$ )

Business capacity is also considered a limiting factor for suppliers with a very small number of distribution channels, especially considering the operational amount of work involved in offering services on an island.

"The factor is because our team is only me and my business partner. I don't feel I'm an entrepreneur, I feel like I am slave of my business. 
Imagine organising a wedding on the island, where everything (all supplies) comes from Recife." (tourist activity $\mathrm{N}$ )

"If we promote our company to consumers directly we may get more demand and we do not have staff, nor physical structure to receive them (like cars)." (ground operator F)

Experience gained by trying different distribution channels after numerous attempts was also another reason involved on channels' choice.

"After 18 years you have experience in everything, right!? At the beginning we invested on many things, then we came up with the conclusion about what is best. After that, we started choosing what best worked for us." (tourist activity Q)

Having flexibility is also another issue for tourist guides at Fernando de Noronha, and the distribution channel chosen is only influenced by this factor. The great majority of tour guides at the island work with a ground operator, but there is still a small number of independent tour guides

"I have a small kid. So, I cannot be on a trail every day. I try to dedicate my weekends to my daughter. Additionally, every day clients come here to go to the Atalaia beach. Every day they chose the same trail. I don't want to be fixed at the same thing." (tourist activity $\mathrm{J}$ )

\section{Factors influencing direct distribution}

There are four reasons for using direct distribution channels. Firstly, they lead to higher profitability; this happens when the company does not need to pay commission or even provide a net rate to an intermediary which means mark up on the price to consumers. Consequently, suppliers stated that they may get more profits from this channel. Secondly, direct channels reflect market trends: it is believed that direct online booking is a trend due to the increase use of technology nowadays.

"There's a trend of people making online bookings (...) the direct booking is good for the customer because the person can choose the quality of the services they want. To me it is the best channel because I have better profitability since I don't have to pay commissions" (accommodation

C)

"Nowadays, people do not read printed newspapers. People read things on the internet. Even children go online to look for information. Any information about country, city and hotels is usually researched online." (accommodation D) 
Thirdly, direct channels are chosen to match expectations of consumers with the price paid for the accommodation. Suppliers feel that when they have direct contact with consumers they are more able and knowledgeable to work on the expectations of their potential clients.

"I prefer the direct channel because I can explain to potential clients what to expect. This doesn't happen when the client makes use of an intermediary because the middleman sells my product for a higher price and creates a wrong idea about my business. So, when customers arrive here they ask for better quality of services according to the price they have paid to the travel agency." (accommodation $G$ )

And finally, the direct channel of 'word-of-mouth' recommendation is used because it is easy and brings good results.

"Word-of-mouth is more used because it is the easiest channel for us. We receive a lot of clients recommended by previous customers." (accommodation A)

"Many of tourists come because of word-of-mouth. The people that have been in my accommodation recommend us to their friends." (accommodation E)

\section{Factors influencing indirect distribution}

On the other hand, interviewees also stated five factors influencing their use of intermediaries and indirect distribution channels. The first factor is high customer numbers. Intermediaries usually send a lot of clients throughout the year to their business partners because they are located 'in market', that is close to the customer's home, workplace or in shopping malls (convenient complex of shop); and also because people that travel regularly use them often.

"We work with intermediaries because they have many (hundreds) clients that they send to us." (ground operator $\mathrm{H}$ )

"I like to work with them because they send us a lot of customers from July to September; I get sold out." (accommodation E)

Secondly, indirect channels increase business promotion. This happens because some intermediaries also include pictures and details of suppliers' companies on their website and in brochures;..

"I observed that working with travel agencies increases the promotion of the accommodation." (accommodation $\mathrm{C}$ )

Thirdly, indirect channels provide easy payment options for consumers wishing to go to the destination. And this aspect is very important since the destination is expensive. 
"Because they provide payment ease for customers. So it is easier to the client buy a package from them as they can divide the payment in 10 months for example." (accommodation $\mathrm{C}$ )

Fourth, intermediaries help suppliers to sell their products. So, they increase the number of points of sale for the company and they expand its market coverage. Of course something must be given in return, and for that commissions are paid:

"Commissioning is a great motivation [for business partners to sell your products]." (tourist activity I)

And lastly, indirect channels are chosen because of the price of direct media advertising and promotion. Some participants expressed that having a partnership with intermediaries is better than spending lots of money on promotion trying to reach customers directly.

"I would like to have more distribution channels, but the ones I have is due to promotion costs, which are very high." (ground operator B)

\subsubsection{Challenges in the distribution channels of intermediaries and suppliers}

Suppliers and intermediaries were asked if they have any challenges regarding the distribution channels they use. A total of thirteen challenges were identified. Below, these challenges are explained in order according to the number of responses. However the major challenges are: the price of the destination as a product (with special emphasis on the high prices of transportation and accommodation), the unfair competition between licensed and unlicensed businesses (where the latter provides services for very low prices); and the limited number of air tickets available.

Price is on the top of the list with six interviewees who were concerned about this factor. Suppliers and intermediaries feel it is very hard to get clients because the destination is expensive. As a consequence it is not easy to sell the destination and usually the number of people returning to destination is low. Research (EMPETUR, 2010) shows that over a period of one year, $81 \%$ of the tourists were visiting the island for the first time. Interviewees compared the island to overseas destinations with similar overall prices to Fernando de Noronha. However, in the specific case of this destination, prices of transportation and accommodation were the main issues inhibiting the destination competitiveness.

"Noronha is an expensive destination. Although we are always trying to provide easy payment options, it is an expensive tourist destination. That's the biggest challenge to sell the island. If it weren't the exorbitant prices of some things, I think we would sell it more easily. (...) We have already received comments, comparisons, that sometimes it is cheaper to 
buy a return ticket to New York than if you buy a package to Noronha." (intermediary G)

"The biggest problem is that we have a flight issue, and lack of reasonably-priced accommodation for the people who come for fishing. (...) And the price of the accommodation here is very high." (tourist activity K)

Five participants reported that unfair competition due to unlicensed providers with unbeatable prices is another challenge. During fieldwork it could be noticed that the destination has a lot of unlicensed companies creating informal jobs and not paying governmental fees. Consequently, they are able to provide services for lower prices than the licensed suppliers but at a much lower quality. Even intermediaries complained about other intermediaries selling the destination for unreasonable prices:

"The challenge is because sometimes the price does not reflect the reality." (intermediary A)

"I have worked with this for twelve years. (...) Some companies offer their services for around 50 Reais less than the real price because they are not a company, they do not pay taxes." (transport provider A)

A crucial challenge reported by both suppliers and intermediaries is the lack of flight tickets to the destination. This situation happens especially with tickets for the summer high season, from December to February. On the other hand, participants communicated that since the first semester when the research was conducted tickets were already allocated to tour operators; who buy bulk quantities in advance..

"The biggest difficulty is to find a seat. As we have only one daily flight with around 72 seats. Many times we want to sell and there are no places left on the flights. (...) Sometimes you want to make a group so you have to find a date that the flight is not with all seats blocked by tour operators. So this is a limitation!" (intermediary C)

Infrastructure of the destination is another issue that is affecting the companies on the island. As it was already been mentioned on section 4.4.1, the speed of internet on the island not only affects the channels they use but their ability to contact their suppliers off the island:

"Our internet is very slow. (...) My web designer is outside the island and it is complicated to talk to him and say what I want on my website. So, it delays my work." (tourist activity I)

Moreover, infrastructure can even affect the selling of a product, which is the case of the luxury accommodation located in a street without pavement. A product for a very 
demanding public must have high standards as well as meet all the expectations of this public.

"In my case I need the street to have pavement. It is a local matter that needs improvement and impacts on my sales." (luxury accommodation I)

Also, infrastructure alters the perceived value of some adventure activities like scuba diving. The higher skilled and international scuba diving tourists require destinations to provide a specific hospital with hyperbaric chamber in case of accidents occur during the activity. As a result, to keep competing in the international market as a scuba diving destination and even receiving this type of tourists the destination needs to improve this specific infrastructure as well.

"We are finally installing a hyperbaric chamber. We bought a hyperbaric chamber ten years ago and we were not able to install it because we had to build a hospital. (...) So, actually the scuba diving companies have to build their own hospital; the three companies are doing this via their association. (...) It took a lot of time to get the licence to be able to build the hospital. (...) This is one of the things we need to do - to show that the island has a hyperbaric chamber (...) because the international market constantly asks us if we do." (tourist activity Q)

Another challenge is the provision of false images about competitors. In a small island with many small business owners lacking formal education about tourism products and segments it is hard for them to deal with new products appearing at the destination. So, this lack of understanding about distinct markets and tourist products is leading to bad behaviour by some suppliers that lie about their competitors' product.

"We established a new business on the island and it disturbed the other services. Because we have high quality standards in our equipment and maintenance, the market felt scared and now we suffer from heavy campaign of counter-advertisement. (...) They believe that saying bad things about our product is helping them to keep their place in the market." (tourist attraction $\mathrm{M}$ )

Two participants offering products to a different segment (for demanding customers with a high purchasing power, like the luxury tourists) explained that since the destination is expensive and they offer services of high quality, they try to compete based on product quality rather than price; although it is hard to compete this way:

"So, in my market niche, I try to hold clients based on quality. As an example, in our marketing plan it says that we should not promote our prices. To make us have the opportunity to make a very good offer based on quality. So, we don't show our prices on the website, magazines etc. 
To have the opportunity to sell here, with my reservations assistant." (luxury accommodation F)

"We offer a service of high quality, but we have competitors that offer a similar service for half the price. However, we have distinct products and people get deluded by price. Sometimes we receive clients that have already been our customers, had become clients of other boats and came back to us because they were not happy with the service provided. And it happens frequently." (tourist activity $\mathrm{K}$ )

The destination image is another aspect challenging suppliers. Since the destination is expensive, it is important to work on the image of the island as a worthwhile destination despite its costs when compared to other international destinations. As a consequence, suppliers are trying to convince the Brazilian biggest outbound market (São Paulo and Rio de Janeiro) that the destination has good infrastructure, nice accommodations and unique features.

"Our clients are travelling to other countries because it is cheaper. So, our challenge is to convince the people (...) that we have a good product, that we have good accommodation and good infrastructure." (tourist activity Q)

Similar to what has already been mentioned on the section 4.4.1, low budget is an issue to suppliers when trying to reach consumers directly at the destination. This is a problem especially for taxi drivers, who are unable to improve the promotion of their services without money. Some of them are also tour guides and offer the 'Island tour'. However this information is unavailable to consumers unless if they take a taxi.

"It is a financial issue. If we had financial resources we could promote our services better." (tourist activity $\mathrm{O}$ )

Global economy is a challenge to any business in tourism. At Fernando de Noronha there is the issue of dealing with Brazilian people's increased purchasing power over the last few years. Now the middle class and higher classes have the opportunity to go overseas more often and spend money abroad. Alongside this some other countries are facing an economic crisis and for that reason are reducing long-haul travel. So, there has been a shift in the outbound markets and if Brazilians are travelling overseas the Brazilian destinations may see the number of domestic tourists fall along with the number of inbound international tourists. Consequently suppliers may be unsure about choosing channels to focus on and may feel the need to try all possible channels.

"Firstly, we are in a country that is growing. On the other hand there is an external economic crisis happening: the European crisis, we still do 
not know when it is going to end. This influences our business as well." (luxury accommodation $\mathrm{F}$ )

Lack of knowledge on how to promote their services is a challenge to independent tour guides. This situation is leading the great majority of guides to make use of only one channel to provide their services: via ground operators. If most of tour guides work for ground operators, the independent tour guides are competing against this channel and probably losing this battle since tourists cannot easily find this type of suppliers while at destination and even before that.

"The fact that the great majority of the tourists who make use of the services provided by tourist guides are through ground operators." (tourist activity A)

Offering new experiences to retain customers is a challenge for scuba diving suppliers that have returning customers as an important market for their business. These companies are constantly offering innovation and novelty when providing their services. However, they stated that there is also a need to the destination do the same because when their clients return to Fernando de Noronha to scuba dive, they also have one morning and afternoon free to enjoy the island since they cannot scuba dive on the day of arrival and departure because of pressure issues. As a consequence these people look for new activities to experience at the already known destination.

"Now we are trying to provide rappelling. We want to provide new activities to the people that have already been in the island many times and want new things. So, provide new tourist attractions and entertainment." (tourist activity Q)

In a destination with capacity management where it is hard to get a concession and open a business, the office location may play a significant role in attracting customers. If the company is not located at the centre of the island where there is the biggest concentration of restaurants, accommodations and public transportation, it is likely that the number of clients will be low.

"To have the office located here is a challenge because our location is not in the centre of island" (ground operator B)

Online company domain names can be quite a challenge to intermediaries trying to call the attention of clients on the internet. So, getting the right keywords in the title of the website is essential to the success of online travel agencies specializing in the destination that have Google or other web search engine as their main distribution channel. 
"In the Internet I have focused in only one competitor. (...) Someone was lucky to get the domain name 'Island of Noronha' because sometimes people search for 'island' as a keyword on Google." (intermediary A)

The influence of higher commissions on recommendations is a challenge to all businesses at the destination. However ground operators are the ones that suffer more from this issue since they are able to sell any kind of service. Locals know that they can get commissions if they call the companies to book an activity for tourists or take tourists to a company's office to purchase a product, so they take these opportunities to make more money; even while they are working (at a gas station, bakery, supermarket etc) or when they are walking on the streets.

"They could sell to me, but it does not happen often. They sell to (the person) who pays the highest commission."'(ground operator F)

There is a great competition between ground operators and other sectors at the destination. The 'package tourists' that go to the island already have a ground operator working for them; as consequence ground operators do not compete much with each other to get independent travellers at the destination. However, independent travellers that book the accommodation and flights by themselves may go through other channels rather than ground operators when booking and purchasing the tourist activities. These people usually hire a car, get recommendations at the accommodation, supermarket, bakery, restaurants, gas station or souvenir shops and by talking to people from the community in any place they go. The issue is that all the workers from other sectors make recommendations to them about activities to do. They recommend companies in order to get commission or to help the business of a family member. So, ground operators have the challenge of competing with people from other sectors especially in the low season.

"The passengers that do not come with a ground operator attached to the services previously hired fall into other channels and do not reach the ground operator (...) So, the biggest challenge of our company to survive in the most critical months of the year is this, to compete with everybody. As a consequence in the low season everyone is desperate about money and it is the moment when we have less tourists and more competition. ", (ground operator F)

Travel agent training is a big concern to tour operators trying to sell the destination because if they are not knowledgeable about the product it is unlikely that they will be able to sell it to consumers. These agents play a key role in the decision making of consumers and if they lie or do not provide enough information about a destination it may affect the destination's image. 
"There is an issue of preparation of the travel agent to be able to sell Fernando de Noronha. Many still have some apprehension, many still do not have knowledge about the island. And a great majority also do not have interest in gaining more knowledge to make a better sale." (intermediary D)

\subsection{Capacity management as a factor influencing the tourism distribution channels of} suppliers and ground operators

All suppliers interviewed were directly asked if the capacity control of the island is a factor influencing their distribution channels and how important it is. Only three suppliers - of the thirty interviewed - could make a connection between capacity control and distribution channels. The other participants said that it is not a factor influencing their distribution channels (a total of fifteen respondents) or they did not know what to say because they cannot understand the question (a total of eight respondents). This could reflect the lack of knowledge about the concept of distribution channels and/or capacity management.

Nevertheless, data gathered from other questions could provide relevant information about the issue.

The capacity controls of the island were shown to be influencing suppliers via the number of seats in the flights that go to the destination as well through the number of accommodations available. Access and accommodation availability are the main variables influencing the amount of tourists the destination can get:

"This thing of carrying capacity of the island... I feel that the flights are a natural limiting factor for the numbers of clients I get. I am always promoting my business and looking for clients. The flights and the number of accommodations at the island are the natural limits. So, I don't think that I've reached a limit to stop my business promotion. I feel that as long as there is a seat on a flight, I can sell my services." (ground operator $\mathrm{H}$ )

Another participant reported that the number of rooms available is higher than the total number of seats in the two daily flights during the high season. One reason for this is the existence of unlicensed accommodations. Many people in the community are transforming their home into accommodation without any permit from the government. By doing so, they put pressure on the government to increase the number of flights available. There is even the suggestion of asking the government to provide the opportunity for one more airline to work along this route in order to compete with the two already operating in order to reduce the price of air tickets. 
"Today the island has more rooms available than the number of visitors we receive. We need to receive more visitors, we need to have more flights. As Noronha is isolated because it is an island we have an issue with the number of flight seats. To receive more visitors, we need more flights. To have more flights we need authorization from the institutions that manage this. And these institutions manage the island according to the carrying capacity plan; which is directly related to them." (accommodation C)

The issue of the lack in more airline seats is especially disturbing to all stakeholders during the high season. During this crowded period, extra flights are authorized by the local government (ADEFN). This authorization happens via a formal request from the airlines sent to the government where each request is analysed and if the flights are proven to be sold out, the administrator has the power to allow one more flight. An intermediary interviewed reported asking the government for more flights during the high season but this has always been denied. In addition, a representative from the Ministry of Environment declared they do not control the authorization of extra flights, they only manage transportation by sea, such as cruise ships and boating activities.

Another response came from one of the only two accommodations in Fernando de Noronha which has the ISO 14,001; which is the stamp given to companies that operate in an environmentally sustainable manner according to the International Organization for Standardization. Since these two luxury accommodations act as a channel providing their customers with all the tourist activity the island offers, they see the importance of having suppliers also operating under sustainable principles:

"Actually this does not influence(me)?. But how should it influence me?! I should require my suppliers and the entire range of distribution channels I have to be also working and operating in a sustainable way. So, we try to look for a high quality in these distribution channels we have. But we cannot demand this because it does not exist at the island; but this would be the perfect scenario. This way we would be speaking the same language." (luxury accommodation $\mathrm{F}$ )

If suppliers do not work under the same principle of sustainability in a conservation area like Fernando de Noronha, it may affect business image and the sale of the destination to ecotourists. Also, repositioning the image of the destination to an ecotourism destination rather than sun and beach will be complicated if previous tourists do not perceive the sustainable practices of suppliers especially in a place where unlicensed businesses exist and are providing low quality services. As a result, it may look like some suppliers in the community are not committed to the sustainable future of tourism on the island and any educating initiative about sustainability may be ineffective. 
On the other hand, when talking about the availability of seats in the flights for the destination, it was observed that suppliers - especially luxury accommodations - are obliged to work with some tour operators not specialized in their niche because they are blocking flights in advance for the high season:

"But I have been noticing that rich clients are getting in contact with the accommodations. When they do not get the flight tickets, they see themselves obliged to contact the agency to buy everything. We do not sell them only the flight ticket. We give them what is best! So, we sell them the travel package." (intermediary A)

"This week I lost a sale to a resort in Aruba. Although the client wanted to stay here and the problem was not price, it was not possible to find flight tickets in December during our new year package dates.. So, there are some tour operators and travel agencies with the flight tickets bought and they are holding these tickets and we do not know who they are. They have purchased these tickets in advance sell them on for three times the price. This is the main problem that I have today. This is also related to the unethical way of working from my distribution channels." (luxury accommodation $\mathrm{F}$ )

As a consequence luxury accommodations are being induced to pay commissions to tour operators in order to provide access for their clients travel to the destination in certain months. Consequently they may lose the opportunity of selling their services if they do not make use of some channels.

There is no regulation regarding the relationship between tour operators and airlines when it comes to blocking the seats of the flights in the high season. Hence, it is possible that during this season the amount of independent travellers may be very low.

\subsection{Promotion, destination image and capacity management: the public sector's roles} and views

The interviews with the public sector involved the three main organizations involved in the development and management of tourism and the natural resources of the island: (1) the Chico Mendes Institute of Biodiversity - ICMBio (which belongs to the Ministry of Environment and is responsible for managing all national parks in the country), (2) the State Tourism Organization - EMPETUR and (3) Fernando de Noronha State District ADEFN (responsible for the management of the limited human settlement zone within the island's environmentally protected area). For the purpose of presenting these findings, the order will follow the same as above. 
ICMBio manages the federal conservation units, which include the national parks (protected areas for ecosystem protection and recreation, the PARNAMAR as mentioned in Chapter 1) and environmentally protected areas (APA). Fernando de Noronha has both types of conservation units (Oliveira, 2008). ICMBio's job is to propose, implement, manage, protect, supervise and monitor protected areas established by the central government. It also supports and implements programs of research, protection of biodiversity and has authority to police the environmental protection of the federal conservation units (ICMBio, 2012).

In an interview with a representative from the ICMBio, it was identified that since the focus of their role is to manage natural resources, they do not engage in planned tourism promotion; and marketing is last minute opportunities or activities undertaken in response to being contacted by the media. When they promote the destination their attitude is focused on environmental awareness and biodiversity conservation. For that reason their information provision function happens via documentaries about the environment, magazines specializing in scuba diving, trekking and with the visit of VIPs to the island: encouraging them to experience activities like nature observation rather than having a sun and beach experience.

ICMBio controls the sprawl of companies by limiting their geographical expansion, the number and the size of businesses as well as any renovation of the companies' premises. They also restrict the increase of the population on the island and are responsible for authorizing the access to the island: by planes, private boats or cruise ships (PNUD, IBAMA \& elabore, 2007). If by one side it seems to be very restricting, on the other hand they can work on the quality of the businesses that exist and this creates the focus on maintaining the exclusivity of those that are already there. Also, this is good for the community because the jobs available are offered firstly to local residents.

Regarding the destination image, although ICMBio is targeting ecotourists in their promotion, many of the companies commercializing the destination are selling the island to 'sun and beach' tourists, who prefer to spend their holiday sunbathing and enjoying refreshments at the beach. So, there is a mismatch between the destination image when sold by intermediaries and maybe suppliers and the destination characteristics of being more suitable to ecotourists. As it was said:

"The destination is still being sold to a public that is not the one which would make the most of it because many of the tourists do not take the 
trails; and there is a huge concentration of people at the beaches." (governmental organization A)

As a result of this mismatch, ICMBio created one national project (called the Project to promote tourism in the national parks and surroundings) with the idea of raising awareness of the conservation area to the community and businesses (i.e. suppliers) located at the national parks in Brazil.

Recently, ICMBio has given a concession to a company called Econoronha to provide quality improvements to the infra-structure of the Fernando de Noronha's national park and to improve the provision of services for ecotourists. The company is responsible for providing trails on platforms made from sustainable resources; maintaining these trails; providing access for disabled people to the main beaches, trails and viewpoints; providing information for tourists about their services and attractions (distributing leaflets); providing interpretative signs on trails and stations of information and control where many services are offered (e.g. guided snorkelling, snorkelling equipment to hire, food, toilets etc). However, to be able to provide all these services the company is charging all tourists another fee (besides the daily conservation fee) upon arrival at the island. The prices differ for domestic and international tourists (where the latter pay more) and the permit has a validity of 10 days. This kind of concession is based on the successful model that happens at Iguazu National Park, also in Brazil. As a consequence, the interviewee from ICMBio believed it to be a good opportunity to increase the image of an ecotourism destination to Fernando de Noronha.

The interviewee also said that the situation regarding the capacity of the island is currently complicated; therefore the destination should not be promoted as a product for the high season because it does not have the capability of receiving more people during those months. Consequently, ICMBio has used its control over company establishments and operations to progressively reduce the number of tourists allowed to go to the destination by cruise ship.

The State Tourism Organization - EMPETUR is responsible for supporting the development of tourism in destinations within the State of Pernambuco of which Fernando de Noronha is part. The institution is guided by the "Pernambuco to the world: Pernambuco's Strategic Tourism Plan"; to which the researcher only had access to its public version. In this document there are goals to be met from 2008 to 2020. Fernando de Noronha is considered a consolidated destination which could take the course to stagnation 
and decline. To avoid this situation, some actions are proposed. In summary they are: (a) to recover the idea of an ecotourism destination by giving emphasis to the trails, wildlife observation and scuba diving; (b) to provide excellence in service quality; (c) to reposition the destination based on strategic promotion which will attract quality tourists and (d) to have meetings with the companies at the destination to make them understand the need to keep their high price levels rather than trying to discount their services. As a result it is expected that these actions will encourage: the exclusion of a certain type of tourists to occur naturally, to keep the high prices of the services offered, the provision of air tickets with prices above the national average, some rises in the conservation fee and restrictions regarding the types of ships allowed to go to the island (Governo de PE, Fundação CTI Nordeste \& Indústrias Criativas, 2008).

The calendar of events and activities on the island is updated by EMPETUR annually and it also includes promotional activities to all destinations of Pernambuco State. So, this organization also has the function of providing information about Fernando de Noronha., Fernando de Noronha is represented in all promotional material created by the organization but the island is only one product among all the other tourist destinations of the State. . Only in very specific occasions is the destination promoted solo, specifically for the sports events that happen there, e.g. the regatta and the surf competitions. There is also an investment in promoting the destination in scuba diving magazines and nautical tourism.

When asked if EMPETUR is worried about creating a huge demand, bigger than the Island can absorb, through the destination promotion the answer was negative. The organization did not appear to have any concerns or actions involving the avoidance of such a situation:

"As it is a destination that does already have a regulation, has a limited number of people that can get there, the destination has always been promoted without any worries about it." (governmental organization B)

It is believed that the island is an object of desire for the domestic market, where most people want to go despite knowing that it is an expensive destination with limitations. Even a huge number of potential tourists from Recife and Natal, located near the destination, have not been on the island yet. To counter this problem, they have supported the promotion of the 'Campaign More Noronha' which will be explained below in more detail, but basically it is the promotion of discounted prices to attract domestic visitors during the low season months . But at the same time, the interviewee mentioned that this 
promotion is also important for the businesses on the island to economically maintain their business throughout the year.

In the interview with the Ecotourism Department of the Fernando de Noronha State District - ADEFN, it was identified that they are still creating a tourism strategic plan to manage this activity at the destination. Currently their main activities are: (1) to provide tourist infra-structure, (2) to provide qualifications for the community and businesses (since $90 \%$ of the population make a living through tourism, directly and indirectly) and (3) to promote the destination, mostly with the support of the State Tourism Organization EMPETUR. Furthermore, in partnership with the local associations, a guide for accommodation and another for dining are under creation to promote these businesses.

Among the promotional activities, they have two main activities: (1) to provide training to the travel agents that sell the packages of tour operators from the main outbound markets in Brazil (São Paulo and Northeast region: but specially Pernambuco) and (2) through the partnership with EMPETUR to participate in national tourism events and fairs and support familiarisation tours and press trips on the Island.

To qualify the island's workforce, they provide a lot of courses in partnership with the Brazilian Service of Support for Micro and Small Enterprises - SEBRAE and with National Service for Commercial Education - SENAC. Some of the courses involved: selling of products and social media; which are courses explaining concepts of distribution channels and how to better use social media as a channel. These qualification courses are included in EMPETUR's strategic tourism plan (Governo de PE, Fundação CTI Nordeste \& Indústrias Criativas, 2008). This is probably because of the identified need for more skills for businesses' owners run their companies since many, as identified in section 4.4.2, lack formal education in tourism and management due to the historical development of the destination.

ADEFN also plays a significant role in the distribution channels of the destination when they authorize extra flights for the island in the high season months (ADEFN, 2000). This authorization happens without the need to have an agreement from ICMBio. It happens when an airline makes a formal request proving that they have already sold out all seats to the island in a given date: usually on holidays and over the summer. The approval of a request for extra flight from a tour operator has also happened; but it is not common. 
One project they have undertaken that is influencing the distribution channels is the 'Campaign More Noronha', started in 2011 and targeting the domestic market. The main idea of the project is to provide discounts on the prices of suppliers and intermediaries for the low season (from March to June). The discounted rates vary from 15\% to $30 \%$. The idea has its origins in a meeting between suppliers and ADEFN. The latter asked the support of EMPETUR. Together, government and suppliers encouraged the airlines to partake in the project. After their agreement, suppliers and airlines provided discounted rates to intermediaries sell cheaper packages to consumers. At the same time, suppliers were also providing discounted rates for direct sales as well; even restaurants and taxi drivers provide discounts. The government is providing support for the promotion of the campaign by providing information for consumers through advertising on radio, TV, billboards and magazines, as well as creating and distributing all promotional material for the campaign including the logo of the project: as seen on Figure 22.

Figure 22: Photos of the 'Campaign More Noronha' in practice.

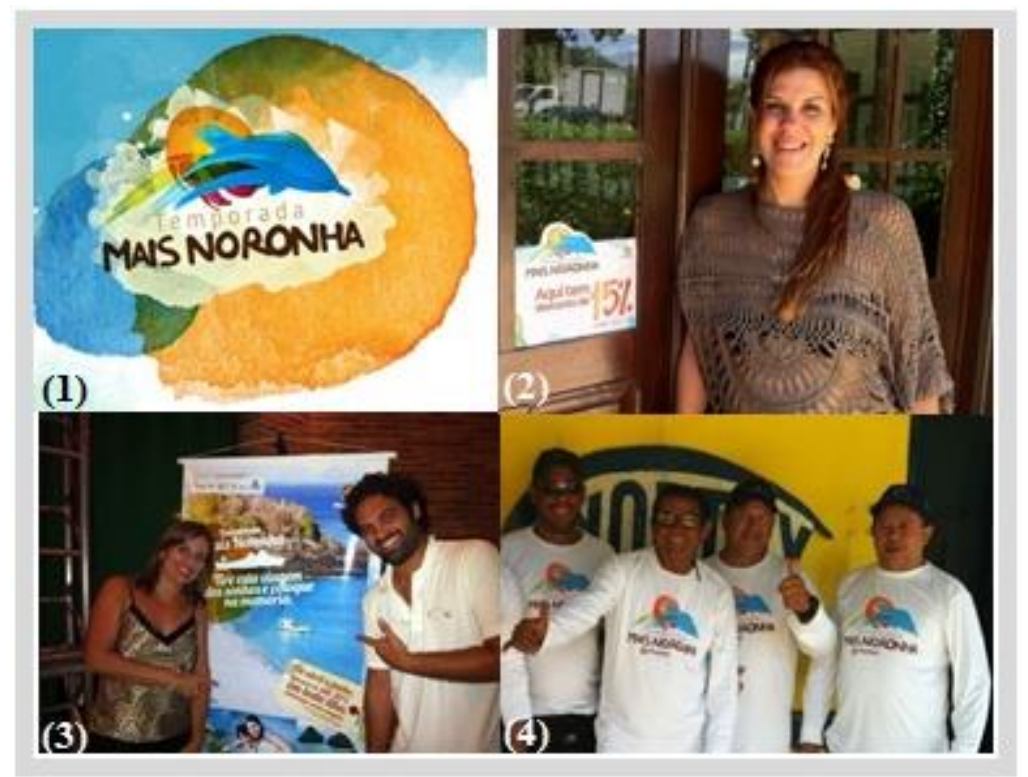

(1): Logo of the 'Campaign More Noronha' in 2013; (2) Accommodation owner with the stamp of the campaign in the entrance of her business; (3) A representative from ADEFN (left) with a supplier (right) promoting the campaign at an event; (4) Taxi drivers with the campaign shirt in 2013. Sources: http://g1.globo.com/platb/pe-viver-noronha http://parnanoronha.com.br/paginas/226-fernando-de-noronhacom-precos-mais-baratos.aspx

As a result of the first year of the campaign, there was an increase of $31 \%$ in visitor numbers. About 100 suppliers participated in the campaign in 2012. The package prices offered were from $\mathrm{R} \$ 900$ to $\mathrm{R} \$ 1,100$ (NZD542-NZD662) for 3 nights (including tickets, accommodation, transfer, travel insurance and a guided historical trail or tour) compared with the usual price of $\mathrm{R} \$ 1,500$ (NZD903) or more. The airlines: provided rates up to $40 \%$ 
of discount for a ticket from the following domestic destinations spread throughout three macro-regions of Brazil: Recife, Natal, São Paulo, Rio de Janeiro, Vitória, Campinas, Belo Horizonte and Goiânia (Viver Noronha, 2012).

ADEFN identified that the carrying capacity management and its impacts on the distribution channels of the destination is a limitation for intermediaries. These vendors cannot make use of economies of scale in this situation to compete among themselves; because the volume of air tickets they can sell per day cannot increase:

"If the tour operator gets a good ticket price with the airline and accommodation, he will be able to sell a package cheaper than his competitors. But with the limitation on access he will not have any advantage in doing so because he won't sell more packages! It would only be interesting to sell cheaper packages if the intermediary could sell three times the amount he actually can. So, why would he sell cheaper packages if he can only sell the same amount of flight seats?!" (governmental organization C)

The organization also believes that potential tourists are interested in the destination because it is an island where limited numbers of people are allowed per day. They also want to learn about the island's environmental conservation. However, ADEFN recognizes that the destination still has not defined the profile of tourists they want to get since they still get many sun and beach tourists.

It was said that ADEFN intends to promote the destination as a place of ecotourism; consequently they intend to change the destination's image:

"We want to increasingly sell Noronha as an ecotourism destination." (governmental organization $\mathrm{C}$ )

Based on the survey they conduct with visitors, it was identified that the domestic market still has not been looking for ecotourism; with the exception of tourists from a few states (like São Paulo and Rio de Janeiro), while the great majority of potential tourists in the Northeast region of Brazil still look for sun and beach destinations so they go to the island for this purpose. However, ADEFN states that Fernando de Noronha is an ecotourism destination that is still getting ready to receive this kind of tourists with the infrastructure needed. As a result the recent work of Econoronha plays an important role for the destination. 


\subsection{Conclusion}

To understand the mix of distribution of Fernando de Noronha in detail four categories of tourism products were created: luxury accommodations, non-luxury accommodations, scuba diving and other activities. This division allowed a comparison of the structures of the many different types of companies interviewed. Thus, the dominant indirect channels were identified as mass-market channels since they rely on travel agencies, especially those with vertical integration (which means those companies with a tour operator, switch company and travel agency).

The factors influencing the distribution channels structures of Fernando de Noronha are very diverse and for this reason they were categorised into three groups: general, the reasons for using direct distribution and the motives for having indirect channels. Many of the factors found had already been found in previous literature and for this reason the next chapter will present a comparison of the findings with previous studies.

Some challenges suppliers have are issues influenced by the capacity management of the destination. There were some complaints about the lack of flight tickets (especially in the high season) and the image of the island as an expensive destination which leads some businesses try to sell their products based on quality. The lack of infrastructure, specifically the installation of a hyperbaric chamber, is affecting the destination's ability to compete in -international markets to sell its most iconic activity: scuba diving. Moreover, the global economic crisis and the lack of formal education of some businesses owners and managers (in tourism or management) are confusing suppliers on how to choose their distribution mix.

Above all, since there is high demand from tourists during the summer months the shortage of supply in airplane seats is making some tour operators powerful; in the sense that they are holding many tickets in advance. When air tickets cannot be bought directly, it obliges luxury accommodations to make partnerships with tour operators not specialized in their niche in order to get their clients to the destination.

Regarding the government's function of promoting the destination, it could be noted that many of their activities include distribution channels for a mass audience. In addition, the strategic marketing plan of EMPETUR shows that their strategy to change the image of destination to ecotourism is twofold: high prices on all services offered and promotional actions not further explained on the plan. Therefore, there is still the need to understand and design a distribution mix appropriate to the intended destination image. 


\section{Chapter 5: Discussion}

\subsection{Introduction}

The previous chapter highlighted the different distribution channels structures for the four categories, identified the factors influencing the structures and presented the challenges experienced by suppliers. This chapter aims at firstly presenting the overall tourism distribution channels structure for Fernando de Noronha and secondly to evaluate and explain the relationships between the Island's management with its capacity planning, and supplier's channels of distribution.

Initially, there will be a discussion about the commonalities found in the four different categories of distribution channels structures presented in chapter four. Splitting the structures of the destination into four categories: Luxury Accommodation, Non-luxury Accommodation, Scuba Diving and Other Activities was useful for understanding the particularities of the main products Fernando de Noronha offers. In addition it provided an opportunity to identify some patterns. To further explain the similarities the discussion in this chapter will cover the importance of the structures and the factors influencing suppliers' decisions on their mix of distribution channels. In addition a discussion will be made on what the literature says about the factors influencing suppliers' distribution channels and how this compares to the situation in Fernando de Noronha. As well as this, the most relevant "at the destination" distribution channels impacting suppliers will be identified.

Many studies have focused on the distribution channels structures of destinations and some mention the factors influencing them (see Chapter 2). However there is no previous study aiming at explaining the relationships of capacity management of a destination with the choice of distribution channels by suppliers. Consequently, this chapter will finally provide an explanation of the relationship between the capacity management of Fernando de Noronha and suppliers' choices of channel mix.

\subsection{Tourism distribution channels structures and factors at Fernando de Noronha} From a supply-side perspective, the distribution channel structures of Fernando de Noronha and the factors influencing them will be presented below based on the conceptual framework of this research.

The most common channels' members used by suppliers at Fernando de Noronha are: direct channel, online reservation websites (third-party website), travel agencies, tour 
operators, switch companies, specialist cruise trip tour operator, cruise ship operator, ground operators and suppliers' associations. These channels were selected based on the frequency of their appearance in the previous four groups of structures (Figures 17, 18, 20 and 21). The most relevant factors influencing these structures were divided in four groups: general factors, the factors influencing direct distribution, the factors influencing indirect distribution and the factors that are influenced by capacity management of the destination.

The structure of the tourism distribution channels of the destination, including the factors influencing these structures, is summarised in Figure 23. The colour of the boxes represents the location of the company: grey is "in market" and black is "at destination". The colours of the arrows represent the functions performed between the channel members: green shows the function of information provision, black symbolises the booking and purchasing functions while light blue indicates the sorting and bundling functions.

The functions of information provision and booking and purchase are always performed between consumers and suppliers (when direct distribution occurs) or consumers with intermediaries (in the case of indirect distribution). After the first level of indirect distribution, the relation between intermediaries and suppliers is mostly to provide the sorting, bundling, booking and purchasing functions. A couple of exceptions happen in the relationship of the third and fifth indirect structures (from left to right) where the relationship between the travel agency and the first tour operator is performing the information provision function rather than sorting and bundling.

Figure 23: Distribution channels structure and factors of Fernando de Noronha 


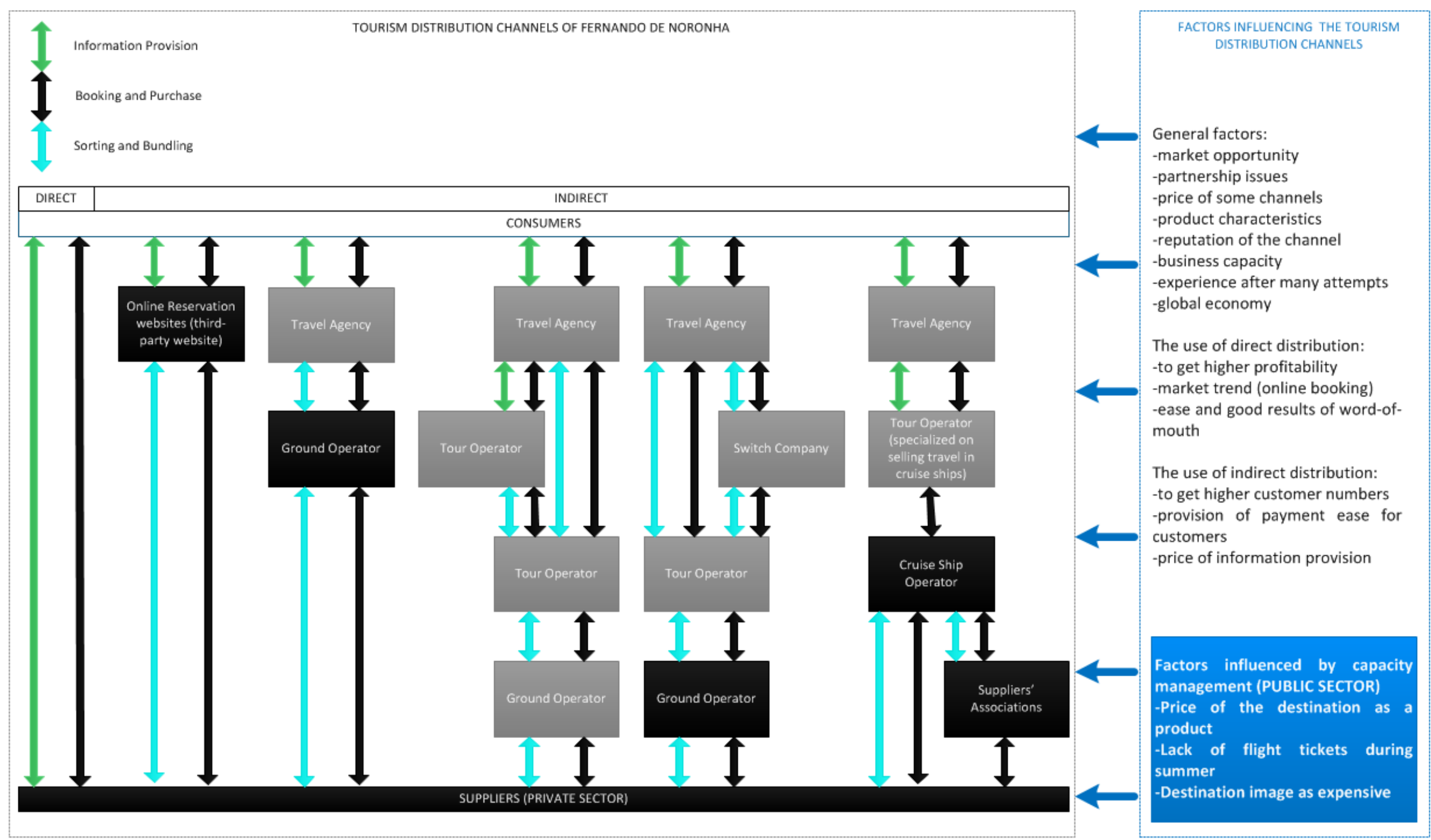


The direct channel is a common and very useful channel for many suppliers; word-ofmouth and company's website are seen as the most effective ways of linking consumers to suppliers. This channel is especially important for the accommodations (luxury and nonluxury), to all suppliers providing tourist activities and to ground operators only when trying to get business from independent travellers at the destination. The importance of this channel is heightened because there is no tourist information centre at the airport and there is no brochure distribution with a list of all services tourists can get at the destination. As a result, independent travellers that have pre-booked accommodation will depend on the ground operator that provides the transport to the accommodation for getting information about activities. Independent travellers without pre-booked accommodation will depend on the approach of ground operators and taxi drivers upon arrival for recommendations and transport to suitable accommodation.

The importance of direct channel was also highlighted in other studies. This channel is used in Brazil with rural tourism as noted by Lohmann and Nascimento (2007). The tourists in this segment usually travel as independent travellers and prefer to book and purchase both accommodation and activities directly with suppliers; with $60 \%$ of sales from activities providers happening via direct channels. Also in Brazil, Filho and Lohmann (2012) pointed out direct sales 'at origin' is the most common practice in Brotas: the Brazilian adventure capital. Similarly, New Zealand's adventure capital, Queenstown, relies heavily on 'at destination' distribution because their travellers like to have flexibility, which means that direct distribution is also important for them. Likewise, Liu (2012) indicated that Marlborough and Auckland wineries receive most domestic corporate groups from direct distribution "at destination".

At destination purchases of activities are mostly influenced by ground operators and accommodations. Ground operators provide good prices when selling tourist activities because they include the transportation between the accommodation and the activity location. Consequently, they provide value for money to consumers because if consumers buy suppliers' products directly they will probably not have the transportation included. The great majority of suppliers do not have permission to have transport on the island, except for scuba diving operators and the 'island tour' provided by taxi drivers. Moreover, accommodations are such an important channel because they can provide recommendations to tourists about any service on the island. Also, when tourists have not previously planned their activities they will ask for help from the accommodation staff. 
The commissions paid by activity providers to accommodations acknowledge the importance of their role as a channel for other types of suppliers at the destination. Therefore, they may strongly compete with ground operators whose efforts are focused on selling at destination rather than in market. Even when accommodation providers have a partnership with ground operators for providing transportation between the airport and the accommodation and recommending tourists to buy their chosen activities from that specific ground operator, the accommodation providers still can get commissioned directly by suppliers of activities when the tourist decides not to use that ground operator.

The indirect channels involve the online reservation websites which are important for all types of accommodations on the island. On the other hand, all the following structures in Figure 23 show the presence of travel agencies and ground operators; with the exception of the cruise ship operator which performs the function of a ground operator by sorting, bundling, booking and purchasing the services of suppliers. These channels represent similar structures of tourism distribution channels previously singled out by Pearce and Tan, (2004); Pearce, (2007); Pearce, (2008); Schott, (2007) and Liu, (2012) and differ from the structure of rural tourism in Brazil identified by Lohmann and Nascimento (2007). However, previous studies on the structure of distribution channels have not included cruise ship operator and supplier's association as members of their structures.

Lohmann and Nascimento (2007) analysed a product different from Fernando de Noronha because rural tourism in Brazil has different features from ecotourism. The brazilian rural accommodations studied act as an attraction rather than being only a place to stay because they also offer events, trainings, restaurant, many activities and parties. Another reason for the differences is because the rural tourism in the region researched attracts more tourists from the State of São Paulo, while Fernando de Noronha receives tourists from all over the country as well as international tourists. In addition, their study mentions a communication problem between suppliers and intermediaries associated with low commission and the characteristics of the rural tourists of being more independent (Lohmann and Nascimento, 2007). In their structure as previously presented in chapter 2 , there is not the presence of tour operators as intermediaries. When travel agencies are used as intermediaries, they contact customers directly or through a sales representative or schools. In addition, when suppliers are selling to corporations they make use of the human resources department as an intermediary. Ground operators are also used as intermediaries to get consumers but the difference is that in Fernando de Noronha ground operators also sell to other intermediaries 
like tour operators and travel agencies. The only similarities found were the use of accommodation as an intermediary for suppliers that offer activities (see Figure 7 and 21) and the use of word-of-mouth as an important direct channel.

Access plays a significant role to islands, which are a remote and isolated destination. The transportations providing the means to reach Fernando de Noronha are important stakeholders responsible for the development of the destination. Although the companies providing both types of transportations (by air and by sea) to the island could not be interviewed, as detailed in Chapter 3, data from the interviews with the government, businesses, on websites and from documents allowed an understanding of the distribution channel structure of the cruise ships. On the other hand, the lack of an interview with the airlines prevented the gathering of more detailed information about the channels that hold the great majority of tickets to the island.

Cruise ships operate as suppliers since they offer accommodation, all meals and entertainment but they also work as intermediaries - specifically like ground operators - in the case of Fernando de Noronha because they perform the sorting and bundling functions: selecting the activities (suppliers) to work with and adding a mark-up when selling these services to customers. Therefore, there is a clash between cruise ship operator and ground operators and non-luxury accommodation providers because the cruise ship tourists do not make use of these services. As an interviewee mentioned:

"When the cruise ship arrives here it brings 500 to 700 people at the same time. Noronha has a high turnover of tourists. So, these cruise ship tourists are added to the already satisfactory amount of tourists the island receives by air, a number that everyone can work with and gain from it. But these cruise ship tourists do not consume much at the island. In this case I feel that they cause an impact." (intermediary K)

The same issues regarding the negative impact of cruise ships happen in other destinations. As observed by Pender (2001) they usually disturb eco-systems by the number of visitors they take to destinations and they reduce economic opportunities for local businesses due to the short time they spend at destinations. To solve this last problem and in response to many complaints from their customers, the cruise ship operator recently announced that in 2013 it will operate differently. The idea is to provide packages including accommodation at the destination. The tourists will be able to go to the island by cruise ship and return to the continent the next time the cruise stops at the island again (Viver Noronha, 2013). This may provide a better image for the cruise ship operator since there have been many complaints from their clients because they were attracted to take the cruise by the price and 
their motivation to visit the "Brazilian paradise" but they were extremely dissatisfied to have only one day or one day and a half to experience the destination. An intermediary stated:

"The cruise ship tourist travels to Noronha motivated by the destination" (intermediary $\mathrm{H}$ )

Concerning price, Pender (2001) also noted that cruise ships are leaders in flexible production because they are able to create "flexible" trips at fairly low prices for large numbers of consumers. Consequently, they "mass customize" the market. Moreover, the use of mini-cruise ships as in the case of Fernando de Noronha (compared to most cruise ships that transport thousands of people) usually allows for lower prices when compared to the average price of the packages for bigger vessels (Pender, 2001).

Relating back to Figures 8 and 9 in Chapter 2 from the publication of MTur and ABETA (2011), the figures presenting the structures of distribution channels for Fernando de Noronha were very superficial in comparison with the detailed structures presented in Chapter 4. The information provided in this research has allowed a deeper understanding of how consumers may purchase services for travelling to the destination and activities to do while 'at destination'. A larger diversity of members in the distribution channels were interviewed and the relationships between suppliers and intermediaries were deeper analysed. Moreover, the methodology in this study is more focused and includes interviews with intermediaries located on gateways to the Island.

\subsection{Factors influencing the Tourism distribution channels at Fernando de Noronha}

This research found that most of the factors influencing the distribution channels of suppliers had already been identified on previous studies conducted in New Zealand (Pearce and Tan 2004; Stuart 2004 and 2005; Schott 2007; Smith 2007a; Smith 2007b; Smith 2008; Liu 2012). However, new factors were also identified.

This research found that the factors: matching customers with the channels they use, price of some channels, decisions based on experience and high cost of information provision were similar to what was discovered by Smith (2008). She observed that the adoption of different promotional tools aims to attract different audiences and the factors influencing the choice of promotional channels are: purpose, target audience, cost effectiveness and partnerships. Although the author noted that the nature of the event and the target audience were key factors for choosing a distribution mix, some event organizers still rely on past 
experience and gut feeling. This was also the case for the activities providers and accommodations on Fernando de Noronha.

Fernando de Noronha also shares some similarities with Southland, the peripheral region of New Zealand studied by Stuart (2006). He found that market coverage, business generated and the use of direct channels to lift yield were factors influencing suppliers in this region. In Fernando de Noronha the similar factors would be the increase of business promotion, attracting higher customer numbers and getting greater profitability, respectively.

Other similar factors influencing the businesses on the island were the factors influencing wine tourism businesses in New Zealand as identified by Liu, (2012); as previously mentioned in chapter two. For example: information cost, businesses' attitudes towards tourism, accessibility (location), availability, market segments, reputation of intermediaries. Although capacity was also mentioned, it was regarding the transportation size to take tourists to the wineries and cellar door size of wineries.

At Fernando de Noronha, the product's characteristics affect the channel mix of suppliers, which in this case is related to environmental conditions affecting the visibility of services. Similarly, Schott (2007), mentions that weather conditions can affect the safety of the attraction. For this reason suppliers from both Fernando de Noronha and Queenstown understand that it is a lot of effort (costly and time consuming) to deal with cancelations for intermediaries outside the destination or overseas.

Research conducted in a developing country, in this case Tanzania, showed the following factors to be similar to Fernando de Noronha: lack of marketing knowledge, lack of formal business knowledge (many are family owned and run), ground operators located at gateway airport, suppliers cannot handle all the functions of distribution channels alone, some dependent on 'at destination' distribution strategy due to the nature of the activity and its appeal, distribution costs, use of internet distribution and cost of promotion (Mkumbo, 2010).

While the current literature showed these factors were similar, new general factors were identified in this research which are distinct from other studies. These symbolize specific aspects of the local Fernando de Noronha businesses' owners' behaviour. The partnership issues (involving the difficulties in establishing and keeping partnerships, the need to have more harmonious partnerships and make a fair deal on the price of commissions) could be 
something that does not happen in other cultures or businesses. Two other distinct factors are infrastructure with regards to the poor performance of the free internet, and the need to have flexibility relating to the choice of the channels by independent tour guides.

When direct distribution takes place, the factors previously not covered by the literature are following market trends and matching expectations with the price paid. The first refers to recognition by suppliers of the importance of direct online bookings to consumers. This is leading them to continue investing in their virtual presence through the company's website. The matching expectations with price factor refers to a specific situation that sometimes the mark up intermediaries add is higher than previously agreed with the non-luxury accommodation and consumers are dissatisfied with quality of the services for the price they have paid.

Concerning the importance of having intermediary, the provision of payment ease for consumers is seen as an important factor that persuades suppliers when choosing how to reach customers.

The final new factor influencing distribution channels which emerged was capacity of the destination. Previous studies have discussed capacity but this has been in relation to the capacity of an individual business. For example Pearce and Tan (2004) commented on capacity constraints as a factor which is preventing heritage and cultural tourism attractions in Rotorua to work with tour groups since a large number of tourists at the same time would cause physical degradation of the property and reduce visitor satisfaction with the tourist experience. Similarly, Schott (2007) pointed out the issue of capacity constraint also affects smaller businesses at Queenstown. This is inhibiting them to receive group bookings and is resulting in their reliance on independent travellers. Likewise, Liu (2012) mentioned capacity referring to vehicle size and cellar door size. Vehicle size of wine tour operators restricts the market segments they cover and the channels they choose. The cellar door size of wineries is hindering wineries' ability to receive tour groups. The same problem of business capacity is experienced by the smaller ground operators at Fernando de Noronha who focus on recruiting travellers at the destination and event organizers who attract clients mostly through the internet. Smith (2007a) mentions site capacity of an event and again Smith (2007b) makes a case that capacity of events are defined by venue capacity, the weather, the experience the organizers want to provide for participants and the destination's available infrastructure (regarding the availability of rooms at the city on the month of the event, if it is high season or not). 
In these cases, capacity was an internal business constraint. The difference in Fernando de Noronha is that capacity was an external constraint beyond the control of the individual tourism businesses; it is the government's management of the destination overall carrying capacity that is the factor influencing distribution channel decisions. This will be discussed further in the next section.

\subsection{Capacity management of the destination as a factor influencing the tourism distribution channels}

No study has analysed capacity management of a destination as factor influencing the tourism distribution channels. This research found three factors that are influenced by the capacity management of the destination. These factors are: price of the destination as a product, lack of flight tickets during summer and holidays and the destination's image as expensive. Together, these factors are interrelated.

Since the destination has only three regular flights per day and the return ticket is usually not cheap, this influences the prices of travel packages to the island. This reason, combined with other operational costs such as the two environmental conservation fees and the lack of local production of goods, food and other community needs, makes a holiday to the destination expensive. As a consequence, when potential tourists compare the price of going to Fernando de Noronha with other domestic and international destinations, they can realize that the island is actually expensive. Nonetheless, there are still many potential domestic tourists with money to go there. Most of these people are concentrated over the summer months and holidays: which are the seasons when extra flights are requested by airlines and granted permission by ADEFN to land on the Island (ADEFN, 2000). This happens in the same months as cruise ship visits, which usually happen twice a week transporting up to 700 passengers each time.

Over the summer months, which include Christmas and New Year's Eve, the demand for flights to the island is really high. So, if tourists are really committed to go to Fernando de Noronha and if accommodations, virtual distributors, airlines and travel agencies are trying to sell the destination at the same time, it all will come down to the number of seats available. As a result, tour operators who are responsible for buying flight tickets in bulk from airlines (even months in advance) become the most important member of the distribution channel of Fernando de Noronha for 'in market' purchases. As mentioned in the previous chapter, suppliers - especially accommodation providers - may lose business if their clients cannot get plane tickets to the destination over summer. Consequently, there 
is the need for suppliers - especially accommodations - to identify what are the tour operators holding these flight tickets and enter into a partnership with them. These tour operators are virtual distributors, two-channel distributors or multi-channel distributors belonging to a big travel agency with vertical integration. Some of them are specialized in ecotourism and adventure, while others are targeting mass tourism and corporations.

The purpose of the government's capacity management is to prevent environmental deterioration and mitigate the impacts of tourism. However, it seems that there is a clash between the role of ICMBio as an environmental protector and the role of EMPETUR and ADEFN as promoters of the destination's tourism development. As a result, while exercising the function of information provision for the destination, it seems that these latter two organizations are struggling to target the Island to consumers who would best enjoy the destination's characteristics and activities. There is no initiative from them explaining what kind of tourists they are actually targeting. The strategic tourism plan was only mentioned that they want to recover the idea of an ecotourism destination but it does not explain how they will do it in detail. There is no plan clearly stating what type of behaviour they expect to get from the tourists they are currently targeting in their promotional actions. In addition, it seems that their main strategies for getting highly spending tourists are via visitor number control and the high price of the destination as a product.

There is a complaint from ICMBio and a supplier of tourist activities that the great majority of tourists do not make use of the many trails offered and that it is hard to get clients to do adventure activities (like rappelling):

"I work with ground operators. But the type of tourists from one of them generally has no interest in our services." (tourist activity C)

Furthermore, it may be hard for suppliers and intermediaries to understand and believe that the destination image they are selling is actually influencing the sustainability of the Island. Especially when the great majority of companies (intermediaries and suppliers) seem to be more focused on selling rather than targeting specific consumers who would match with the destination's characteristics. It is probably even harder for them to get out of the comfort zone and change their approach to selling the destination. As mentioned in the previous chapter, a tour operator expressed the concern with the travel agents' training:

"I am really worried about how the travel agent is selling to the client. It is much better to say the truth: what the island has and has not, what the 
person will find on the island, how is the island... than selling just for selling and when the client arrives there he/she may not adapt to the environment of Fernando de Noronha. There are many people that do not like sea, vegetation or to go to an isolated place." (intermediary D)

Unqualified and irresponsible travel agents may think of quick sales to meet goals and get commissions rather than focusing on transmitting to the buyer the real image of destination: which is more of an ecotourism destination rather than sun and beach given its infrastructure and nature.

Based on the TALC model by Falcão (2010), Fernando de Noronha is at both "development" and "consolidation" stages which means that the destination is in a crucial moment of its "life" and strategic measures should take place in order to lead the destination to the best stage of these three possible outcomes: stagnation, rejuvenation or decline. The "consolidation" stage means that the island is at the carrying capacity threshold range. It requires immediate measures to avoid unsustainable and dysfunctional states of the destination. These two states seem to be already in place based on the interview with the ICMBio which showed that the physical, environmental and infrastructure types of carrying capacity were at their limits or maybe have already been exceeded especially in the high season.

ADEFN and EMPETUR must make an effort to plan and clearly define what type of tourists they want to target for the destination. Right now the businesses are selling the destination to 'psychocentric' and 'near psychocentric' customers: especially the 'cruise ship tourists' (who are people that cannot afford to go there by plane; MTur and ABETA, 2011) and the 'party tourists'. The 'Campaign More Noronha' seems to be aiming at 'midcentric' to 'psychocentric' tourists since the government is using mass media like radio, billboards and TV to reach consumers. On the other hand, ICMBio is doing well in focusing on documentaries which are channels to reach allocentrics and near-allocentrics. As a result, the destination is confused regarding the tourists it has been targeting because of its characteristics of having beautiful sunsets and beaches and at the same time being more related to ecotourism due to its number of trails offered (many of which involve walking on loose rocks and going up and down hills), its fragile wildlife, its suitability for water sports and adventure activities, its rustic infrastructure and rugged topography. So, if Fernando de Noronha is to be considered a product, the nature of this product is ecotourism and adventure tourism (since scuba diving is considered the iconic activity, MTur and ABETA, 2011). The strategic tourism plan of EMPETUR only mentions repositioning the 
destination through a strategic promotion that will attract quality tourists, but it does not include distribution. As a result the government seem to be influencing only the 3 'P's of the marketing mix: product, price and promotion; neglecting the place, which means the distribution. However, distribution is important since the nature of components in the marketing mix is to be inter-dependent. The reason that the government neglects distribution seems to come from the idea that they do not feel responsible for interfering the distribution to the companies, which could be understood as saying to whom the businesses at the island should sell their services; and this could create a tension between the public and the private sectors, as suppliers do not understand distribution as a strategic tool.

In addition, as shown in Figure 4 (Chapter 1), the great majority of tourists stay from 3 to 4 days in the destination, which means that they probably cannot afford to stay longer and this short time limits their options for many reasons. On the first day the only activity possible is the seminar on the TAMAR Project due to the flight arrival time, in the afternoon. On the second day most people take the 'Island tour' an activity which takes the whole day moving from one place to another. Usually people also decide to go to the famous Atalaia beach, and the time to visit the place depends on when the person was scheduled if there is any vacancy; because there is capacity constraint on accessing this beach. Lastly, on the final day only one morning activity can be enjoyed - probably a boat tour to swim and watch the dolphins. Consequently, this type of tourist would also fit into the psychocentric and near psychocentric characteristics.

The publication of MTur and ABETA (2010), defined the types of tourists of Fernando de Noronha into four categories: cruise tourists, party tourists, open tourists and adventure/sport tourists. As mentioned, these first two are psychocentric and near psychocentric types of tourists. However, the 'open tourist' could be classified as midcentric to near psychocentric because they are motivated by idea of "Brazilian paradise" but not ecotourism and are concentrated over the main holiday periods. There are some international 'open tourists' motivated by ecotourism but they are a minority. The 'adventure/sport tourist' could be classified as near allocentric as they are mainly focused on specific activities (MTur and ABETA, 2010; Plog, 1974).

For all of these reasons, stakeholders must consider de-marketing the destination (discouraging potential visitors via marketing mix manipulation) for the high season especially and what approaches should be taken between: places, peak periods and people. 
The approach of de-marketing place means that the distribution of package holidays to the island should be restricted. When using the 'people' approach to de-marketing, tour operators selling to sun and beach tourists and cruise ship tourists should be prevented from organising holidays to the destination. The approach for de-marketing in peak periods is about controlling the pre-bookings via both direct and indirect channels. However, it seems that the government plans to use price to discourage low spending tourists and mass tourism.

Define how to undertake this de-marketing is also essential in order to keep suppliers satisfied. This might seem an extreme situation but it should be taken as an opportunity to create a competitive advantage to the destination. Maybe de-marketing and retargeting visitors could be better than keeping or maybe increasing the restrictions and price of the destination as measures for controlling the impact of tourism. To start, perhaps something should be done to avoid the types of unwilling tourists and the concentration of visitors that has been emphasized by intermediaries during the high season. According to Plog (1974), destinations receiving more mid-centric to psychocentric tourists will probably have problems in the future. Based on the information obtained in this research it can be concluded that the destination is already struggling and consequently is in need of replanning tourism in the Island with more specific goals to change its current state.

All together, the importance of travel agents, in market, for targeting the 'right' consumers is essential for the sustainability of the island because of the behaviour the different types of tourists have when at the destination. As an example of travel agents failure to meet the expectations of clients when selling the Island, some tourists complained about the lack of activities for their child:

“... a couple was dissatisfied with the services of Fernando de Noronha, for prohibiting children to do snorkelling and for not offering activities directed to them." (MTur and ABETA, 2010, pp.49)

In this situation, travel agents' training is important in showing them that they are the people responsible for the selling the destination to unsuitable clients and for spreading the message of sun and beach. Above all, the public and private sectors must understand and recognize that their decisions and actions are moving the island through the current critical stages of the tourist area life cycle (Butler, 2006). Currently suppliers and intermediaries seem to be very focused on selling. So, more information about theories in tourism with illustrations about tourism in other islands is needed to provide them with an understanding of the practical implications of their actions by comparing to similar destinations. 
Stakeholders need to remember that distribution is the key element of the marketing mix. It should therefore be more carefully planned and used as their main strategy to reposition the destination, with aim of providing sustainable development for the island and preserving its natural resources. The current distribution of the destination represents a mass market approach, so this could be changed. Mass market distribution channels are: (1) The multichannel distributors that target the mass market and have a big market-share in the country. These are vertically integrated: the same company has a tour operator, switch company and travel agency. Especially those distributors promoting their services on TV. (2) Virtual distributors: online reservation websites (third-party websites) that sometimes promote their services on TV and non-specialized tour operators because they usually sell to a mass audience of tourists directly online or via travel agencies. (3) Every channel selling the cruise ship package in the way these cruise ships have been operating so far. However, their operation is predicted to change by allowing tourists to overnight at the destination as previously explained.

Ground operators and accommodation providers (including both non-luxury and luxury) could replace the above mass-market channels with channels specializing in ecotourism, adventure, sports, luxury, scuba diving and wedding planning companies. In the case of suppliers already having a channel mix involving both mass market distribution and specialized tour operators, the best option would be to give preferential bookings to specialized tour operators during the high season.

Many suppliers expressed a preference for direct channels because they are more profitable. However, very few suppliers and ground operators offer online purchasing, and usually potential customers have to send a message to the company to ask about price and check availability. An increase of direct distribution from suppliers with the possibility of purchasing their products online by consumers is important to independent travellers, but it also will generate the need for more qualified information on the websites of the companies 'at destination' which is generally lacking at present. More investment in the websites of these companies must be made in order to provide online content that is attractive to consumers. This needs to include websites that work on mobile technologies, like tablets and smartphones.

There is a need for ground operators to shift the emphasis on providing their services to mass market tour operators and start to focus on specialized tour operators in the segments of ecotourism, adventure, sports, luxury, scuba diving and wedding planning companies. 
The importance and relevance of tour operators includes their function of information provision to both consumers and travel agencies. They are the most qualified members to position products in the market because they are experts on product quality and consumers' expectations (Gartner and Bachri, 1994). Since tour operators also provide training to the travel agencies they work with, they are responsible for the image formation of destinations because travel agents that had never been on the island will have an idea of the destination based on the information provided by the tour operator. Above all it is believed that these specializing tour operators are more concerned about the overall tourism experience their clients have rather than focusing on selling only to meet sales' goals; which is like many travel agencies behave.

Word-of-mouth was shown to be a very important channel for many suppliers. However most of the suppliers did not reveal any plans to enhance this channel. The interview with ADEFN made mention of the need to give training to the community about how to make better use of this channel. So this organization is planning to teach suppliers how to promote the destination to their customers in order to make them want to return to the destination and experience what was missed, as well as to highly recommend it to friends. Additionally, very few suppliers mentioned doing something to exceed the expectations of customers and thus increase word-of-mouth recommendations.

There is also the need for suppliers to improve the information they provide about their businesses to both consumers and intermediaries. This could be done by drawing attention to the quality of the product they offer by informing about their sustainable practices (e.g. making use of the local workforce in locally owned non-luxury accommodations or maybe showing the measures taken to avoid harming the environment) and by exploiting local uniqueness (e.g. in decorations making use of locally produced handicrafts or by representing the local iconic symbols in the name of the business as well as on the promotional material and website). As previously mentioned on section 4.5 by one of the suppliers interviewed, there is the need to suppliers providing tourist activities to operate under sustainable principles. This way, luxury accommodation providers competing on the international markets based on the high quality of their services would be able to receive more tourists willing to buy products working under sustainable practices. In addition, having more suppliers offering sustainable products would enhance the destination image for ecotourism. 


\subsection{Conclusion}

This chapter discussed the structure of the distribution channels in Fernando de Noronha and the factors influencing these structures; both, structure and factors, were illustrated on Figure 23. However, the indirect distribution structure of the destination is largely depending on mass-market distribution channels. For this reason, low spending tourist is the most common type of visitors the destination receives. The factors influencing the structures of distribution channel are diverse but the great majority of these factors had been identified in previous studies. In these previous studies capacity had already been showed regarding the limitations of businesses; but not related to capacity management of a destination.

This study stressed the importance of considering capacity management of the destination as an external constraint influencing suppliers' distribution mix choices. It was also shown that the government is missing the use of distribution channels as a strategic tool of the marketing mix which could enhance their plans to reposition Fernando de Noronha as an ecotourism destination and attract high spending tourist. The next and final chapter will revisit the research objectives. 


\section{Chapter 6: Conclusion}

\subsection{Introduction}

This qualitative research has examined the tourism distribution channels of Fernando de Noronha, an island recognised as a natural World Heritage Site by UNESCO since 2001. The main objective was to investigate how the capacity management of the destination is influencing the tourism distribution channels of suppliers; such a perspective had never been taken before in the literature. As distribution channels link suppliers with consumers, they have a significant role for islands such as Fernando de Noronha due to its remoteness and isolation. For this reason, a distribution strategy for the destination is an essential supporting instrument to enhance the controlled development of a site with vulnerable biodiversity depending on the carrying capacity measures of the government as the main tool for conservation.

A supply-side perspective was taken in this research due to stakeholders' involvement in site governance and management. This case study conducted a total of forty-one in-depth interviews with suppliers, intermediaries and governmental organisations (local, regional and central). The interviews mainly happened at the destination but also in the two cities which are the gateways to the island: Recife and Natal. Most of the interviews occurred with business owners or managers of the companies. Suppliers located in all villages with tourist companies on the island were approached. The limitation of the research was the non-participation of airlines and the impossibility of interviewing virtual distributors and specialized tour operators (focused on luxury and ecotourism) located at São Paulo: the largest source market for domestic tourists in Brazil.

Fragile destinations like islands suffer pressures from visitor numbers especially when there is a seasonal concentration of tourists. To avoid environmental degradation, carrying capacity measures are implemented. In the case of Fernando de Noronha, these measures include: restrictions on access with a limited number of tourists allowed to visit the destination per day by air and by sea on the cruise ship, a controlled number of daily regular flights and seats, a restricted number of airlines allowed to operate and the obligatory payment of a conservation fee to gain access to the island..

In this investigation, distribution channels are linked to capacity management (the use of carrying capacity as way of providing sustainable management of a destination) to 
understand how a governmental management mechanism of conservation is influencing the private sector's distribution channels.

\subsection{Structures of tourism distribution channels}

The first object of this research was to identify and present the structures of the tourism distribution channels from a supply-side perspective. It was identified that the main structures of the distribution channels of Fernando de Noronha represent a mass market concept, where the classic structures are in place: the use of direct channels, online reservation websites and travel agencies. The main channel structures of the destination could be seen in Figure 23 in the previous chapter. The presence of the cruise ship operator and the supplier's association as members of the destination's structures had never been seen in previous literature.

'At destination' distribution is also important for some businesses with this focus and it is ruled by commission interests. Tourists usually look for recommendations at their accommodation and sometimes while making use of other services like: car rentals, gas station, pharmacies and supermarkets. Independent travellers without accommodation booked prior to their arrival will rely on ground operators and taxi drivers as their main initial channel.

The distribution via travel agencies involves the use of tour operators and/or ground operators. Tour operators and ground operators usually perform the functions of sorting, bundling, booking and purchase. Some intermediaries are vertically integrated which means that the same company has a tour operator, switch company (to buy air tickets in bulk) and travel agencies with many stores across the country or in big cities.

The distribution structure when cruise ships are involved is different. There is a cruise ship operator responsible for working like a ground operator, which means: making partnerships with suppliers and performing the functions of sorting, bundling, booking and purchase. The payment for suppliers' services is made via this cruise ship operator and sometimes it can involve some suppliers' associations. To reach consumers, the cruise ship operator then provides its services to a tour operator that specializes in selling cruise ship tours who is responsible for providing this product to travel agencies.

\subsection{Factors influencing the structures of distribution mix of the destination}

The second research object was to analyse the factors that influence the structures revealed, including the capacity management as a factor influencing these structures. The factors 
influencing the mix of distribution at Fernando de Noronha were categorised in three groups: general factors, reasons for making use of direct distribution and explanations of the utilisation of indirect channels.

General factors influencing the distribution of intermediaries concern the identification of market opportunities to recruit clients in the neighbourhood of the company. Another general factor is the issues in the partnerships among intermediaries and suppliers which represents conflicts regarding the rate of commissions. The high price for using some channels is also a problem for small enterprises. Some product's characteristics that depend on environmental conditions to operate are preventing the opportunity of suppliers to broaden their channels. The reputation of some channels is especially important when suppliers are approached to work with virtual distributors. Some businesses prefer to rely on experience when choosing their channels. Some very small companies suffer from capacity constraint of their business and this is leading them to focus on few channels since they cannot handle a large number of clients.

The use of direct distribution provides suppliers with the opportunity to get higher profitability since they do not have to pay commissions to intermediaries. Some companies, especially non-luxury accommodations, believe that online direct booking is a market trend and for this reason they invest in this channel. Some accommodation providers and independent tour guides prefer to rely on the convenience and good results of word-ofmouth.

The advantages of indirect distribution for suppliers is the possibility of getting higher customer volumes, the likelihood of selling their products more easily since payment ease is a good selling point for customers, and the costs of providing information for consumers is transferred to the intermediary.

A number of these factors are similar to those found on the literature (Pearce and Tan 2004; Stuart 2006; Schott 2007; Smith 2007a; Smith 2007b; Smith 2008; Liu 2012; Mkumbo, 2010). Conversely, the capacity management of the destination had never been portrayed as a factor before.

\subsection{Relationships between capacity management and suppliers' distribution channels}

The third and final objective was to evaluate and explain the relationships between the island management and its carrying capacity planning with the supplier's practices in distribution channels. 
In Fernando de Noronha, the capacity management of the destination is influencing suppliers' distribution because its obligation to pay two conservation fees (per day and for each 10 days) increases visitor's expenditure. To get airline tickets to fly to the island during the concentration of tourists over the high season is hard and the prices are really high. Because there are a limited number of seats available on the flights, many intermediaries take the opportunity to increase the prices of the tickets even if tourists try to purchase them months in advance. Accommodation providers usually offer packages of 5 days' stay during the summer months. However, sometimes it is difficult to sell these packages directly to consumers as their clients cannot find flight tickets to the destination. Thus, accommodations are having to pay commission to intermediaries holding flight tickets to the destination, otherwise they may lose sales. For these reasons the destination has an image of being expensive and its package prices are frequently compared to package costs for overseas travels.

Another issue regarding the distribution mix of suppliers is the lack of formal knowledge about distribution and consequently the lack of awareness of the relationships between capacity management and distribution. In addition, distribution has not been managed as a strategic tool for their business. As a result, most suppliers do not monitor nor evaluate their channel mix. Moreover, suppliers are mistakenly using more distribution channels that attract mass tourists rather than focusing on high spending tourists as needed by the destination.

Furthermore, the public sector is also neglecting the use of distribution as a strategic tool in the marketing plan for the island since the plan only emphasizes the other 3 P's of the marketing mix: product, price and promotion. Price is actually being used (via the conservation charges) in order to discourage unwanted tourists and mass tourism. Nevertheless, distribution could be used to reposition the image of the destination and also attract the high spending tourists the government is targeting. The effects capacity management is having on suppliers' distribution are not understood by the government.

\subsection{Implications for businesses}

Many suppliers did not have a clear idea of what distribution channels are and how important they may be for their business due to a lack of formal education in tourism and business management. So, there is the need for them to create a strategic distribution plan for their businesses if they want to succeed on a long-term basis. They should also start to have more control over the channels which are giving them better results rather than 
depending on intuition. As a result, the implementation of a strategic distribution approach will also depend on their constant monitoring and evaluation of their channels.

Accommodation providers simply relying on word-of-mouth recommendations, direct distribution and only one intermediary are unaware of the importance of diversifying their distribution. So, since tour operators play an important role in holding the flight tickets to the island, these businesses should starting thinking of changing their channel mix and look for more business partners to work with.

As seen in the distribution structures of the destination, travel agencies are an important channel for the island. They also are responsible for providing the image of the destination to consumers. Since it could be noted that they are failing to match consumers' motivations with the nature of the destination, travel agents should be encouraged to provide more detailed information to their clients about the destination's characteristics, infrastructure and environment rather the focusing on a selling approach to meet sales' goals. Also, travel agencies could provide their customers with some advice about environmentally responsible attitudes to take while at the destination. Targeting consumers who are more sensitive to ecotourism and adventure is essential if travel agencies are to be more responsible for the sustainable development of tourism at Fernando de Noronha.

Strategic alliances between suppliers are lacking. Some suppliers without transportation to pick-up their independent tourists could make a partnership with taxi drivers to provide this service for their customers. Moreover, adventure suppliers could get together and create a package of activities for independent travellers. These travellers should be able to contact suppliers directly through their websites to purchase these packages. Consequently, suppliers' websites should provide the opportunity for tourists not only to book but also purchase these packages online.

Since the destination is well known in the domestic market, direct distribution could be improved if suppliers decide to have fewer mass-market intermediaries. In addition, there is still scope to improve word-of-mouth recommendations as an important channel.

\subsection{Implications for the government}

Travel agents' training is already an activity performed by ADEFN. However, there should be more attention given to making them understand the importance of their role in supporting the sustainability of the island when targeting customers. It is essential to make them understand the focus on more high spending tourists needs to be less on mass-market 
clients and more on ecotourists and adventure tourists. It must be highlighted the destination does not suit some types of tourists, such as families with children, as the destination does not have activities to provide for children.

Rather than just using price to discourage undesired tourists and get more high spending tourists and avoid mass tourism, making use of distribution as a strategic tool should be considered. Approaches to de-marketing the destination through the manipulation of distribution could also be used. Therefore, the strategic marketing plan including marketing mix activities for Fernando de Noronha must be revisited to include distribution as a way of improving the planned goals.

Considering that many suppliers are having difficulties contacting customers directly and have little budget to get out of the island to look for more business partners, more investment in infrastructure is needed. There should be special emphasis on the implementation and maintenance of the hyperbaric chamber since scuba diving is an iconic activity for the island; and on the provision of better free internet connection that would allow suppliers to invest on their online presence. More efficient direct distribution to consumers is needed and suppliers could improve their websites to allow booking and purchases online rather than paying commissions to online intermediaries, such as the third-party reservations websites used by accommodations. Both of these investments play a crucial role when targeting high spending ecotourism and adventure tourists because internet is the channel they use. In addition, ADEFN and EMPETUR could get together with the associations of suppliers on the island and create one online platform for direct distribution between domestic consumers and suppliers and also include ground operators. This website should include booking and purchasing functions and provide emphasis on niche markets and themed or segmented itineraries that focus on the activities offered by the destination.

The importance of becoming a licensed company at the destination could be emphasized if the government improves its actions on using direct distribution for promoting the businesses 'at destination'. A travel guide for the destination could be distributed by ADEFN upon arrival of independent tourists (or those who request it) along with the brochures they already distribute on the airport along with the conservation fee tickets that give access to the destination. This guide could have a list of the licensed companies, their contacts and some information about the services they provide by type of company. In addition, a more attractive and interactive official website of the destination is needed 
which, if promoted well, could become the main online channel for tourists to find suppliers and ground operators while 'in market';

\subsection{Recommendations for suppliers, ground operators and the government}

A key recommendation that applies to suppliers, ground operators and the government is to create a distribution strategy by using the design process created by Pearce (2009). As part of this, it may be necessary for the governmental organization to provide training for suppliers about how to create a strategy. Since many suppliers do not know how to monitor and evaluate their channel mix, this is one more aspect needing more attention from them. The government could also assist suppliers by providing this kind of training since much of the literature on distribution channels is in English.

If ecotourists and adventure tourists are taken as the main type of consumers to be targeted, it will be important for ground operators to look for business partners to distribute their services at events specializing in ecotourism like the Adventure Travel World Summit (organized by the Adventure Travel and Trade Association) in the international market, and the ABETA Summit and the Adventure Sports Fair in the domestic market.

In addition, it would be essential to map all ecotourism and adventure tour operators in Brazil and provide the opportunities for suppliers and ground operators to do business with them or strengthen their relationships. This could be done not only in the domestic market but also in the international markets since the travel behaviour of these types of high spending tourist is not affected even during economic crises. Suppliers mentioned had received more European tourists which means that the Latin American countries are a good potential market to target in the future focusing on these high spending and greener tourists.

The local government should engage more in conferences about sustainable and responsible tourism, like the one from The International Centre for Responsible Tourism. This would bring them up to date about the global issues on managing destinations but also importantly provide insights and assist them to regularly review their strategic plan for the island.

\subsection{Avenues for future research}

This study emphasized a supply-side perspective involving a broad representation of attractions on Fernando de Noronha. A holistic approach was undertaken since different channel members were interviewed: intermediaries, governmental organizations and suppliers. 
The limitation of this research is the absence of participation from the airlines and the cruise ship operator. As a result, there is still scope to collect data with these transport providers. For example, it would be interesting to identify from the airlines what percentage of flight tickets is distributed directly, via virtual distributors and through tour operators during the high and medium seasons of the island. Another example would be to collect information from the tour operators specializing in cruises about what kind of travel agencies they are distributing their products and if they make use of virtual distributors when selling the packages to Fernando de Noronha.

In addition, more research is needed with the biggest Brazilian tour operators specializing in ecotourism and luxury travel to understand how they distribute their products to both the domestic and international markets. Suppliers demonstrated to rely a lot on intermediaries to get international visitors. The reasons for this are that many suppliers still do not provide information in other languages (on their websites) since they usually are not fluent in foreign languages and it does not seem that the great majority is targeting international markets nowadays.

Future research on the distribution channels at Fernando de Noronha could include a tourist-based survey to find out the actual reasons for using direct and indirect channels (e.g. if the issue is price, payment ease, etc). But it must include more details on what indirect channels are being used. This should be done based on the type of tourists the destination receives and considering the different seasons (because in summer sun and beach tourists are more common, while August is usually when the destination receives more international tourists and September is the best season for scuba diving on the island and consequently to scuba divers or adventure tourists). This research must also include details regarding which the sectors (type of suppliers) are mostly purchased at destination and which are purchased in market and the reasons for this.

There is scope in the broad literature of tourism distribution channels to include research with virtual distributors and cruise ship operators, including not only the big cruise ships packages passing through many countries on their itineraries but also the small-sized regional and local cruise ships.

It is also necessary to evaluate the channel performance of suppliers. However, firstly suppliers must be informed of how to use the information about their reservations more 
strategically and collect this data. Currently the great majority of suppliers and ground operators do not monitor nor evaluate their channels mix.

It is relevant to compare the distribution of Fernando de Noronha with other similar destinations. So, more research on distribution channels on small islands within a country is needed, especially vulnerable destinations that besides being an island are also conservation areas or a national park or a natural heritage site with carrying capacity measures including the control over visitor numbers. Furthermore, it would also be worth investigating destinations that have used distribution as a strategy to control visitor numbers or type of tourists.

\subsection{Overall conclusion}

A mass-market approach to the distribution channels of the destination is in place by both the private sector (when selling to consumers) and the public sector (when providing information about the island though its promotion). Fernando de Noronha is a destination that fits between the growth and maturity stages of the tourism area life cycle, which means it is in the carrying capacity threshold range. Therefore, strategic planning to avoid unsustainable outcomes must take place. As decisions must be made, ADEFN and EMPETUR need to make an effort to plan and clearly define what type of tourists they want to target for the destination since at present psychocentric and near psychocentric (the 'cruise ship tourists' and the 'party tourists') are types of tourists visiting the island due to the distribution channels currently used. It should be noted that the "Campaign More Noronha" is ensuring the perpetuation of low spending short stay tourists.

The public and the private sectors should start focusing on heritage visitors, ecotourists and adventure tourists by highlighting the experience these visitors desire. Balancing the type of tourists the island is aiming to receive is key to move the destination through the rejuvenation stage of the tourism area life cycle.

Since the cost of distribution channels for mass-market is very high (due to payment of commissions) compared to the channels used by allocentric and near-allocentric tourists (more inclined to use direct distribution or specialized tour operators) this is an advantage companies should take into consideration.

In conclusion, stakeholders of Fernando de Noronha should think of distribution channels as a key tool to strategically reposition their product in order to provide sustainable development for the destination. Attention must be given to the capacity management of 
Chapter Six: Conclusion

the destination as an external constraint influencing distribution mix choices. Thus, this research contributes to the knowledge of tourism distribution channels by associating the relationships between the management of distribution with capacity management of a destination. 


\section{REFERENCES}

ADEFN - Fernando de Noronha State District, (2000). Instrução Normativa $N^{o} 001 / 2000$. Available: http://www.noronha.pe.gov.br [12 August 2012].

ADEFN - Fernando de Noronha State District, (2007). Instrução Normativa N 002/2007. Available: http://www.noronha.pe.gov.br [12 August 2012].

ADEFN - Fernando de Noronha State District, (2012). Collected data about visitors at Fernando de Noronha. Unpublished material.

Buhalis, D., \& Laws, E. (2001). Tourism distribution channels: practices, issues and transformations. Continuum: New York.

Butler, R. W. (Ed.) (2006). The tourism area life cycle vol.1: applications and modifications. Channel View Publications: Clevedon; Buffalo.

Butler, R. W. (2010). Carrying capacity in tourism: paradox and hypocrisy? In Pearce, D.\& Butler, R. W., (Eds.). (2010). Tourism Research: A 20-20 Vision. Goodfellow Publishing. Oxford pp.94

Cooper, C., Fletcher, J., Gilbert, D., Fyall, A. \& Wanhill, S., (2005). Tourism: principles and practice. Pearson Education: England.

Creswell, J. W. (2009). Designing research: qualitative, quantitative and mixed methods approaches. $3^{\text {rd }}$ ed. SAGE: USA.

Econoronha, (2013). Website of Econoronha. Available: http://www.parnanoronha.com.br [18 April 2013].

EMPETUR. (2010). Sinopse da pesquisa do perfil do turismo receptivo do arquipélago de Fernando de Noronha. Unpublished material.

Falcão, M. C. (2010). A sustentabilidade do destino turístico de Fernando de Noronha: uma análise a partir da abordagem do cilco de vida de areas turísticas e das dimensões da sustentabilidade. A thesis submitted in partial fulfilment of the requirements for the Degree of Master of Management at Federal University of Pernambuco.

Fernando de Noronha - Pernambuco Website. (2012). Official tourism website of Fernando de Noronha. Available: http://www.noronha.pe.gov.br [11 March 2012].

Filho, W. L. (1996). Putting principles into practices: sustainable tourism in small island states. In Briguglio, L., Archer, B., Jafari, J., \& Wall, G., (Eds.). (1996). Sustainable tourism in islands and small states. Pinter: New York, pp.61.

Filho, S. C., \& Lohmann, G. (2012). Tourism Development and Distribution Channels in Brotas: Brazilian Adventure Capital. In Lohmann, G. \& Dredge D. (Eds.), Tourism in Brazil: Environment, Management and Segments. Routledge. UK pp.91. 
Finn, M., Elliot-White, M., \& Walton, M. (2000). Tourism and Leisure Research Methods: data collection, analysis and interpretation. Longman: England.

Flecha, A. C., \& Costa, J. I. P. (2004). O impacto das novas tecnologias nos canais de distribuição turística um estudo de caso em agências de viagens. Caderno Virtual de Turismo, 4: 44-56.

Gartner, W. C., \& Bachri, T. (1994). Tour operators' role in the tourism distribution system: an Indonesian case study. Journal of International Consumer Marketing, 6: 161179.

Governo de PE, Fundação CTI Nordeste \& Indústrias Criativas. (2008). Pernambuco para o mundo: Plano Estratégico de Turismo de Pernambuco (Versão Pública). Available: http://setur.pernambuco.googlepages.com/PlanoEstrategicodeTurismodePE.pdf [12 August 2012]

ICMBio - Chico Mendes Institute of Biodiversity. (2012). Quem somos: o instituto. Available: http://www.icmbio.gov.br/portal/ [13 November 2012]

Jennings, G. (2010). Tourism research. $2^{\text {nd }}$ ed. Milton, Qld.: John Wiley \& Sons.

Johnson, P., \& Thomas, B. (1996). Tourism capacity: a critique. In Briguglio, ... [et al.] (Eds.). (1996). Sustainable tourism in islands and small states. Pinter: New York, pp.118.

Kotler, P., Bowen, J. T., \& Makens, J. C. (2006). Marketing for Hospitality and Tourism. $4^{\text {th }}$ ed. Pearson: New Jersey.

Liu, Y. (2012). Distribution Channels for Wine Tourism in New Zealand: a thesis submitted in partial fulfilment of the requirements for the Degree of Master of Tourism Management at Victoria University of Wellington.

Lohmann, G. (2006). Análise da literatura em turismo sobre canais de distribuição. Observatório de Inovação do Turismo, 1: 1-15.

Lohmann, G., \& Nascimento, G. M. L. (2007). Mapeando os canais de distribuição do turismo rural na região de Ribeirão Preto (SP). Paper presented at XXVII Congresso Brasileiro de Turismo 2007, Gramado, Brazil.

Lohmann, G., \& Netto, A. P. (2012). Canais de distribuição em turismo. In Teoria do turismo: conceitos, modelos e sistemas. Aleph. São Paulo pp.285.

Longhini, F. O., \& Borges, M. P. (2005). A influência do internet no mercado turístico: um estudo de caso nas agências de viagens de Piracicaba (SP) e região. Caderno Virtual de Turismo, 5: 1-8.

Malcolm-Davies, J. (2006). The TALC and Heritage Sites. In Butler, R. W. (Ed.) (2006). The tourism area life cycle vol.1: applications and modifications. Channel View Publications: Clevedon; Buffalo pp.162.

Martínez, B. A. (2002). Los canales de distribución en el sector turístico. ESIC Editorial: Madrid. 
Medlik, S. (2003). Dictionary of travel, tourism and hospitality. Oxford: ButterworthHeinemann.

Middleton, V. T., \& Clarke, J. R. (2001). Distribution channels in travel and tourism: creating access. In Middleton, V. T., Clarke, J. R. (2001). Marketing in travel and tourism. Butterworth-Heinemann. Oxford pp.288.

Ministry of Tourism - MTur \& Brazilian Association of Ecotourism and Adventure Tourism - ABETA. (2011). Cadeia produtiva do turismo em parques nacionais e entorno: resumo executivo.

Mkumbo, P. J. (2010). Tourism distribution channels in the northern tourist circuit of Tanzania: a thesis submitted in partial fulfilment of the requirements for the Degree of Master of Tourism Management at Victoria University of Wellington.

O'Leary, Z. (2010). The essential guide to doing your research project. SAGE Publications: London.

Oliveira, J. A. P. (2008). Implementation of environmental policies in developing countries: a case of protected areas and tourism in Brazil. Albany: State University of New York Press.

Pearce, D., \& Tan, R. (2004). Distribution Channels for Heritage and Cultural Tourism in New Zealand. Asia Pacific Journal of Tourism Research, 9: 225-237.

Pearce, D. G. (2007). Paths to the market: developing an effective tourism distribution strategy. Victoria University of Wellington.

Pearce, D. G. (2008a). A needs-functions model of tourism distribution. Annals of Tourism Research, 35: 148-168.

Pearce, D. G. (2008b). Beyond tiers: A network approach to tourism distribution. Tourism Analysis, 13: 517-530.

Pearce, D. G. (2009). Channel design for effective tourism distribution strategies. Journal of Travel \& Tourism Marketing, 26: 507-521.

Pearce, D. G. (2010a). Tourism distribution: a review and strategic research agenda. In Pearce, D., \& Butler, R. W., (Eds.). (2010). Tourism Research: A 20-20 Vision. Goodfellow Publishing. Oxford pp.94.

Pearce, D. G. (2010b). Managing international distribution channel partners: A crosscultural approach. Journal of Marketing Channels, 17: 89-117.

Pearce, D. G. (2011). Distribuição em turismo: da estrutura a estratégia. In Ateljevic, A., Page, S. \& Vilela, M., (Eds.). (2011). Turismo e empreendedorismo. Elsevier Brasil. São Paulo pp.165.

Pearce, D. G. (2012). Frameworks for tourism research. CABI Publishing: Wallingford. 
Pearce, D., Tan, R., \& Schott, C. (2007). Distribution Channels in International Markets: A comparative analysis of the distribution of New Zealand tourism in Australia, Great Britain and the USA. Current Issues in Tourism, 10: 33-60.

Pearce, P. (1991). Analysing Tourist Attractions. The Journal of Tourism Studies. 2:1, 4655.

Pender, L. (2001). Travel trade and transport: an introduction. Continuum: London.

Plog, C. S. (1974). Why destination areas rise and fall in popularity. Cornell Hotel and Restaurant Administration Quartely: 14: 54-58.

PNUD, IBAMA, \& elabore. (2007). Estudo de capacidade de suporte da APA de Fernando de Noronha: Produtos 3 e 4 - Documento para discussão. In Estudo e determinação da capacidade de suporte e seus indicadores de sustentabilidade com vistas a implementação do plano de manejo da área de proteção ambiental e da gestão ambiental no arquipélago de Fernando de Noronha. Brasília pp.123-151 (chapter 5) \& pp206-246 (chapter 10).

Schott, C. (2007). Selling Adventure Tourism: a Distribution Channels Perspective. International Journal of Tourism Research: 9: 257-274.

Sharda, S. (2005). The structure and behaviour of distribution channels linking destination New Zealand to an emerging market: a case of the Indian outbound travel industry: a thesis submitted in partial fulfilment of the requirements for the Degree of Master of Tourism Management at Victoria University of Wellington.

Smith, K. A. (2007a). The distribution of event tickets. Event Management, 10: 185-196.

Smith, K. A. (2007b). Distribution channels for events: supply and demand-side perspectives. Journal of Vacation Marketing, 13:321-338.

Smith, K. A. (2008). The information mix for events: A comparison of multiple channels used by event organisers and visitors. International Journal of Event Management Research, 4: 24-37.

Stern, L. W., \& El-Ansaray, A. I. (1982) Marketing Channels. 2ed. New Jersey: Prentice Hall.

Stuart, P. (2004). Tourism distribution channels for peripheral areas: a case study of Southland, New Zealand: a thesis submitted in partial fulfilment of the requirements for the Degree of Master of Tourism Management at Victoria University of Wellington.

Stuart, P., Pearce, D., \& Weaver, A. (2005). Tourism Distribution Channels in Peripheral Regions: The Case of Southland, New Zealand. Tourism Geographies: 7, 235-256.

Swarbrooke, J. (1999). Sustainable Tourism Management. Oxford: Cabi Publishing.

Tan, R. (2002). Channels of distribution characterising Singapore holiday travel to New Zealand: structure and implications: a thesis submitted in partial fulfilment of the requirements for the Degree of Master of Tourism Management at Victoria University of Wellington. 
Thomas, D. R. (2006). A general inductive approach for Analyzing Qualitative Evaluation Data. American Journal of Evaluation: 27, 237-246.

United Nations Educational, Scientific and Cultural Organization - UNESCO. (2002). Managing Tourism at World Heritage Sites: a Practical Manual for World Heritage Site Managers. Available: http://whc.unesco.org/uploads/activities/documents/activity-1132.pdf [11 March 2012].

United Nations Educational, Scientific and Cultural Organization - UNESCO. (2012). World Heritage List. Available: http://whc.unesco.org/en/list [11 March 2012].

United Nations Educational, Scientific and Cultural Organization - UNESCO. (2012). Brazilian Atlantic Islands: Fernando de Noronha and Atol das Rocas Reserves. Available: http://whc.unesco.org/en/list/1000. [11 March 2012].

Veal, A. J. (2006). Research methods for leisure and tourism: a practical guide. $3^{\text {rd }}$ ed. England: FT Prentice Hall.

Viver Noronha. (2012). Website with the news of Fernando de Noronha, by Ana Clara Marinho. Available: http://g1.globo.com/platb/pe-viver-noronha [17 April 2013]. 


\section{APPENDICES}


VICTORIA UNIVERSITY OF WELLINGTON

Te Whare Wānanga o te Ūpoko o te Ika a Māui

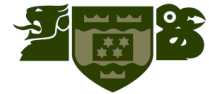

\section{- Information Sheet for Project Participants (Private Sector) -}

"Tourism Distribution Channels and Capacity Management: The Case of the Brazilian Island of Fernando de Noronha, a World Heritage Site"

Researcher: Amalina Andrade - School of Management - Victoria University of Wellington

I am originally from Pernambuco and am studying for my Masters in Tourism Management at Victoria University of Wellington in New Zealand. As part of this degree I am undertaking a research project leading to a thesis.

The project I am undertaking is examining the influences of capacity management on the tourism distribution channels used by suppliers. Ethics approval has been obtained for this research from Victoria University of Wellington.

I am inviting tourism businesses located at Fernando de Noronha Island to voluntarily participate in this study where your contribution is highly valuable since you have a central role in the development of tourist activity at the destination. The research aims at explaining how the capacity management of the island might be influencing the tourism businesses. Participants will be asked to take part in an in-depth semi-structured interview of up to 60 minutes.

Should any participants feel the need to withdraw from the project, they may do so without question at any time before the data is analysed by $13^{\text {th }}$ of August 2012 . In this case all data provided will be destroyed.

Responses collected will form the basis of my research project. Quotes will only be included on a basis where it will not be possible for you to be identified personally, and your business will be grouped under broad categories, e.g. accommodation provider, or transport operator. All material collected will be kept confidential. No other person besides me and my supervisor, Dr Karen Smith, will have access to the data. The thesis will be deposited in the University Library and a copy will be given to the organisation that manages the island. It is intended that one or more articles will be submitted for publication in scholarly journals or conferences. All interviews will be destroyed one year after the project's end (by May 2014).

If you have any questions or would like to receive further information about the project, please contact me at amalina.andrade@vuw.ac.nz, mobile: (81) 9272-8610 or my supervisor, Dr Karen Smith, at the Victoria Management School at Victoria University, P O Box 600, Wellington, phone +64 044635721 Email: karen.smith@vuw.ac.nz

Amalina Andrade 
VICTORIA UNIVERSITY OF WELLINGTON

Te Whare Wānanga o te Ūpoko o te Ika a Māui

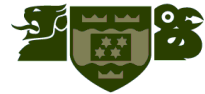

\section{- Information Sheet for Project Participants (Public Sector) -}

"Tourism Distribution Channels and Capacity Management: The Case of the Brazilian Island of Fernando de Noronha, a World Heritage Site"

Researcher: Amalina Andrade - School of Management - Victoria University of Wellington

I am originally from Pernambuco and am studying for my Masters in Tourism Management at Victoria University of Wellington in New Zealand. As part of this degree I am undertaking a research project leading to a thesis.

The project I am undertaking is examining the influences of capacity management on the tourism distribution channels used by suppliers. Ethics approval has been obtained for this research from Victoria University of Wellington.

I am inviting all government organisations involved in the tourist development of the island to voluntarily participate in this study where your contribution is highly valuable since you have role influences the tourist activity at the destination. The research aims at explaining how the capacity management of the island might be influencing the tourism businesses. Participants will be asked to take part in an in-depth semi-structured interview of up to 60 minutes.

Should any participants feel the need to withdraw from the project, they may do so without question at any time before the data is analysed by $13^{\text {th }}$ of August 2012.

Responses collected will form the basis of my research project and will be put into a written report that is neither anonymous nor confidential but is expressed on a nonattributable basis. It will not be possible for you to be identified personally, but your organisation will be identified as a public sector. All material collected will be kept confidential. No other person besides me and my supervisor, Dr Karen Smith, will have access to the data. The thesis will be deposited in the University Library and a copy will be given to the organisation that manages the island. It is intended that one or more articles will be submitted for publication in scholarly journals or conferences. All interviews will be destroyed one year after the project's end (on May 2014).

If you have any questions or would like to receive further information about the project, please contact me at amalina.andrade@vuw.ac.nz, mobile: (81) 9272-8610 or my supervisor, Dr Karen Smith, at the Victoria Management School at Victoria University, P O Box 600, Wellington, phone +64 044635721 Email: karen.smith@vuw.ac.nz 


\section{- Consent Form for Project Participants -}

VICTORIA UNIVERSITY OF WELLINGTON

Te Whare Wānanga o te Ūpoko o te Ika a Māui

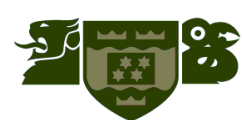

"Tourism Distribution Channels and Capacity Management: The Case of the Brazilian Island of Fernando de Noronha, a World Heritage Site"

Researcher: Amalina Andrade - School of Management - Victoria University of Wellington
I have read the Information Sheet concerning this student project and understand what it is about. All my questions have been answered to my satisfaction.

I know that:

- my participation in this project is entirely voluntary;

- I am free to withdraw from the project at any time before the analysis period on $13^{\text {th }}$ of August 2012 in which case all data collected will be destroyed;

- the interview will be recorded unless requested otherwise;

- digital records will be destroyed one year after the completion of this project in May 2014;

- in the event that the line of questioning during the interview develops in such a way that I feel hesitant or uncomfortable I may decline to answer any particular question(s) and/ or may withdraw from the project immediately;

- the research is not anonymous but is confidential, consequently I will not be identified personally and the organisation will be grouped under broad categories, e.g. accommodation provider, or transport operator.
- I agree to take part in this project.

(Name of business)

(Name of participant)

(Signature of participant)

(Date)

$\square \quad$ I would like to receive a summary of the findings.

Researcher's consent:

I confirm that I will act in accordance with all confidentiality requirements as outlined in the information sheet for this project. 
"Tourism Distribution Channels and Capacity Management: The Case of the Brazilian Island of Fernando de Noronha, a World Heritage Site"

VICTORIA UNIVERSITY OF WELLINGTON

Te Whare Wānanga o te Ūpoko o te Ika a Māui
I have read the Information Sheet concerning this student project and understand what it is about. All my questions have been answered to my satisfaction.

I know that:

- my participation in this project is entirely voluntary;

- I am free to withdraw from the project at any time before the analysis period on $13^{\text {th }}$ of August 2012 in which case all data collected will be destroyed;

- the interview will be recorded unless requested otherwise;

- digital records will be destroyed one year after the completion of this project in May 2014;

- in the event that the line of questioning during the interview develops in such a way that I feel hesitant or uncomfortable I may decline to answer any particular question(s) and/ or may withdraw from the project immediately;

- the research is neither anonymous or confidential, but I will not be identified personally and the organisation will be identified as a government body.
- I agree to take part in this project.

(Name of organisation)

(Name of participant)

(Signature of participant)

(Date)

$\square \quad$ I would like to receive a summary of the findings.

\section{Researcher's consent:}

I confirm that I will act in accordance with all confidentiality requirements as outlined in the information sheet for this project.

(Researcher) 


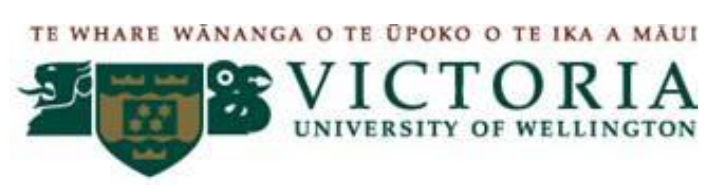

School of Management

Researcher: Amalina Andrade

"TOURISM DISTRIBUTION CHANNELS AND CAPACITY MANAGEMENT: THE CASE OF THE BRAZILIAN ISLAND OF FERNANDO DE NORONHA, A WORLD HERITAGE SITE"

- Interview questions -

\section{Private Sector (Suppliers and Intermediaries)}

SECTION A - General Company Profile

1. How long is the company established?

2. What is the mission and objectives of the company?

3. What type (and characteristics) of products do you offer?

4. About the size of the company:

a. Ownership of the company:

b. What is the number of employees?

c. How would you classify this business? Small ( ) Medium ( ) Large ( )

d. What is the scale of your operation? National? International? Both?

e. Do you have branches anywhere else in Brazil? If yes, where?

SECTION B - Distribution Channels and Capacity Management

5. What are your main markets? (Domestic and/or International)

6. How many per cent of your business is represented by the domestic market? And how many per cent is represented by the international market?

7. What types of tourists do you receive?

( ) Cruise ship tourist

( ) Domestic open tourist (couples or families motivated by the idea of paradise)

( ) International open tourist (motivated by the nature and ecotourism)

( ) Other(s), please explain:

8. Do you receive return customers? What types of tourists are they?

( ) Party tourist

( ) Tourists motivated by specific activities (e.g. fishing, scuba diving, surfing, regatta)

( ) Other(s), please explain:

9. What percentage of your clients are independent travellers? And what percentage is the tour group visitors?

10. What are the tourism distribution channels you use? (examples in the list below)

( ) Provide commission for offshore tour operator

( ) Provide commission for offshore travel agent 
( ) Reservations websites

( ) Visitor Information Centres

( ) Brochures and/or commission at accommodation and or transport providers

( ) Inbound operator

( ) Onshore travel agent

( ) Other(s), please explain:

11. What factor(s) influence(s) on the channels you choose?

12. How important is the factor of the capacity management of the island if compared to the other factors that influence on the distribution channels you use?

13. Which of the channels members would you consider to be the most significant to influence on the consumer's travel decision making process? Why?

14. During the season of events that attract more tourists to the island (e.g. 'New Year's Eve', 'Recife-Fernando de Noronha International Regatta' and the 'Hang Loose Pro Contest'), is there any specific distribution channel(s) used (or do you have any preference) that differs from what is used during non-event season?

15. How your distribution channels are linked to the overall goals and marketing plan of the company?

16. Have you defined the business capacity to reflect the carrying capacity of the island? Why? or Why not?

17. What are the main challenges you face on the distribution of your product(s)?

18. Do you think the distribution channels you use are influenced by any tourism governmental organization (ICMBio, EMPETUR, ADEFN, MTur and EMBRATUR)? Is it related to the concession the business has? 


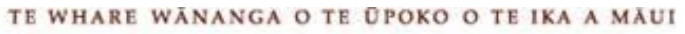 \\ School of Management}

Researcher: Amalina Andrade

“TOURISM DISTRIBUTION CHANNELS AND CAPACITY MANAGEMENT: THE CASE OF THE BRAZILIAN ISLAND OF FERNANDO DE NORONHA, A WORLD HERITAGE SITE"

\section{- Interview questions -}

\section{Government Organisations}

1. What roles do you have towards the destination studied?

2. Do you also promote the destination? In what markets? Why? How often? Is there a promotional plan specific for the destination?

3. What are the distribution channels you use to promote the destination?

4. Do you think the capacity management of the island influences on your promotion of the destination? How?

5. Do you think the capacity management of the island may influence the businesses at the destination? How?

6. Do you think the distribution channels used by suppliers can influence the sustainability of the island? 